DANILO FUJII DE MATOS PRUDÊNCIO

Avaliação no desempenho de longa duração do Polietileno de Alta Densidade

São Paulo 
DANILO FUJII DE MATOS PRUDÊNCIO

Avaliação no desempenho de longa duração do Polietileno de Alta Densidade

Dissertação apresentada à Escola Politécnica da Universidade de São Paulo para obtenção do título de Mestre em Ciências.

São Paulo 
DANILO FUJII DE MATOS PRUDÊNCIO

\section{Avaliação no desempenho de longa duração do Polietileno de Alta Densidade}

\section{Versão Corrigida}

Dissertação apresentada à Escola Politécnica da Universidade de São Paulo para obtenção do título de Mestre em Ciências.

Área de Concentração: Engenharia Metalúrgica e de Materiais

Orientador: Prof. Dr. Hélio Wiebeck

\section{São Paulo}


Autorizo a reprodução e divulgação total ou parcial deste trabalho, por qualquer meio convencional ou eletrônico, para fins de estudo e pesquisa, desde que citada a fonte.

Este exemplar fol revisado e corrigido em relaçăo à versâo original, sob responsabilidade única do autor e com a anuência de seu orientador:
Sáo Paulo, 03 de Novembro de 2021

Assinatura do autor:

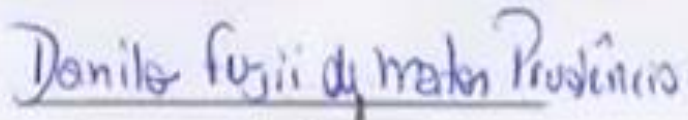

Assinatura do orientador:

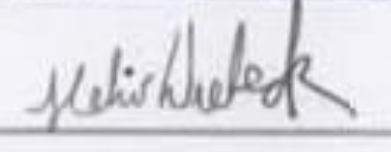

\section{Catalogação-na-publicação}

Prudêncio, Danilo

Avaliação no desempenho de longa duração do Polietileno de Alta

Densidade / D. Prudêncio -- versão corr. -- São Paulo, 2021.

$103 \mathrm{p}$.

Dissertação (Mestrado) - Escola Politécnica da Universidade de São

Paulo. Departamento de Engenharia Metalúrgica e de Materiais.

1.Fissuramento sob tensão 2.NCLS 3.PEAD 4.Reciclagem 5.Desempenho de longa duração I.Universidade de São Paulo. Escola Politécnica. Departamento de Engenharia Metalúrgica e de Materiais II.t. 
Nome: PRUDÊNCIO, Danilo Fujii de Matos

Título: Avaliação no desempenho de longa duração do Polietileno de Alta Densidade Dissertação apresentada à Escola Politécnica da Universidade de São Paulo para obtenção do título de Mestre em Ciências.

Aprovado em: 02 de Setembro de 2021.

Banca examinadora

Prof. Dr. $\quad$ HÉLIO WIEBECK

Instituição: PMT-EPUSP

Julgamento: APROVADO

Prof. Dr. DERVAL DOS SANTOS ROSA

Instituição: UFABC

Julgamento: APROVADO

Prof. Dr. LEONARDO GONDIM DE ANDRADE E SILVA

Instituição: $\quad$ CTR.IPEN

Julgamento: APROVADO 
Dedico este trabalho a minha esposa Michelle, por todo apoio, atenção, dedicação e compreensão nesta fase de nossas vidas, centenas de finais de semana estudando, pela paciência e carinho nos momentos de dificuldade, e especialmente pelo seu amor. Aos meus pais pelo amor incondicional. 



\section{AGRADECIMENTOS}

Agradeço a Deus, por estar aqui, por me dar forças e sabedoria para concluir esta etapa da minha vida. Por me permitir estar próximo e no caminho de pessoas iluminadas.

Aos meus pais, Almir e Sônia, pela vida, pelos valores, por me proporcionar uma educação verdadeira, pelo apoio, sem nunca poupar esforços.

A minha esposa Michelle por todo o amor e carinho dedicados ao relacionamento, pela paciência, por estar sempre ao meu lado, especialmente naqueles mais difíceis, sem seu apoio eu não conseguiria, te amo muito. As nossas filhas Brenda e Milena por nos mostrarem sempre que for preciso os verdadeiros valores de uma família.

As minhas irmãs Juliana e Patrícia, tenho saudades da nossa infância.

Ao companheiro de trabalho Gibran, pela paciência, pelos ensinamentos, pelos milhares de cafés, almoços divertidos e pelas cervejas também.

Aos colegas de laboratório Ademir, Renato, Victor, Marta, Adrian pelo apoio e pelos ensinamentos.

A Prof. ${ }^{a}$ Dra. Ticiane pela orientação, pelas ótimas dicas e conhecimentos compartilhados.

Ao Prof. Dr. Hélio Wiebeck pela orientação, por toda compreensão e paciência, por resolver os problemas sempre com muita calma, obrigado por acreditar em mim.

Aos outros inúmeros amigos que me ajudaram de forma a contribuir na realização deste trabalho. 
"Seja você quem for, seja qual for a posição social que você tenha na vida, a mais alta ou a mais baixa, tenha sempre como meta muita força, muita determinação e sempre faça tudo com muito amor e com muita fé em Deus, que um dia você chega lá. De alguma maneira você lá" (SILVA, 1990). 


\section{RESUMO}

PRUDÊNCIO, Danilo Fujii de Matos. Avaliação no desempenho de longa duração do Polietileno de Alta Densidade. 2021. 103 f. Dissertação (Mestrado em Ciências e Engenharia de Materiais) - Escola Politécnica, Universidade de São Paulo, São Paulo, 2021.

A evolução, o domínio e as vantagens da utilização dos materiais plásticos em diversos setores e tipos de aplicações tem gerado polêmica nos últimos anos. Não em relação a sua utilização, mas em relação ao seu curto tempo de vida em serviço e posterior descarte inadequado, gerando assim grandes impactos ambientais, e uma forma de mitigar o uso de resinas virgens é o aumento do uso de materiais reciclados. O polietileno de alta densidade é um deles (PEAD) e quando reciclado, apesar de apresentar propriedades compatíveis com diversas aplicações e ainda que similares ao material virgem, quando diversas cores, grades, diferentes aditivos e cargas são misturados no processo, podem atuar como concentradores de tensão, provocando efeito deletério nas propriedades e uma redução no tempo de falha, inviabilizando sua reutilização para aplicações estruturais. Este estudo teve como objetivo avaliar o desempenho de longa duração do polietileno de alta densidade (PEAD) virgem e reciclado (PEAD-R) quanto a resistência ao fissuramento sob tensão constante $e$ entalhe (NCLS). Por meio da construção e validação de um dispositivo de ensaio, seguindo os requisitos das normas ASTM F2136-18 e D5397-20, os principais requisitos preconizados foram avaliados: homogeneidade do banho, método de entalhe, reposição do banho, e ajustes das cargas aplicadas. Adicionalmente foi efetuada microscopia eletrônica de varredura (MEV), visando analisar os entalhes nos corpos de prova, a formação de trincas no PEAD e validação do processo de entalhamento. O PEAD e o PEAD-R foram avaliados no desempenho de curta e longa duração. Adicionalmente afim de aproximar e simular o PEAD reciclado pós-consumo e pós-industrial e verificar se há alterações no desempenho de curta duração, diferentes misturas com polipropileno (PP), carbonato de cálcio $\left(\mathrm{CaCO}_{3}\right)$, dióxido de titânio $\left(\mathrm{TiO}_{2}\right)$ e dióxido de silício $\left(\mathrm{SiO}_{2}\right)$ foram preparadas em frações mássicas variando de 2 a $8 \%$. Os materiais foram caracterizados por meio de ensaios mecânicos de tração, flexão, impacto e NCLS. Os resultados para os ensaios de curta duração para o PEAD-R e as misturas realizadas não apresentaram diferenças estatisticamente significativas para um intervalo de confiança de $95 \%$. Os resultados 
de longa duração NCLS para o PEAD-R mostraram uma dispersão elevada de 15,2\% para os corpos de prova estampados, e uma dispersão de $8,7 \%$ e $9,6 \%$ para os corpos de prova injetados, abaixo dos $10 \%$ que preconiza a norma, que validaram 0 dispositivo construído, viabilizando o PEAD-R para aplicações estruturais.

Palavras-chave: PEAD, desempenho de longa duração, NCLS, fissuramento sob tensão constante e entalhe. 
ABSTRACT

PRUDÊNCIO, Danilo Fujii de Matos. Evaluation of High-Density Polyethylene on long-term performance. 2021. 99 f. Dissertação (Mestrado em Ciências e Engenharia de Materiais) - Escola Politécnica, Universidade de São Paulo, São Paulo, 2021.

The evolution, domain and advantages of using plastic materials in different sectors and types of applications has generated controversy in recent years. Not in relation to its use, but in relation to its short service life and subsequent inappropriate disposal, thus generating great environmental impacts, and one way to mitigate the use of virgin resins is to increase the use of recycled materials. High density polyethylene is one of them (HDPE) and when recycled, despite having properties compatible with several applications and even if similar to virgin material, when different colors, grades, different additives and fillers are mixed in the process, they can act as concentrators of stress, causing a deleterious effect on the properties and a reduction in the failure time, making its reuse unfeasible for structural applications. This study aimed to evaluate the long-term performance of virgin and recycled high-density polyethylene (HDPE) and recycled (HDPE-R) as its resistance to notched constant ligament stress (NCLS). Through the construction and validation of a test device, following the requirements of ASTM F2136-18 and D5397-20 standards, the main recommended requirements were evaluated: bath homogeneity, notch method, bath replacement, and adjustments of applied loads. Additionally, scanning electron microscopy (SEM) was performed, aiming to analyze the notches in the specimens, the formation of cracks in the HDPE and validation of the notching process. HDPE and HDPE-R were evaluated for short-term and long-term performance. Additionally, in order to approximate and simulate post-consumer and post-industrial recycled HDPE and check for changes in short-term performance, different blends with polypropylene (PP), calcium carbonate $\left(\mathrm{CaCO}_{3}\right)$, titanium dioxide $\left(\mathrm{TiO}_{2}\right)$ and dioxide of silicon $\left(\mathrm{SiO}_{2}\right)$ were prepared in mass fractions ranging from 2 to $8 \%$. The materials were characterized through mechanical tests of tensile strength, flexural strength, impact resistance and NCLS. The results for the short-term trials for the HDPE-R and the blends performed did not show statistically significant differences for a $95 \%$ confidence interval. The NCLS long-term results for HDPE-R showed a high dispersion of $15.2 \%$ for the die cutting specimens, and a dispersion of $8.7 \%$ and $9.6 \%$ for the injected specimens, 
below $10 \%$ that recommends the standard, which validated the device built, enabling the HDPE-R for structural applications.

Keywords: HDPE, long term performance, NCLS, notched constant ligament stress. 


\section{LISTA DE ILUSTRAÇÕES}

Figura 1 - Consumo aparente de resinas termoplásticas em milhões de toneladas . 28 Figura 2 - Principais resinas termoplásticas consumidas no Brasil (2012) ...............28 Figura 3 - Resinas termoplásticas consumidas no Brasil em 2016 (\%) ...................29 Figura 4 - Fluxograma de reciclagem mecânica de resíduos plásticos......................31 Figura 5 - PEAD após processo de moagem 32

Figura 6 - B) $\mu-X R F$ - Espectros obtidos pela técnica de Fluorescência de Raios X para a) PEAD virgem, b) mistura de PEAD virgem e de PEAD reciclado em concentrações mássicas de 80/20(\%) respectivamente, c) PEAD reciclado pós-industrial com adição de antioxidantes e d) PEAD reciclado pós-consumo. C) XPS - Espectros obtidos pela técnica de Espectroscopia de Raios $X$ fotoelétron usada como análise quantitativa de c) PEAD reciclado pós-industrial com adição de antioxidantes e d) PEAD reciclado pós-consumo

Figura 7 - A) - Imagem obtida por microscopia eletrônica de varredura de uma área típica do PEAD reciclado, e os mapeamentos elementares de raios $\mathrm{X}$ de $\mathrm{Ti}$ ka e Ca Ka medidos na mesma área 35

Figura 8 - Influência do teor de polipropileno na propriedade de alongamento na ruptura 39

Figura 9 - Influência do teor de polipropileno na densidade da mistura 40

Figura 10 - Influência do teor de polipropileno no índice de fluidez 40

Figura 11 - Efeitos do teor de polipropileno no ensaio de NCLS 41

Figura 12 - Tempo de vida hipotético do PEAD 48

Figura 13 - Moinho de facas utilizado na pulverização dos polímeros PEAD e PP...53 Figura 14 - Misturador tipo $\vee$ Kotobuki utilizado para homogeneização das misturas .53

Figura 15 - Extrusora dupla rosca AX 16-DR usada na granulação das misturas....54

Figura 16 - Prensa hidráulica utilizada para confecção das plaquetas .55

Figura 17 - Plaqueta para obtenção dos corpos de prova para ensaio de NCLS .....56 Figura 18 - Prensa Pneumática, fabricante Zwick, para estampagem dos corpos de prova. .56

Figura 19 - Furadeira de bancada usada para furar os corpos de prova .57

Figura 20 - Imagem dos corpos de prova usados para ensaio de NCLS .57

Figura 21 - Máquina entalhadora - Entalhe [1] - a) vista lateral e b) vista superior.. 58 
Figura 22 - Máquina entalhadora - Entalhe [2]. 58

Figura 23 - Máquina entalhadora - Entalhe [3]

Figura 24 - Exemplo de entalhe e medição no estéreo microscópio para validação do processo de entalhamento 60

Figura 25 - Corpo de prova injetado para realização do ensaio NCLS 60

Figura 26 - Balança usada para validação das massas em função da área, da profundidade dos entalhes e a tensão aplicada em cada corpo de prova

Figura 27 - Dispositivo de ensaio de fissuramento sob tensão constante e entalhe .61 Figura 28 - Dispositivo para realização de ensaio de fissuramento sob tensão constante e entalhe NCLS

Figura 29 - Injetora de bancada usada para confecção dos corpos de prova para os ensaios de tração, flexão e impacto 63

Figura 30 - Dispositivo para realização dos ensaios de fissuramento sob tensão constante e entalhe NCLS 66

Figura 31 - Resistência à tração do PEAD e do PEAD-R ...................................... 70

Figura 32 - Alongamento do PEAD e do PEAD-R …....................................... 70

Figura 33 - Resultados de resistência à flexão do PEAD e do PEAD-R ....................72

Figura 34 - Resultados dos módulos sob flexão do PEAD e do PEAD-R ..................72

Figura 35 - Resultados de resistência ao impacto do PEAD e do PEAD-R ...............74

Figura 36 - Micrografias obtidas por MEV das amostras de PEAD destacando: a) a presença significativa de material plastificado na ponta da trinca e b) microfissuras na ponta da trinca 76

Figura 37 - Micrografias obtidas por MEV das amostras de PEAD destacando: a) redução significativa de material plastificado na ponta da trinca e b) redução na quantidade de microfissuras na ponta da trinca .77

Figura 38 - Curva de calibração - Índice de refração BRIX versus concentração de surfactante usando regressão linear para análise quantitativa. .78

Figura 39 - Índices de refração BRIX versus concentração de surfactante .81

Figura 40 - Altura remanescente do banho versus concentração de surfactante com os respectivos índices de refração BRIX.

Figura 41 - Micrografias obtidas por MEV das amostras de PEAD destacando: a) e b) redução significativa de material plastificado na ponta da trinca e redução na quantidade e extensão de microfissuras na ponta da trinca; c) e d) trincas encontradas em regiões distantes ao entalhe .82 
Figura 42 - Principais variáveis descritas na norma ASTM F2136-18 em função da redução dos respectivos coeficientes de variação com $30 \%$ da tensão de escoamento

Figura 43 - Gráfico dos resultados de resistência à tração no escoamento das amostras de PEAD e misturas de PEAD/PP, PEAD/CaCO ${ }_{3}, \mathrm{PEAD} / \mathrm{SiO}_{2}$ e PEAD/TiO ${ }_{2}$ para frações mássicas de $2 \%$ a $8 \%$ de contaminante .88 Figura 44 - Gráfico dos resultados de resistência à tração quanto ao alongamento das amostras de PEAD e misturas de PEAD/PP, PEAD/CaCO ${ }_{3}, \mathrm{PEAD} / \mathrm{SiO}_{2}$ e PEAD/TiO 2 para frações mássicas de $2 \%$ a $8 \%$ de contaminante

Figura 45 - Gráfico dos resultados de resistência à flexão para o PEAD e as misturas de PEAD/PP, PEAD/CaCO $3, \mathrm{PEAD} / \mathrm{SiO}_{2}$ e $\mathrm{PEAD} / \mathrm{TiO}{ }_{2}$ variando de $2 \%$ a $8 \%$ em concentração mássica de contaminante 91 Figura 46 - Gráfico dos resultados quanto ao módulo sob flexão para o PEAD e as misturas de $\mathrm{PEAD} / \mathrm{PP}, \mathrm{PEAD} / \mathrm{CaCO}_{3}, \mathrm{PEAD} / \mathrm{SiO}_{2}$ e $\mathrm{PEAD} / \mathrm{TiO} \mathrm{O}_{2}$ variando de $2 \%$ a $8 \%$ em concentração mássica de contaminante 92 Figura 47 - Gráfico dos resultados de resistência ao impacto para o PEAD e as demais misturas de $\mathrm{PEAD} / \mathrm{PP}, \mathrm{PEAD} / \mathrm{CaCO}_{3}, \mathrm{PEAD} / \mathrm{SiO}_{2}$ e $\mathrm{PEAD} / \mathrm{TiO} \mathrm{O}_{2}$ variando de $2 \%$ a $8 \%$ em concentração mássica de contaminante .94 


\section{LISTA DE TABELAS}

Tabela 1 - Índice de refração de alguns minerais utilizados em plásticos. 43

Tabela 2 - Parâmetros obtidos dos resultados dos ensaios de fissuramento sob tensão 49

Tabela 3 - Denominação das amostras e teores mássicos das misturas de PEAD/contaminantes ... .52

Tabela 4 - Denominação das máquinas entalhadoras e os métodos utilizados para realização do processo de entalhamento dos corpos de prova

Tabela 5 - Resultados dos ensaios de resistência à tração das amostras de PEAD 69 Tabela 6 - Resultados de resistência à flexão das amostras de PEAD e de PEAD-R

Tabela 7 - Resultados de resistência ao impacto das amostras de PEAD e de PEAD$\mathrm{R}$

Tabela 8 - Resultados de fissuramento sob tensão e entalhe NCLS para a matriz de PEAD a fim de validar o dispositivo construído e o método de ensaio .74

Tabela 9 - Resultados de NCLS - parâmetros avaliados: homogeneidade do banho Entalhe [1], Entalhe [2], reposição do banho, homogeneidade do banho - Entalhe [3] e ajustes das cargas aplicadas .75

Tabela 10 - Diferentes concentrações de surfactante versus índice de refração BRIX para criação da curva de calibração e validação da concentração, perda e reposição do banho

Tabela 11 - Índices de refração BRIX sem reposição de água deionizada por seis dias consecutivos em intervalos de 24 horas. .79

Tabela 12 - Resultados de NCLS para os corpos de prova injetados de PEAD .......85 Tabela 13 - Resultados de NCLS para os corpos de prova injetados de PEAD-R ...85 Tabela 14 - Resultados de resistência à tração no escoamento, alongamento e módulo de rigidez das amostras de PEAD e misturas de PEAD/PP, PEAD/CaCO ${ }_{3}, \mathrm{PEAD} / \mathrm{SiO}_{2}$, $\mathrm{PEAD} / \mathrm{TiO}_{2}$ para as frações mássicas de $2 \%$ a $8 \%$ de cada contaminante

Tabela 15 - Resultados de resistência à flexão das amostras de PEAD e misturas de $\mathrm{PEAD} / \mathrm{PP}, \mathrm{PEAD} / \mathrm{CaCO}_{3}, \mathrm{PEAD} / \mathrm{SiO}_{2}$ e $\mathrm{PEAD} / \mathrm{TiO}_{2}$ para as frações mássicas de $2 \%$ a $8 \%$ de cada contaminante .90 
Tabela 16 - Resultados de resistência ao impacto para o PEAD e as demais misturas de $\mathrm{PEAD} / \mathrm{PP}, \mathrm{PEAD} / \mathrm{CaCO}_{3}, \mathrm{PEAD} / \mathrm{SiO}_{2}$ e $\mathrm{PEAD} / \mathrm{TiO}_{2}$ variando de $2 \%$ a $8 \%$ em concentração mássica de contaminante .93

Tabela 17 - Análise estatística pelo método Tukey para os ensaios de resistência à tração no escoamento e alongamento do PEAD e das misturas de PEAD/PP $\mathrm{PEAD} / \mathrm{CaCO}_{3}, \mathrm{PEAD} / \mathrm{SiO}_{2}$ e $\mathrm{PEAD} / \mathrm{TiO}_{2}$ para as frações mássicas de $2 \%$ a $8 \%$ de contaminante .95

Tabela 18 - Análise estatística pelo método Tukey para os ensaios de resistência à flexão e módulo sob flexão do PEAD e das misturas de PEAD/PP PEAD/CaCO ${ }_{3}$, $\mathrm{PEAD} / \mathrm{SiO}_{2}$ e PEAD/TiO $/ 2$ para as frações mássicas de $2 \%$ a $8 \%$ de contaminante .96 Tabela 19 - Análise estatística pelo método Tukey para os ensaios de resistência ao impacto do PEAD e das misturas de PEAD/PP PEAD/CaCO $\mathrm{CO}_{3}, \mathrm{PEAD} / \mathrm{SiO}_{2}$ e $\mathrm{PEAD} / \mathrm{TiO}_{2}$ para as frações mássicas de $2 \%$ a $8 \%$ de contaminante 


\section{SUMÁRIO}

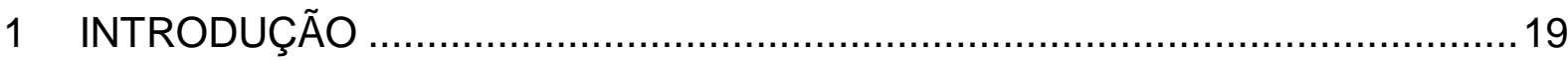

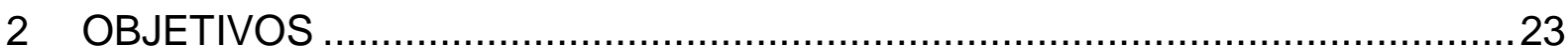

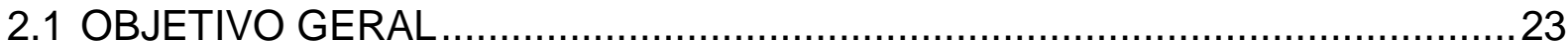

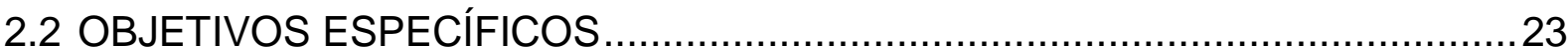

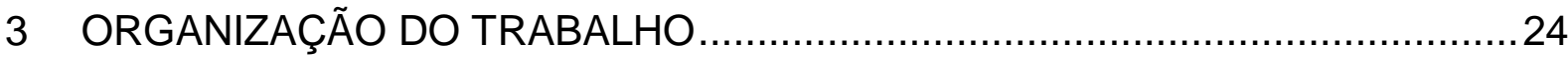

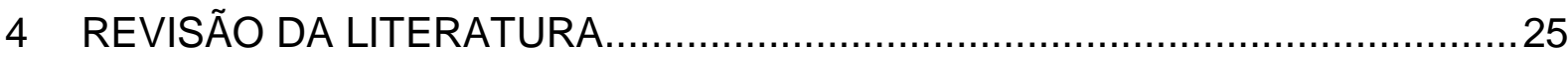

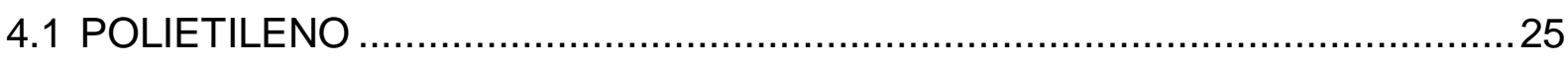

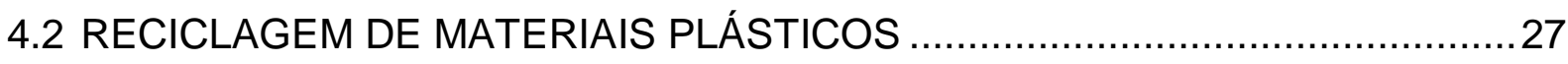

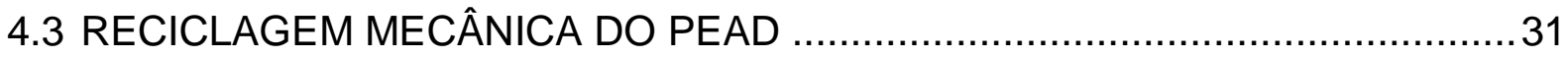

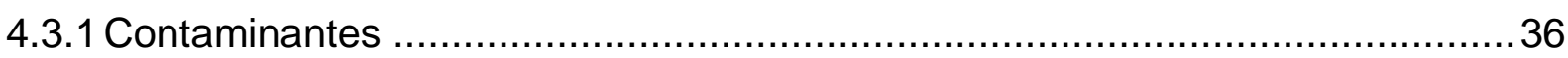

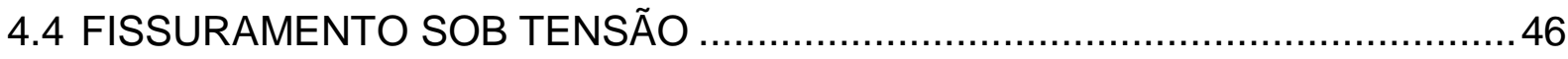

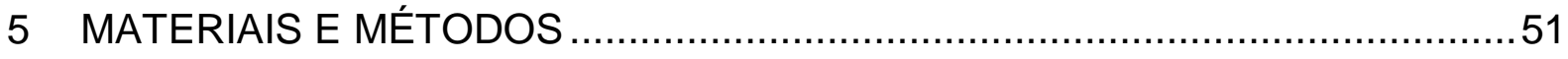

5.1 MISTURAS DE PEAD VIRGEM/CONTAMINANTES .....................................51

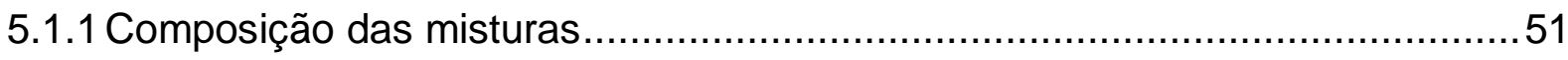

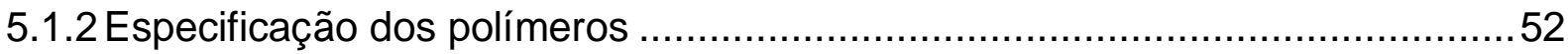

5.1.3 Preparo das misturas: PEAD virgem/contaminantes ....................................53

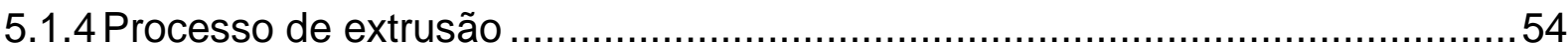

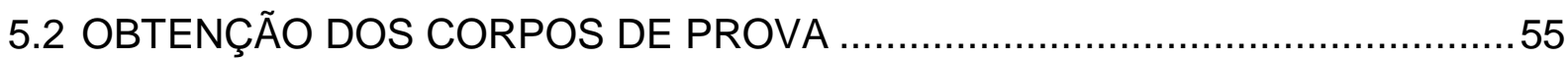

5.2.1 Obtenção dos corpos de prova para o ensaio de fissuramento sob tensão

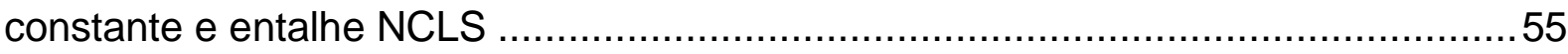

5.2.2 Injeção dos corpos de prova para os ensaios de curta duração .......................63

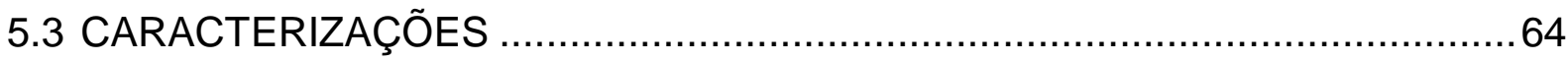

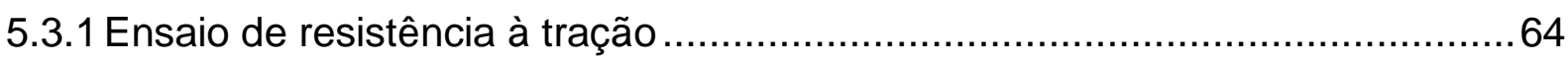

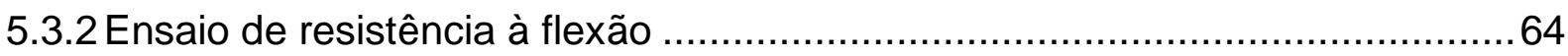

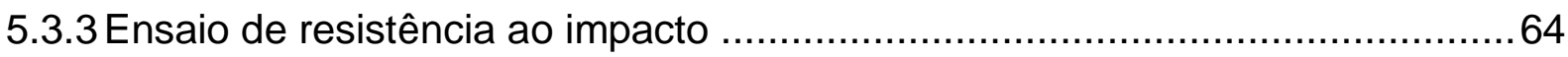


5.3.4 Ensaio de fissuramento sob tensão por ligamento constante e entalhe (NCLS)

5.3.5 Microscopia Eletrônica de Varredura (MEV), Emissão por Efeito de Campo (FEG)

6 RESULTADOS E DISCUSSÃO 69

6.1 RESULTADOS DOS ENSAIOS DE CURTA DURAÇÃO PARA A MATRIZ DE PEAD E DE PEAD-R 69

6.1.1 Resultados dos ensaios de resistência à tração 69

6.1.2 Resultados dos ensaios de resistência à flexão .71

6.1.3 Resultados dos ensaios de resistência ao impacto .73

6.2 RESULTADOS DE NCLS PARA O PEAD 74

6.3 RESULTADOS DOS ENSAIOS DE CURTA DURAÇÃO PARA AS MISTURAS DE PEAD/CONTAMINANTE 86

6.3.1 Resultados dos ensaios de resistência à tração para as misturas de PEAD/contaminante.

6.3.2 Resultados dos ensaios de resistência à flexão para as misturas de PEAD/contaminante .90

6.3.3 Resultados de resistência ao impacto de PEAD/contaminante .93

6.3.4 Análises estatísticas pelo método Tukey para os ensaios de tração, flexão e impacto de PEAD/contaminante .95

7 CONCLUSÕES .98

REFERÊNCIAS 100 


\section{INTRODUÇÃO}

Com a constante evolução e exigência dos produtos cada vez mais resistentes e sofisticados, surge a necessidade do homem descobrir ou modificar os materiais, surgindo os produtos sintéticos, como os plásticos, que desde sua descoberta têm sido empregados em praticamente todos os setores da indústria.

Os avanços tecnológicos e os novos desenvolvimentos dos materiais, combinados ao uso de aditivos, cargas, fibras naturais e sintéticas tem possibilitado uma vasta gama de aplicações, e o surgimento de diversos tipos de novos produtos. Ao passo que os avanços tecnológicos contribuem para produtos cada vez mais sofisticados, o consumo de materiais plásticos em excesso combinado a uma incorreta destinação final, podem apresentar problemas ambientais severos.

No ano de 2000, a produção nacional de resinas termoplásticas foi de 3,9 milhões de toneladas, já no ano de 2009, a produção foi de 5,5 milhões de toneladas. O consumo aparente de transformados plásticos em milhões de toneladas em 2014 foi de 7,7 milhões de toneladas, o que mostra um aumento no consumo destes materiais (ABIPLAST, 2017). Dentre as resinas mais consumidas no mercado do plástico está o PEAD (polietileno de alta densidade) representando $13,2 \%$ do consumo total de materiais plásticos, perdendo apenas para o PP (polipropileno) que apresentou 20,1\% no ano de 2020 (ABIPLAST, 2020).

O crescimento da produção e consumo de plástico, contribui para maiores problemas ambientais, devido a sua elevada resistência a decomposição. Gera-se assim a necessidade de se encontrar soluções inteligentes para diminuir ou solucionar tais impactos (BARTOLOMEI, 2016).

No ano de 2010, foi aprovada a Política Nacional de Resíduos Sólidos, que incentiva a reutilização de resíduos pós-consumo, que são aqueles que chegaram até o consumidor final, e após seu uso foram descartados. As empresas transformadoras e distribuidoras deverão buscar soluções para reutilizar tais resíduos de forma a minimizar os impactos ambientais.

$\mathrm{Na}$ tentativa de minimizar os impactos ambientais causados pelo uso significativo de materiais virgens, muitos estudos têm observado as propriedades dos materiais plásticos reciclados. Pesquisas mostram que as propriedades do PEAD pós-consumo não são muito distantes das propriedades do material virgem, o que permite uma vasta gama de aplicações, com custos reduzidos (CANDIAN, 2007). 
Dentre as diversas aplicações com PEAD, em sua grande maioria encontram-se as de curto tempo de vida em serviço, tais como certos tipos de embalagens, filmes, sacolas, frascos, garrafas para leite, utensílios domésticos, cabides, entre outras, gerando assim um volume de resíduos descartados muito elevado. Quando se pensa na reutilização desses resíduos para aplicações mais simples como baldes, bacias, cestos, cabides, entre outras, o PEAD se apresenta como um excelente candidato a diversos tipos de produtos, porém quando se deseja reutilizá-lo para aplicações estruturais o PEAD pode apresentar propriedades não compatíveis, pois os materiais plásticos reciclados são provenientes de diversas fontes e podem estar misturados com outros polímeros. Estes materiais muitas vezes apresentam diferentes cores, cargas, diferentes condições de processamento e diferentes níveis de degradação, e quando misturados, podem acabar atuando como contaminantes, produzindo efeito deletério nas propriedades desejadas, demandando estudos mais aprofundados e uma série de avaliações técnicas com relação a aplicabilidade dos produtos (KURDZIEL, 2014).

Um dos grandes inconvenientes encontrados no reaproveitamento de materiais pós-consumo para aplicações estruturais são os chamados contaminantes e a sua possível limpeza e remoção, o que contribui significativamente na durabilidade do material (KURDZIEL, 2014).

Valera (2019) ${ }^{1}$ define contaminante como um material que vai degradar, deteriorar, denegrir o próprio meio ambiente, ou material ao qual está inserido (informação verbal). Portanto ao longo deste trabalho serão chamados de contaminantes os materiais encontrados no PEAD reciclado, pois podem reduzir o desempenho de curta e de longa duração, este último está diretamente relacionado com aplicações estruturais, ou seja, quando o material está submetido a uma carga constante por longos períodos de tempo.

\footnotetext{
1 Informação fornecida por Valera durante o exame de qualificação como parte do programa de mestrado da universidade de São Paulo para obtenção do título de mestre em engenharia, São Paulo, 2019.
} 
A utilização de materiais plásticos reciclados para fabricação de elementos estruturais tem sido estudada, e uma das grandes dificuldades é a mistura de diferentes tipos de materiais poliméricos, aditivos e cargas, que podem atuar como contaminantes quando estão misturados ao polímero matriz, uma vez que podem degradar o meio ambiente ao qual estão inseridos e/ou dificultar o processamento, reduzindo o desempenho e interferindo na qualidade final dos produtos (NAJAFI, 2013).

Durante o processamento as temperaturas de fusão são críticas quando os materiais reciclados estão misturados com diferentes polímeros que apresentam diferentes temperaturas de fusão. Nesse caso a temperatura de fusão não é única, mas sim uma distribuição de temperatura. Os plásticos com menor temperatura de fusão fluem mais rapidamente quando comparados a aqueles que possuem temperatura de fusão mais alta, resultando num produto final heterogêneo (NAJAFI, 2013).

Para tornar possível a avaliação dos efeitos desses contaminantes nos possíveis produtos é necessário primeiramente avaliar os tipos e as concentrações encontradas, além do que os materiais podem sofrer degradações químicas, térmicas, mecânicas e biológicas que devem ser levadas em consideração especialmente em razão do desempenho de longa duração (KURDZIEL, 2014; NAJAFI, 2013).

THOMAS E CUTTINO (2011), estudaram a fabricação de tubos corrugados para drenagem pluvial a partir do PEAD reciclado. Das 67 blendas analisadas, todas continham teores de aproximadamente $5 \%$ de PP. Adicionalmente neste estudo foram encontrados teores de cinzas em todas as composições variando entre $0,05 \%$ e $3,75 \%$, sendo estes resultados relacionados as possíveis cargas utilizadas no polímero, o que mostra a necessidade de estudos e avaliações para aplicações com funções estruturais. Estes materiais dispersos na matriz polimérica podem atuar como concentradores de tensão e provocar redução de desempenho (KURDZIEL, 2014).

Estudos realizados para avaliação do efeito de contaminantes no desempenho de longa duração do PEAD reciclado para aplicações estruturais, mostraram que para quatro tipos de PEAD reciclados todos continham teores de PP variando entre $5 \%$ e 
$7 \%$, uma vez que muitas das aplicações do PEAD contém a tampa e rótulos fabricados em PP. Pode-se verificar que o material PP, e as cargas como carbonato de cálcio, dióxido de titânio e o dióxido de silício, em concentrações mássicas aproximadas de $2 \%$ a $5 \%$, estão muitas vezes presentes no PEAD reciclado e podem atuar como contaminantes, reduzindo $O$ desempenho para aplicações estruturais (VASCONCELOS; BASSO e VALERA, 2018).

Portanto existe muita disponibilidade de resíduos em PEAD pós-industrial e pósconsumo no mercado de plásticos, mas um dos grandes obstáculos é a correta separação para o posterior aproveitamento, assim os diferentes grades, cores e aplicações, uma vez separados, viabilizam diversas aplicações.

Neste contexto, o presente trabalho se concentra na avaliação do desempenho de longa duração do PEAD. Diferentes condições foram preparadas e testadas a fim de comparar o desempenho do PEAD virgem, em comparação ao PEAD reciclado por uma única etapa de extrusão, simulando assim o material reciclado, e adicionalmente o PEAD foi misturado com alguns materiais que podem atuar como contaminantes, reduzindo o tempo de falha do material, que em muitos casos podem apresentar níveis de mistura significativos, contribuindo para um efeito deletério nas propriedades. 


\section{OBJETIVOS}

\subsection{OBJETIVO GERAL}

O objetivo principal deste trabalho é avaliar o desempenho de longa duração do PEAD, e construir e validar um dispositivo que atenda a norma ASTM F2136-18.

\subsection{OBJETIVOS ESPECÍFICOS}

Visando avaliar o desempenho de longa duração do PEAD simulando os efeitos da reciclagem mecânica por uma única etapa de extrusão, tem-se os seguintes objetivos específicos:

- Avaliar o desempenho de longa duração do PEAD por meio do ensaio de fissuramento sob tensão constante e entalhe (NCLS), de modo a validar o dispositivo construído e o método descrito na norma ASTM F2136-18.

- Caracterizar o desempenho de curta duração do PEAD por meio de ensaios mecânicos de resistência à tração, resistência à flexão e resistência ao impacto.

- Simular o PEAD reciclado mecanicamente por uma única etapa de extrusão por meio de preparação de misturas com incorporação dos contaminantes tradicionalmente encontrados no PEAD pós-consumo e pós-industrial, em concentrações mássicas variando de $2 \%$ a $8 \%$.

- Processar todas as misturas em extrusora dupla rosca afim de homogeneizar as mesmas e simular o PEAD reciclado mecanicamente por uma única etapa de extrusão.

- Caracterizar o desempenho de curta duração das misturas por meio de ensaios mecânicos de resistência a tração, resistência à flexão e resistência ao impacto.

- Realizar análise comparativa entre os resultados dos tempos de falha do PEAD e avaliar se há diferenças estatisticamente significativas. 


\section{ORGANIZAÇÃO DO TRABALHO}

A sequência deste documento foi dividida em 07 capítulos. $O$ capítulo 4 apresenta a revisão bibliográfica que descreve o material PEAD, a reciclagem mecânica do PEAD e o fissuramento sob tensão. $O$ capítulo 05 descreve os materiais e métodos utilizados para a preparação e incorporação das misturas de PEAD e as técnicas de caracterização empregadas para avaliar os materiais estudados. O capítulo 6 descreve os resultados e discussão. Por fim, o capítulo 7 apresenta as conclusões deste estudo. 


\section{REVISÃO DA LITERATURA}

\subsection{POLIETILENO}

A sintetização do polietileno se deu pela primeira vez durante um processo de aquecimento do diazometano pelo químico Alemão Hans Von Pechmaann no ano de 1898. Como resultado final do experimento se obteve um pó branco de aspecto ceroso caracterizado por uma cadeia de $\mathrm{CH}_{2}$ e então denominado polimetileno (MESQUITA, 2010).

Em 27 de março de 1933 o polietileno foi sintetizado por Reginald Gibson e Eric Fawcett na Inglaterra, como é conhecido hoje em dia. Este feito foi conseguido pela aplicação de uma pressão aproximada de 1400 bar a uma temperatura de $170^{\circ} \mathrm{C}$, em uma autoclave obtendo-se um material de alta viscosidade e uma cor esbranquiçada. Com a descoberta dos catalisadores Ziegler-Natta se tornou possível então a polimerização a uma pressão normal (LESTER, 1998).

Atualmente o etileno, monômero para obtenção do polietileno, tem origem oriunda do petróleo em sua maior parte, passando pela extração e refino, craqueamento da nafta, mas também pode ser obtido do gás natural. Além dessas possíveis fontes de obtenção o polietileno pode ser produzido tendo como fonte principal o etanol oriundo da cana-de-açúcar, polietileno de fonte renovável (MESQUITA, 2010).

A demanda global de PEAD apresentou um crescimento significativo nos últimos anos, de 15,5 milhões em 2000 para 23,1 milhões de toneladas em 2009. No período previsto de 2009-2020 a demanda deverá crescer a uma taxa de crescimento anual de $7,3 \%$ (GBI, 2011).

Atualmente os polietilenos são muito utilizados nas indústrias de embalagens e construção civil. Nos países desenvolvidos tubos de PEAD estão sendo cada vez mais utilizados como alternativa aos tubos de metal corrugado, aos tubos de concreto e de ferro fundido, pois apresentam, custo menor, massa baixa e resistência química (DU et al., 2017). 
Muitas aplicações para o PEAD são realizadas em revestimentos de grandes áreas como geomembranas para águas de lagoas, pesqueiros, forros de aterro, remediação de locais contaminados, impermeabilizações, barragens e diques, entre outras, são exemplos deste material aplicado na engenharia civil (MÜLLER, 2006).

PESIC et al. (2016) avaliaram o uso de fibras de PEAD reciclado obtidas por meio de extrusão aplicadas no concreto estrutural. As propriedades mecânicas foram avaliadas entre o concreto puro e amostras de concreto com fibras extrudadas de PEAD reciclado, e enquanto a resistência a compressão e o módulo elástico do concreto não foram afetados, a resistência à tração e a resistência à flexão na ruptura foram marginalmente aumentados entre $3 \%$ e $14 \%$ na presença de fibras de PEAD (PESIC et al., 2016).

Atualmente existem estudos que visam o reaproveitamento de resíduos plásticos e buscam soluções que minimizem os impactos ambientais causados pelo uso e descartes destes materiais. Pode-se reduzir os impactos ambientais usando menores quantidades de materiais virgens e por consequência maiores quantidades de materiais reciclados, que uma vez bem coletados e separados podem ser reaproveitados na forma de novos produtos apenas com a adição de energia do processo de transformação (REIS; PACHECO e MATTOS, 2014). 


\subsection{RECICLAGEM DE MATERIAIS PLÁSTICOS}

A evolução dos materiais, especialmente os plásticos, é indispensável para o cotidiano, atendendo as mais diversas necessidades, desde embalagens mais simples para transportar as compras de mercado, até aplicações técnicas de elevado desempenho, como por exemplo na indústria automotiva, onde os materiais podem ser aplicados em coletores de ar, tanques de combustível, válvulas, corpos de bombas de combustível, entre outras. Tal evolução gera também uma quantidade muito significativa de resíduos, uma vez que, muitas das aplicações têm baixo tempo de vida em serviço, como é o caso de embalagens, sacolas, entre outras. Dessa forma a reciclagem é um processo que pode reduzir a quantidade de matéria-prima virgem utilizada.

A reciclagem de materiais tem se tornado a cada dia uma das atividades mais importantes do ponto de vista ambiental, pois atribui valores econômicos e avanços tecnológicos.

Em 1996 foi estimado que a reciclagem de polímeros no Brasil crescia em média 15\% ao ano desde o início da década. Em 2000 a Plastivida marca registrada da propriedade ABIQUIM (Associação Brasileira da Indústria Química), estimou um índice médio de reciclagem em torno de 17,5\% (MANO e MENDES, 2004; SPINACÉ e PAOLI, 2005).

A quantidade de plásticos consumidos e descartados em 2006 comprova tal fato, do total de 3,97 milhões de toneladas consumidos no Brasil, 1,58 milhões de toneladas foi usada na forma de embalagens e 0,46 milhões toneladas de plásticos foram lançadas em lixões e aterros, o que corresponde a 51,3\% do plástico consumido no país (CANDIAN, 2007). Na Figura 1 é mostrado o consumo aparente de resinas termoplásticas no Brasil em milhões de toneladas, indicando uma forte tendência de crescimento do consumo, tal fato mostra a evolução e também o grande aumento no consumo de materiais plásticos (ABIPLAST, 2017). 
Figura 1 - Consumo aparente de resinas termoplásticas em milhões de toneladas

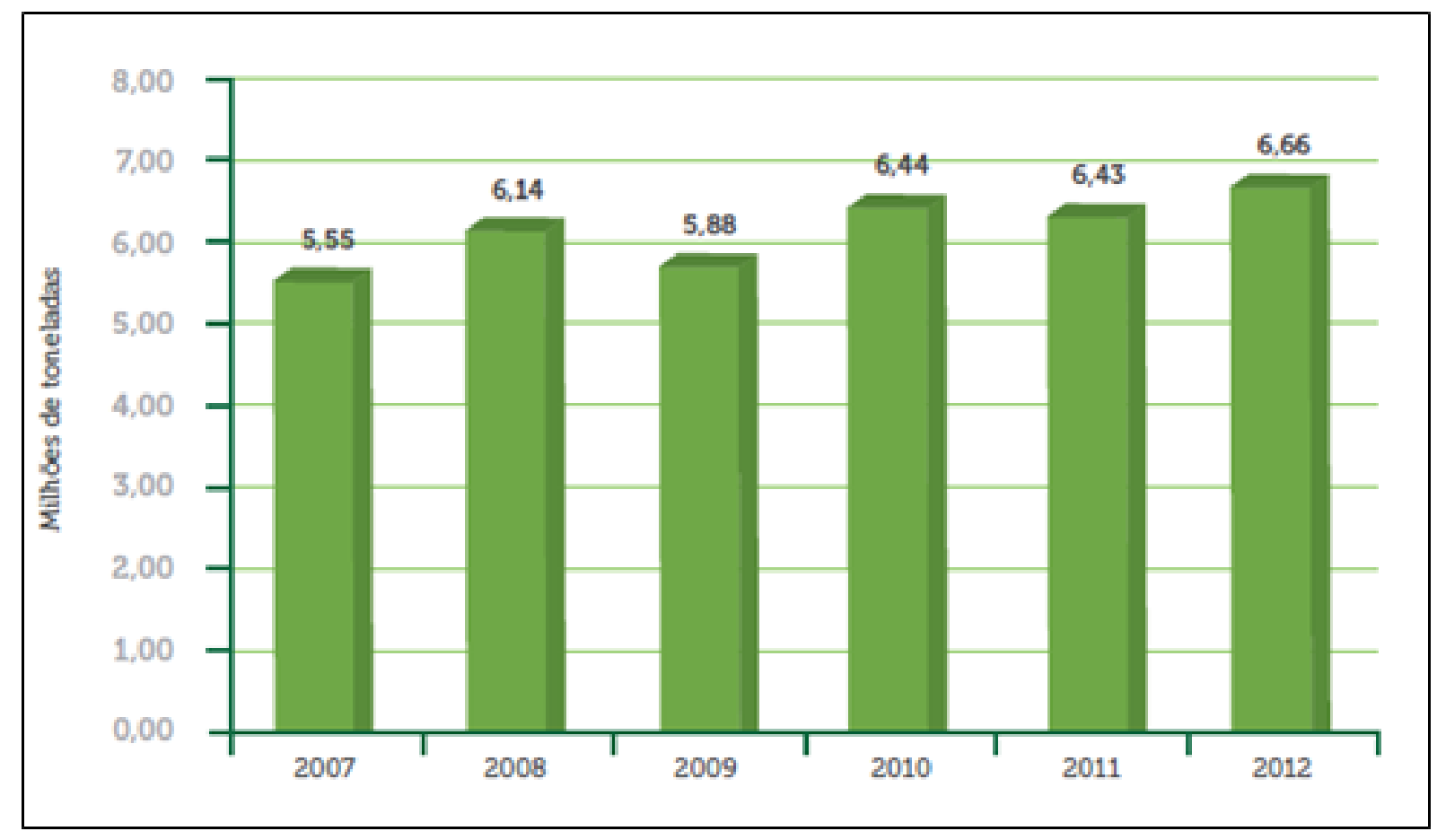

Fonte: ABIPLAST, (2017).

Na Figura 2 são mostradas as principais resinas termoplásticas consumidas no Brasil, sendo que os polietilenos se somadas as quantidades, representam um total de $39 \%$, e o polipropileno com um total de $27 \%$.

Figura 2 - Principais resinas termoplásticas consumidas no Brasil (2012)

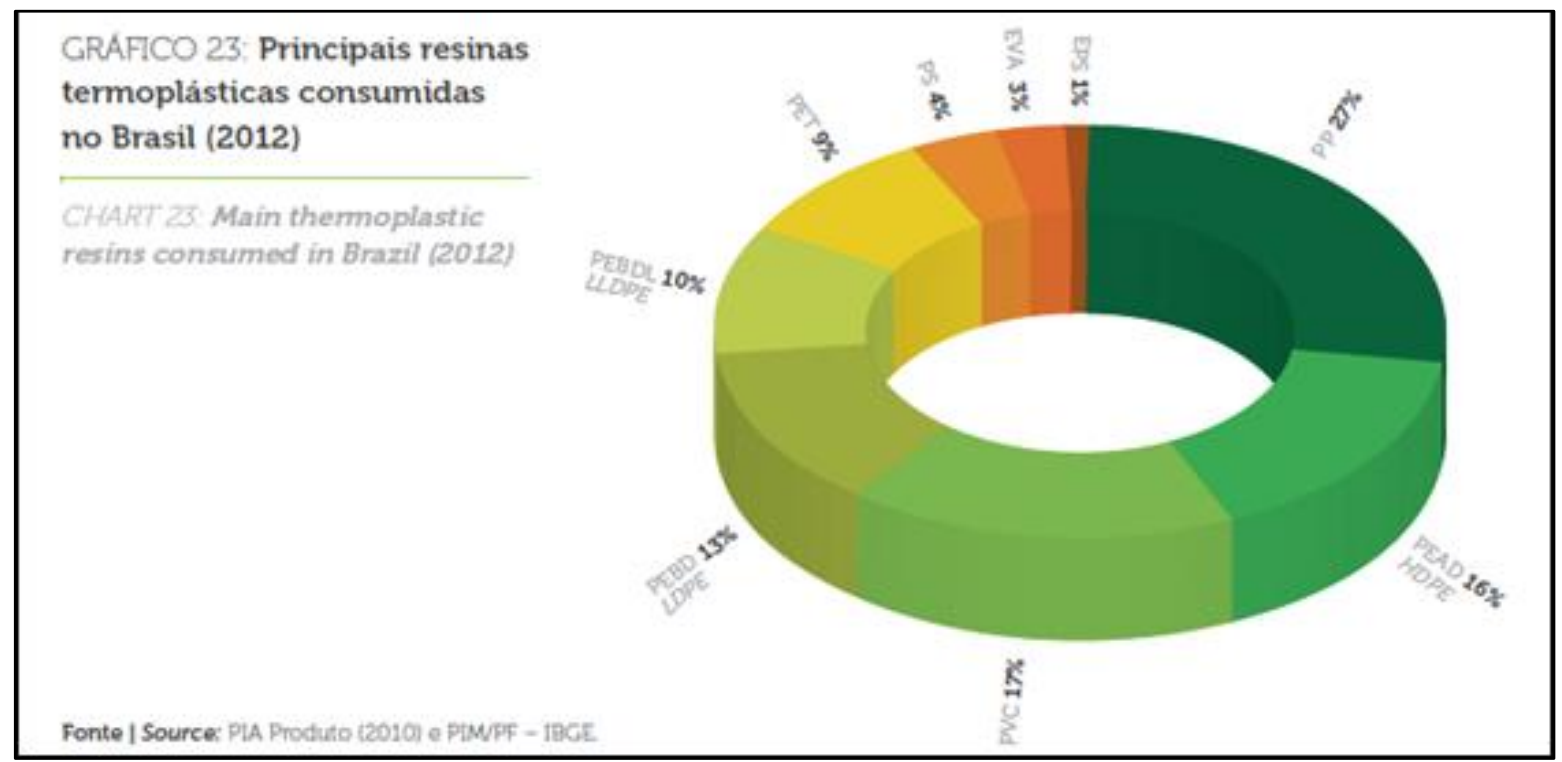

Fonte: ABIPLAST, (2017). 
A reciclagem, portanto, é ligada diretamente a geração de empregos, qualidade de vida da população (ABIPLAST, 2017). Cerca de US\$ 160 bilhões/ano é movimentado neste setor propiciando emprego para mais de 1,5 milhões de pessoas (SPINACÉ e PAOLI, 2005).

Embora os problemas do mal aproveitamento dos resíduos plásticos no mundo ainda seja muito deficiente, apenas $4 \%$ da produção mundial de petróleo se destina a indústria do plástico, sendo que tal fato não justifica a atual situação de lixões, aterros e o próprio meio ambiente (ABIPLAST, 2017).

Em 2014 a aplicação de plásticos reciclados foi de 615 mil toneladas em todo o Brasil. São Paulo representa cerca de $42,5 \%$ na participação no Brasil pelo número de empresas e distribuição de emprego no setor de transformados plásticos (ABIPLAST, 2017).

Na Figura 3 é mostrado que o consumo de resinas termoplásticas consumidas no Brasil em 2016 foi liderado pelos polietilenos e polipropilenos, e posteriormente o PVC.

Figura 3 - Resinas termoplásticas consumidas no Brasil em 2016 (\%)

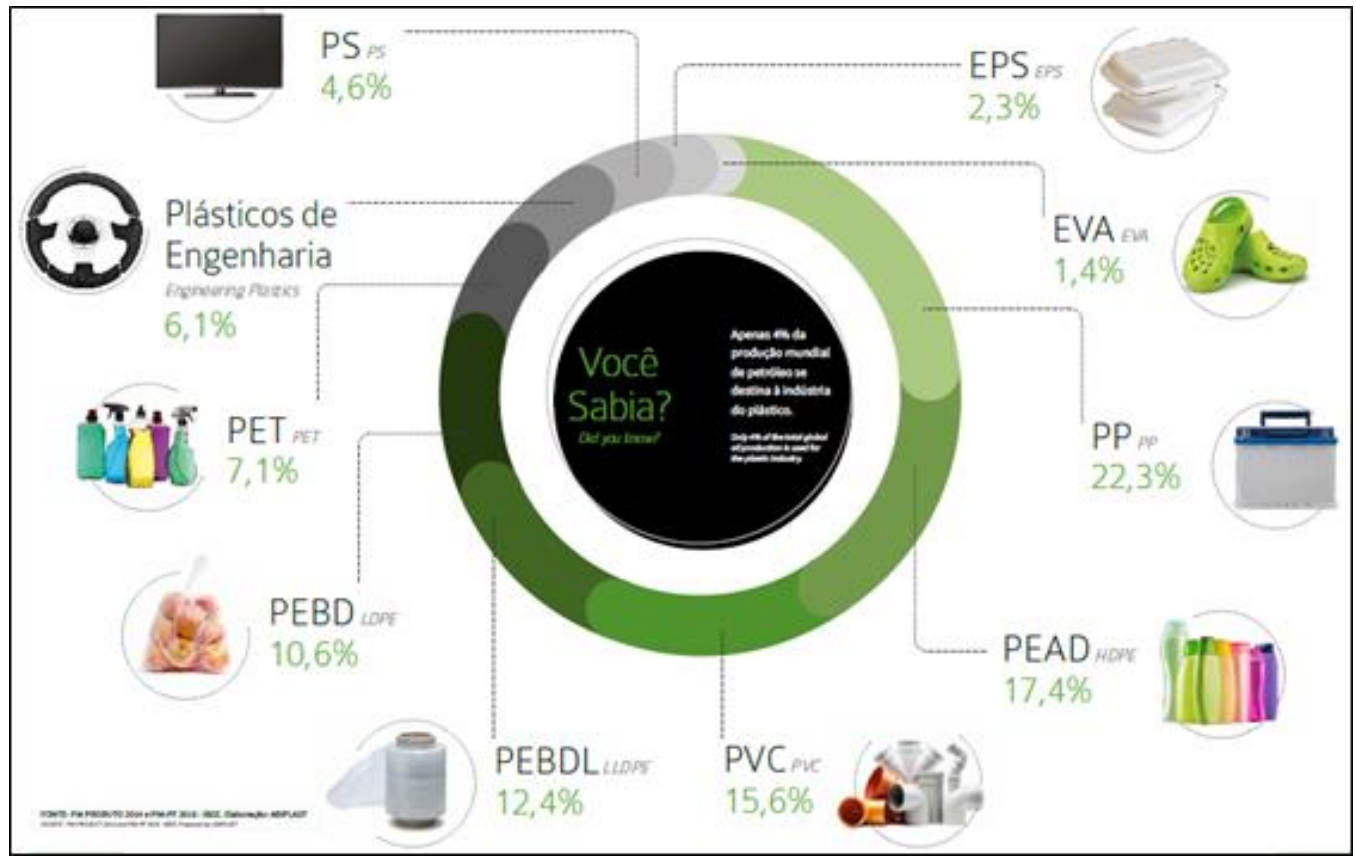

Fonte: ABIPLAST, (2017). 
Harada $(2017)^{2}$ define a reciclagem como meio de reaproveitar ou reprocessar um determinado material para torná-lo novamente como matéria-prima para novas fabricações (informação verbal).

As tecnologias de recuperação de plásticos podem ser divididas em duas classes, conforme a norma ISO 15270:

a) Recuperação de material: reciclagem mecânica, química e orgânica ou biológica.

b) Recuperação de energia em forma de calor, vapor, ou geração de eletricidade usando resíduos plásticos como substitutos de combustíveis fósseis primários.

2 Informação fornecida por Harada durante o curso de pós-graduação em Ciência e Engenharia de Polímeros na aula de Processos de Transformação da Faculdade Oswaldo Cruz, São Paulo, 2017. 


\subsection{RECICLAGEM MECÂNICA DO PEAD}

A reciclagem mecânica consiste na transformação física de resíduos pósconsumo e pós-industrial, em grânulos, ou em outro formato que permita o reaproveitamento para novas aplicações ou novas transformações (PLASTIVIDA, 2018).

Dentro dos tipos de resíduos plásticos encontrados podem-se citar os classificados como pós-industrial ou primários e os resíduos classificados como pósconsumo ou secundários. Os resíduos classificados como pós-industrial são aqueles que foram determinados pela empresa que os transformam como produtos não conforme, sendo descartados após a transformação. Sendo assim são mais limpos, portanto mais fáceis de reaproveitar, não demandando descontaminação e lavagem, e ainda normalmente tiveram perdas menos significativas de propriedades devido a terem sido reprocessados na maioria dos casos uma ou duas vezes. Já os resíduos classificados como pós-consumo são aqueles que de alguma forma chegaram até o consumidor final e descartados juntamente com o lixo comum. Portanto são contaminados, em maior parte por: óleos, gorduras, restos orgânicos, metais como parafusos, alças, cola, adesivos, grampos que dificultam e tornam o processo de reaproveitamento mais oneroso e demorado. Normalmente estes tipos de resíduos possuem valor agregado um pouco menor quando comparados com os resíduos primários. Existe ainda o risco de contaminação com outros polímeros no momento da separação e triagem. Na Figura 4 é mostrado um esquema ilustrativo das etapas da reciclagem mecânica de materiais plásticos como: triagem, moagem, lavagem e eventual separação por densidade, secagem, aglutinação, extrusão com posterior secagem e granulação (PIVA; NETO e WIEBECK, 1999).

Figura 4 - Fluxograma de reciclagem mecânica de resíduos plásticos

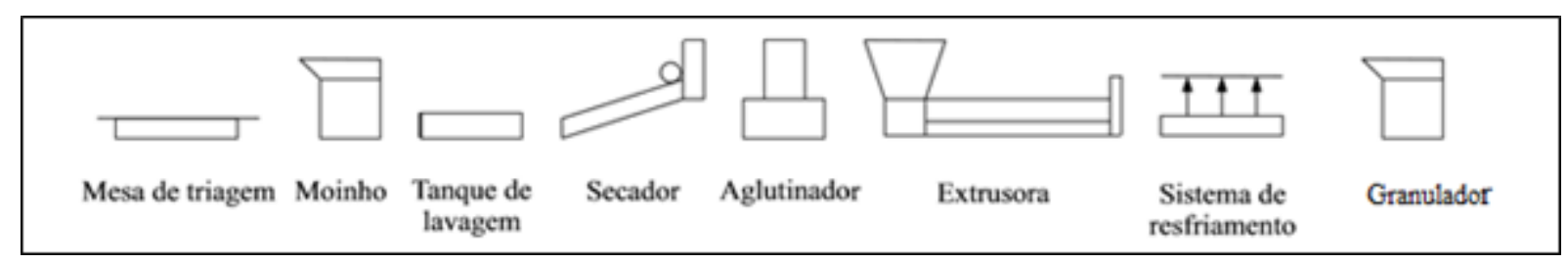

Fonte: Adaptado de PIVA, NETO e WIEBECK, (1999). 
É de extrema importância a correta separação dos resíduos assim que chegam até a recicladora, sendo este o processo de triagem. Diversos tipos de plásticos estão empregados nos produtos, portanto tal etapa é um fator determinante para se agregar valor aos produtos futuramente produzidos a partir destes resíduos. Os trabalhadores envolvidos realizam uma inspeção na separação utilizando técnicas como: amostra, simbologia, densidade e a mais popularmente conhecida por ser barata e de simples realização é a análise de queima. Após a separação os resíduos pré-selecionados são moídos e posteriormente transportados ao tanque de lavagem, ocorrendo a separação ou descontaminação por meio de densidade caso existam resíduos indesejados como metais, ou outros polímeros diferentes e mais densos. Posteriormente ocorre a secagem, armazenamento e o processamento que na maioria das vezes é o processo de extrusão granulação, que consiste em transformar o polímero em grãos, para posterior transformação em novos produtos.

Dentro das indústrias quando se utiliza resíduos primários, pode-se simplesmente realizar a moagem, e já realizar o reprocessamento das resinas, uma vez que estas não estejam contaminadas, como é o caso de diversos segmentos que utilizam diretamente o material moído como mostrado na Figura 5.

Figura 5 - PEAD após processo de moagem

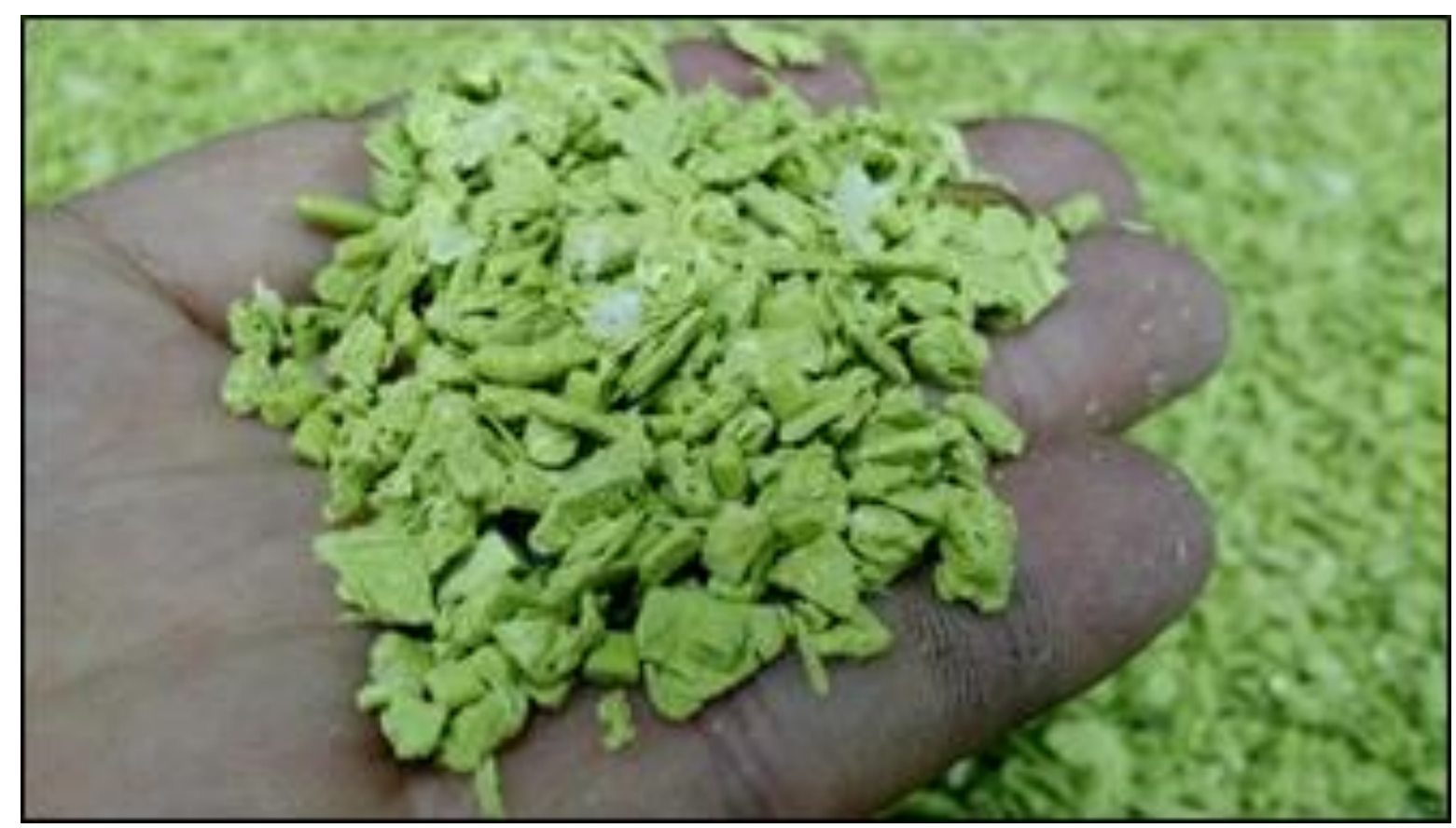

Fonte: Autoria própria. 
Neste contexto o processo de reciclagem mecânica é um processo que é viabilizado pelo volume de resíduos descartados pelas empresas e pelos consumidores, disponíveis para o processo de transformação.

De acordo com o Relatório NCHRP 696 (THOMAS; CUTTINO, 2011) o PEAD reciclado pós-consumo e pós-industrial foi utilizado na obtenção de tubos corrugados para drenagem pluvial. Foram estudadas as propriedades de curta duração por meio de ensaios de teor de cinzas e de resistência à tração e à flexão afim de verificar se de lote para lote as variações seriam significativas, pois os resíduos pós-consumo por exemplo, contêm porcentagens de frascos de leite com outros frascos coloridos podendo assim variar as propriedades e desempenho dos tubos. Os testes de fissuramento com entalhe e carga constante (NCTL) e fissuramento sob ligamento constante e entalhe (NCLS) também forneceram informações de resistência relativa ao fissuramento sob tensão entre os materiais analisados. Os resultados mostraram que os materiais coloridos pós-consumo foram excelentes candidatos a fabricação de tubos corrugados em PEAD. As médias de densidade ficaram bem próximas da resina virgem e as propriedades de resistência e módulo de flexão ficaram dentro das normas descritas na AASHTO M294 (American Associantion State Highway and Transportation Officials), para o tubo que especifica os requisitos e métodos para realização de testes em tubos corrugados de PEAD para drenagem. Porém a média do índice de fluidez ficou em torno de 0,5 g/10 minutos, enquanto o máximo descrito na norma M294 é de 0,4 g/10 minutos, mostrando baixa resistência ao fissuramento, e os contaminantes presentes podem atuar como iniciadores de fissuramento. $O$ contaminante PP foi analisado, e foi constatado que muitas vezes está presente nas tampas dos frascos fabricados em PEAD, o que provoca graus de contaminação entre diferentes polímeros. Os resultados mostraram que a porcentagem de PP até $5 \%$ de concentração mássica no PEAD não diminuiu a resistência sob fissuramento sob tensão.

ALZERRECA et al. (2015) avaliaram o uso de PEAD reciclado pós-consumo e pós-industrial na fabricação de tubos para sistemas de esgoto gravitacional. Por meio de ensaios mecânicos, térmicos e químicos realizados foi possível verificar os efeitos da degradação que ocorrem nos resíduos no momento do reprocessamento. Adicionalmente avaliaram o desempenho de curta e longa duração, como também a presença de possíveis contaminantes. O estudo avaliou quatro tipos de PEAD, sendo 
um deles material virgem indicado para uso em tubulações que atende a norma ISO 4427 que serviu como base para comparação com as demais amostras, e os outros três PEAD reciclados, sendo um de origem pós-industrial aditivado com agentes antioxidantes, o outro uma mistura de PEAD virgem e PEAD pós-industrial na concentração mássica em porcentagem de 80/20 respectivamente, e por fim um PEAD pós-consumo derivado de resíduos diversos. Os resultados para avaliação das propriedades mecânicas como módulo de Young e tensão de escoamento mostraram diferenças significativas entre as amostras, porém o grau de cristalinidade se mostrou praticamente o mesmo, cerca de $60 \%$ entre as amostras. Foi concluído que as diferenças encontradas podem ser associadas aos diferentes teores de contaminantes dispersos nas amostras. Os estudos de raios $\mathrm{X}$ mostraram que teores de cálcio, titânio, ferro e zinco estavam presentes em todos os materiais reciclados, como mostrados na Figura 6, o que pode ter proporcionado diferenciação significativa nos resultados de desempenho de curta e longa duração entre as amostras analisadas (ALZERRECA et al., 2015).

Figura 6 - B) $\mu$-XRF - Espectros obtidos pela técnica de Fluorescência de Raios X para a) PEAD virgem, b) mistura de PEAD virgem e de PEAD reciclado em concentrações mássicas de 80/20(\%) respectivamente, c) PEAD reciclado pós-industrial com adição de antioxidantes e d) PEAD reciclado pós-consumo. C) XPS - Espectros obtidos pela técnica de Espectroscopia de Raios X fotoelétron usada como análise quantitativa de c) PEAD reciclado pós-industrial com adição de antioxidantes e d) PEAD reciclado pós-consumo

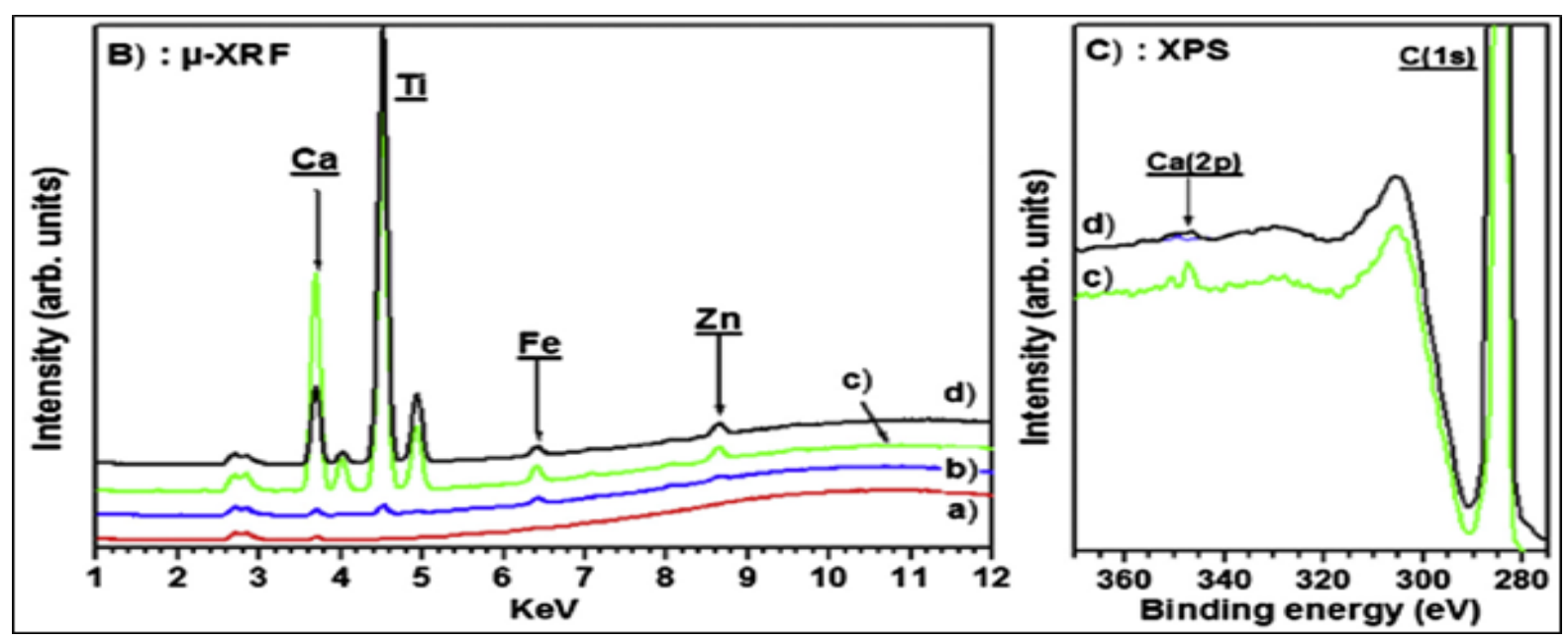

Fonte: ALZERRECA et al., (2015).

O estudo também mostrou que a média das massas molares, a densidade das ramificações curtas e a presença de comonômero na estrutura do material estão correlacionadas com as propriedades de fluência e fadiga que são propriedades 
relacionadas ao desempenho de longa duração, sendo que o PEAD reciclado apresentou propriedades inferiores ao material virgem, uma vez que a taxa de cisalhamento e temperatura durante o processamento podem provocar diminuição das massas molares, e ainda proporcionar ligações cruzadas. O estudo também apontou que a adição de partículas inorgânicas como cálcio e titânio podem melhorar as propriedades de rigidez e dureza reduzindo a susceptibilidade a fluência em vários polímeros matrizes, porém quando a dispersão e a natureza das partículas não são uniformes podem acelerar a ruptura (ALZERRECA et al., 2015).

Na Figura 7 são mostradas as imagens obtidas por microscopia eletrônica de varredura em que há a presença de pequenas partículas na parte inferior dos micro vazios. Tais observações sugerem que estas pequenas partículas desempenham um importante papel como concentradores e facilitadores de nucleação de micro vazios, que promovem o crescimento de trincas. De acordo com o estudo o crescimento dos micro vazios no PEAD sob carga constante é considerado o primeiro estágio no processo de fissuramento, precedendo a propagação e a fratura total, a ruptura total do material ocorre após a propagação da zona de deformação, que inicialmente se forma na ponta da trinca (ALZERRECA et al., 2015).

Figura 7 - A) - Imagem obtida por microscopia eletrônica de varredura de uma área típica do PEAD reciclado, e os mapeamentos elementares de raios $\mathrm{X}$ de Ti ka e Ca Ka medidos na mesma área

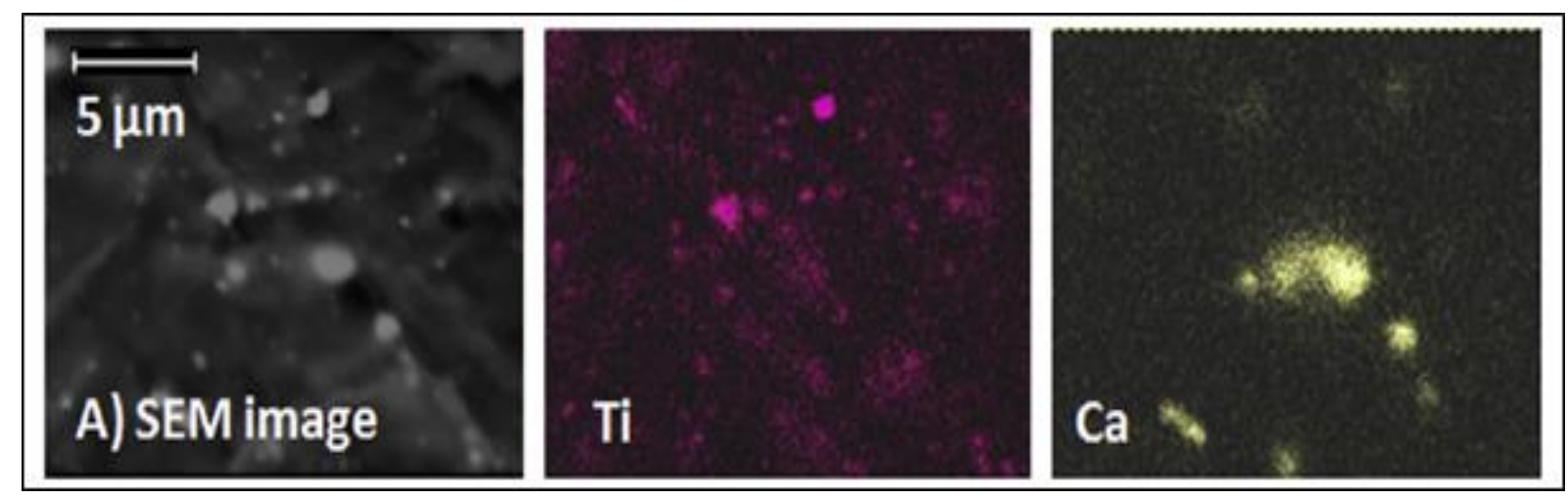

Fonte: ALZERRECA et al. (2015).

Dentro desse contexto pode-se verificar a possibilidade da utilização de PEAD reciclado para certas aplicações estruturais, porém para sua reutilização é preciso caracterizar e quantificar materiais que possivelmente possam afetar as propriedades de longa duração. 


\subsubsection{Contaminantes}

Contaminante é qualquer substância num ambiente ao qual não pertença que pode causar problemas ou impactos significativos (CIMM, 2019). Dentro desse contexto estão classificados neste estudo os materiais adicionados ao material de PEAD como contaminantes, pois podem reduzir significativamente as propriedades de curta e de longa duração. Normalmente em um processo de desenvolvimento de novos produtos, a engenharia visa selecionar materiais que contemplem as exigências técnicas do produto com custos menores. Para tanto, muitos materiais com custo compatíveis ao projeto não possuem todas as propriedades exigidas pelos produtos, necessitando assim de aditivação.

Aditivos são materiais que adicionados aos polímeros visam melhorar o desempenho, tanto do ponto de vista de propriedades quanto de processamento. Diversos tipos de aditivos são usados na indústria de plásticos como por exemplo: antioxidantes, antiestáticos, retardantes de chama, absorvedores de luz ultravioleta, lubrificantes, entre outros (JUNIOR; NUNES e ORMANJI, 2002). Existe ainda a possibilidade do uso de possíveis cargas e reforços como carbonato de cálcio, dióxido de titânio, talco, dióxido de silício, fibra de vidro, fibra de carbono, grafite, bissulfeto de molibdênio, entre outros. Quando estes materiais estão todos misturados como é o caso de materiais reciclados que são provenientes de diversas fontes de resíduos, tais aditivos podem atuar como contaminantes produzindo assim redução de desempenho de curta e longa duração.

ALZERRECA et al. (2015) avaliaram o uso de PEAD reciclado para uso em tubulações de esgoto por gravidade e encontraram por meio de ensaios de fluorescência por raios $X$ nas amostras analisadas teores de cálcio, titânio, ferro e zinco. As avaliações das propriedades de curta duração e longa duração retornaram resultados com diferenciação significativa, porém os graus de cristalinidade praticamente se mantiveram inalterados quando comparados os materiais reciclados com o virgem, sendo assim as diferenças atribuídas aos contaminantes dispersos no polímero matriz. 
O volume de polietilenos consumidos no mercado de transformação vem aumentando gradativamente. Nesse contexto, há uma preocupação em nível mundial para buscar soluções que minimizem os impactos causados pelo uso e descarte destes materiais, uma vez que esses podem ocasionar vários problemas ambientais. O impacto no meio ambiente é reduzido com a diminuição do consumo de plásticos virgens. Isso é possível quando materiais poliméricos pós-consumo são reutilizados. (REIS; PACHECO e MATTOS, 2014).

Umas das grandes dificuldades encontradas também em outros estudos são as grandes concentrações de contaminantes, substâncias que adicionadas aos materiais podem proporcionar um impacto significativo nas propriedades do material, normalmente deletério (REIS; PACHECO e MATTOS, 2014).

De acordo com VASCONCELOS; BASSO e VALERA (2018), em estudo realizado para avaliação dos efeitos de contaminantes no desempenho em longa duração de PEAD reciclado em aplicações estruturais, foram encontrados em todas as formulações apresentadas de PEAD reciclado de origem pós-consumo e também de origem pós-industrial quatro tipos diferentes de contaminantes em razão de que o PEAD possui diversos grades, cores, pigmentos e aditivos incorporados. Foram avaliados três grades de origem pós-consumo e um de origem pós-industrial, sendo este último proveniente de uma empresa fabricante de tubos para drenagem pluvial a partir de PEAD reciclado. O estudo avaliou influência dos contaminantes nas propriedades do PEAD no desempenho de longa duração e para tanto, devia-se conhecer quais eram os contaminantes. As caracterizações foram feitas por difração de raios $X$ e por microscopia eletrônica de varredura após calcinação, a fim de verificar as fases cristalinas presentes nos materiais. Os resultados mostraram que os contaminantes repetidamente encontrados em todas as amostras eram polipropileno, dióxido de titânio, dióxido de silício e carbonato de cálcio.

O polipropileno normalmente é encontrado em polímeros reciclados, uma vez que diversos produtos como garrafas e frascos feitos por exemplo de PEAD possuem a tampa e muitas vezes rótulos confeccionados em PP. Um estudo realizado por (THOMAS e CUTTINO, 2011) para o NCHRP que visava avaliar as propriedades de densidade, índice de fluidez, alongamento na ruptura, e dois ensaios diferentes para 
fissuramento sob tensão, tensão constante e carga constante, avaliou 67 resinas recicladas de PEAD e todas elas apresentaram proporções com $2 \%, 5 \%$, e $10 \%$ de polipropileno. Os resultados mostraram que das propriedades analisadas o índice de fluidez e a densidade variavam previsivelmente conforme as concentrações encontradas, pois o PP tem uma maior fluidez e uma menor densidade. Foram reportados também uma tendência a redução nos valores de alongamento na ruptura com o aumento da porcentagem de polipropileno, o que reflete baixa miscibilidade no momento do processo de extrusão e uma interface pobre dos materiais.

\subsubsection{Polipropileno}

O PP é um material termoplástico semicristalino que começou a ser comercializado na década de 50 devido aos catalisadores tipo "Ziegler - Natta", capazes de produzir polipropilenos de elevada massa molar e alto controle de taticidade (FERNANDEZ, 2014).

Os polipropilenos exibem propriedades compatíveis para aplicações em diversos segmentos, porém a grande concentração de aplicações que geram descartes de resíduos em grande volume, são as de curto tempo de vida em serviço, como embalagens, frascos, utensílios domésticos, filmes entre outras, que muitas vezes são usados em conjunto com produtos fabricados em PEAD, como tampas e rótulos, fato este que propicia a contaminação no momento da separação para posterior reciclagem, uma vez que ambos possuem propriedades e aplicações para embalagens (FREITAS, 2008).

Estudos mostram que a presença de polipropileno em PEAD reciclado não é favorável ao desempenho de curta e longa duração, uma vez que devido as diferenças entre os pontos de fusão dos dois materiais a blenda se torna imiscível, a interface entre os polímeros fica pobre, resultando assim em propriedades físicas e mecânicas não compatíveis com certas aplicações. Por este motivo o uso de agentes compatibilizantes se faz necessário para o processamento desses dois polímeros (DIKOBE e LUYT, 2017).

O estudo realizado pelo departamento de estradas e rodagens americano NCHRP avaliou 67 tipos de PEAD reciclado com diferentes teores de polipropileno 
$2 \%, 5 \%$ e $10 \%$. Os resultados mostraram que para os ensaios de índice de fluidez e de densidade houveram variações significativas e previsíveis, uma vez que o polipropileno apresenta maior fluidez e menores densidades quando comparados ao PEAD. Na Figura 8 é mostrada uma tendência na redução dos valores de alongamento na ruptura com o acréscimo dos teores de polipropileno, mostrando falta de miscibilidade entre os polímeros. Nas Figuras 9 e 10 são mostradas uma tendência a redução da densidade e aumento do índice de fluidez respectivamente, com o acréscimo dos teores de polipropileno (THOMAS e CUTTINO, 2011).

Figura 8 - Influência do teor de polipropileno na propriedade de alongamento na ruptura

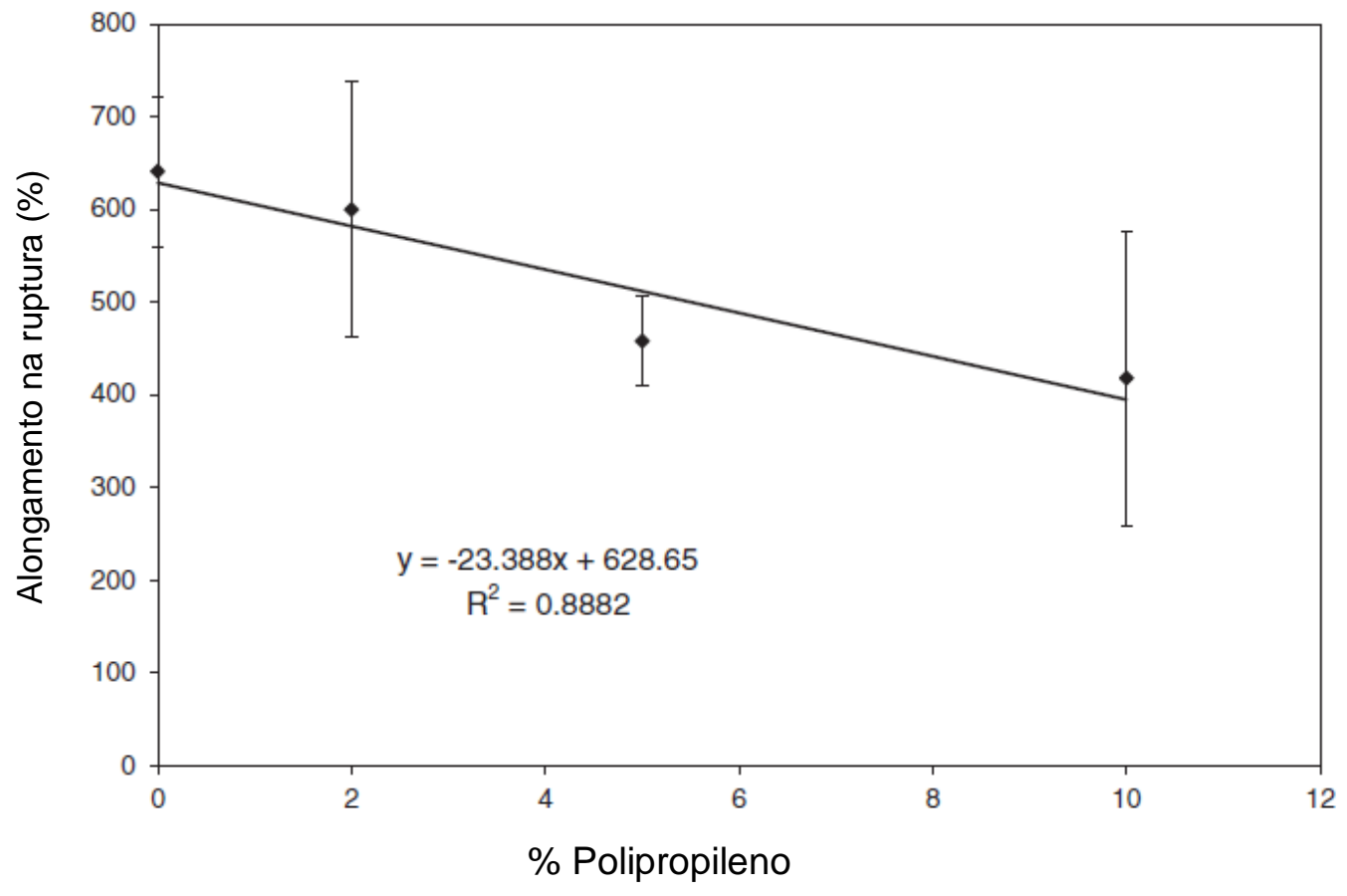

Fonte: THOMAS e CUTTINO (2011). 
Figura 9 - Influência do teor de polipropileno na densidade da mistura

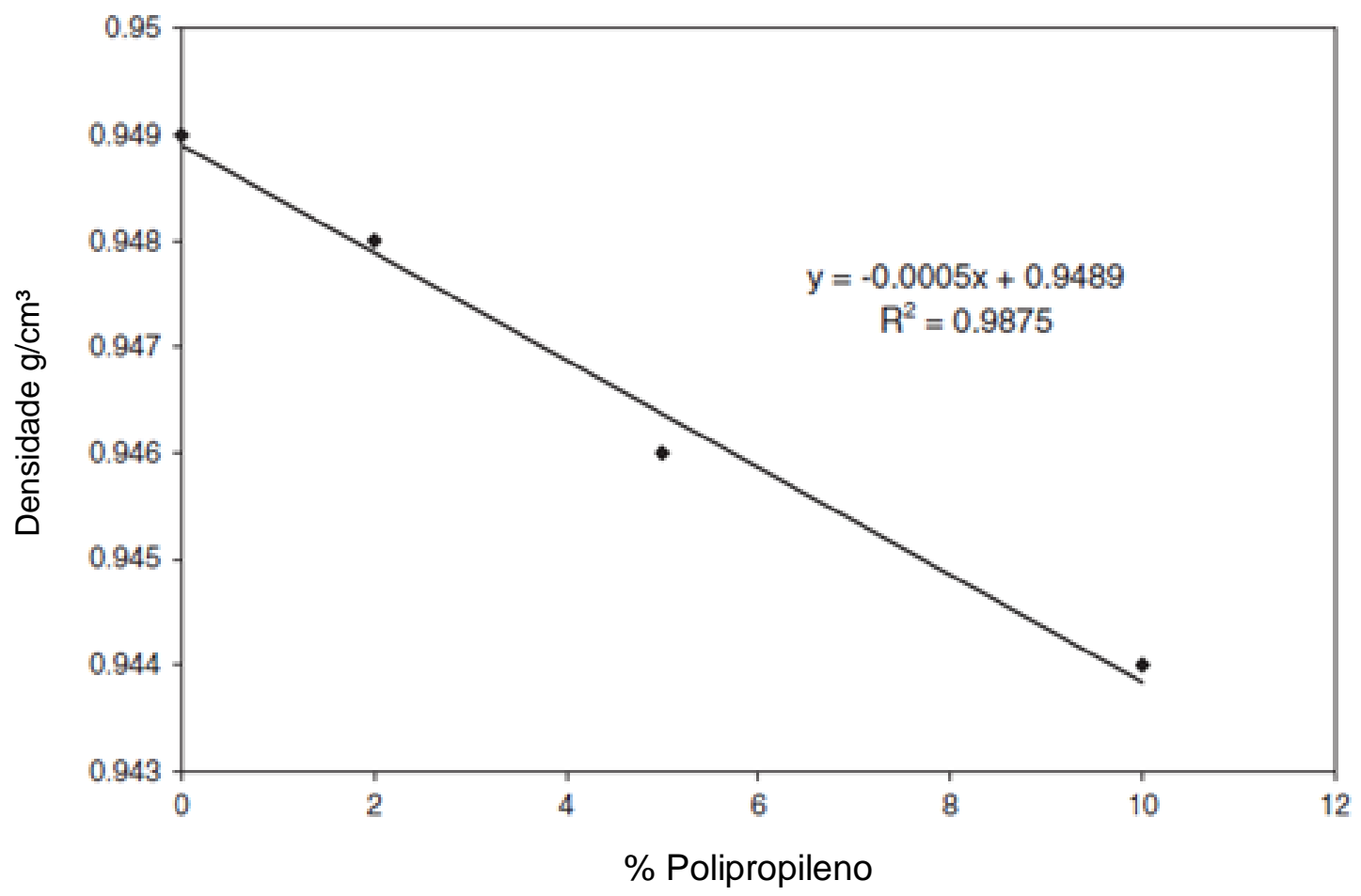

Fonte: THOMAS e CUTTINO (2011).

Figura 10 - Influência do teor de polipropileno no índice de fluidez

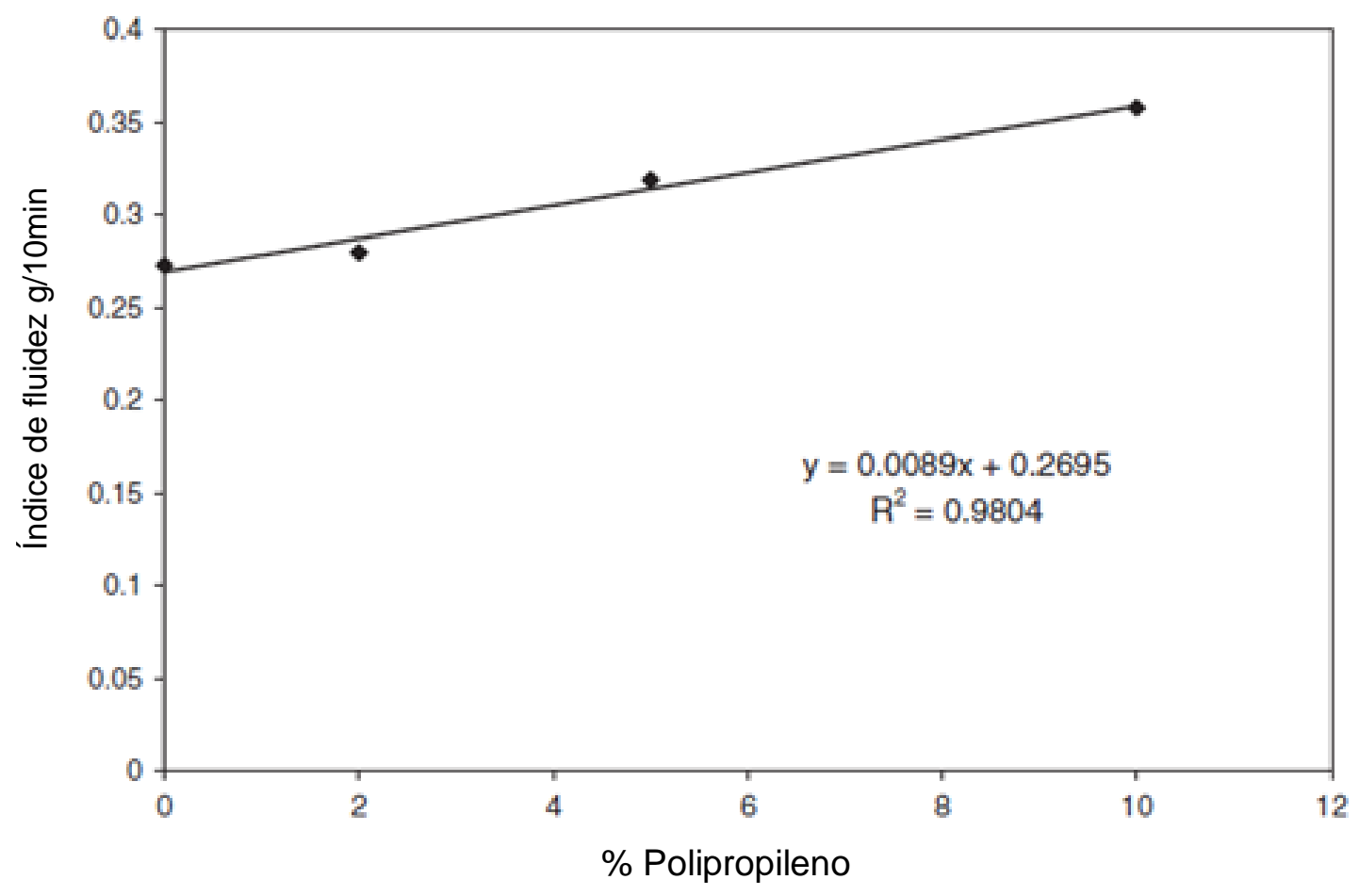

Fonte: THOMAS e CUTTINO (2011). 
O estudo também avaliou a resistência ao fissuramento sob tensão por meio de ensaios de NCLS, em que os resultados mostraram uma redução significativa a resistência ao fissuramento sob tensão com entalhe a partir de cerca de $5 \%$ de polipropileno como mostrado na Figura 11, sendo que os resultados deste ensaio foram normalizados com todas as amostras submetidas a mesma carga aplicada. Diante dos resultados o estudo adotou como critério a concentração máxima de 5\% de polipropileno no PEAD reciclado para a produção de tubos corrugados no processo de extrusão (THOMAS e CUTTINO, 2011).

Dentro desse contexto os resultados permitiram que fossem adotados os teores de $8 \%$ de polipropileno e demais contaminantes no PEAD para este estudo, no intuito de simular o material reciclado, uma vez que são esperadas mudanças significativas no desempenho de longa duração.

Figura 11 - Efeitos do teor de polipropileno no ensaio de NCLS

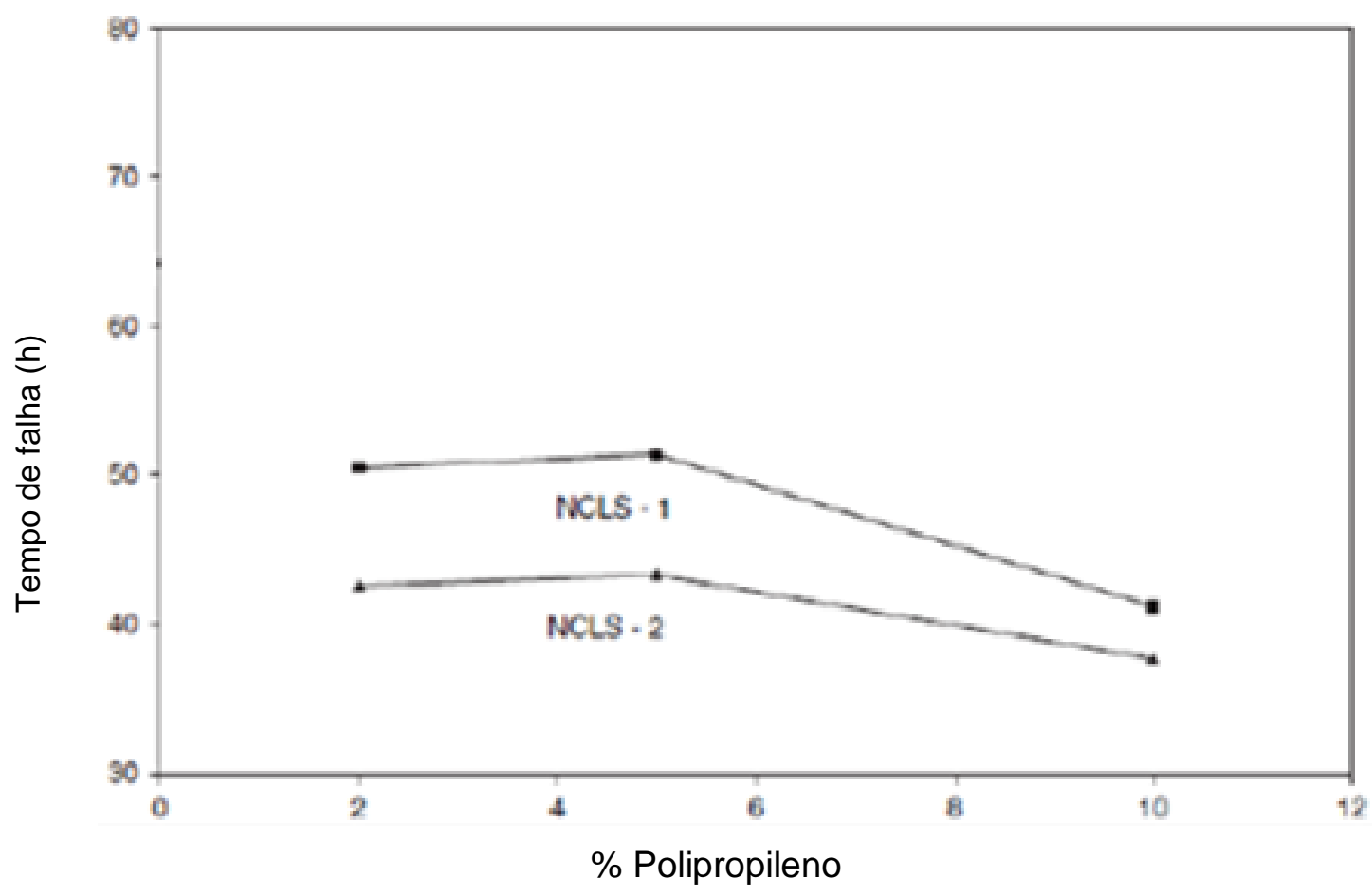

Fonte: THOMAS e CUTTINO (2011). 


\subsubsection{Carbonato de cálcio}

O carbonato de cálcio é abundantemente encontrado na natureza e pode ser encontrado em diferentes formas cristalinas (POVEDA, 2015).

Por meio da exploração de jazidas pode-se obter o mineral de carbonato de cálcio, destacando-se a calcita, calcário e mármore. Com a moagem, o carbonato de cálcio natural é obtido e classificado de acordo com o tamanho das partículas que são selecionadas por peneiras específicas. O tamanho das partículas tem influência direta nas propriedades mecânicas e acabamento superficial do produto final, uma vez que as partículas menores contribuem para estes fatores serem acentuados (JUNIOR; NUNES e ORMANJI, 2002).

Os carbonatos de cálcio podem ter suas partículas revestidas para conferir características hidrofóbicas as suas superfícies, melhorando assim o fluxo do pó, melhor dispersão na massa polimérica, melhores características de fluxo do fundido, menor absorção superficial de óleo ou plastificante, melhor acabamento superficial, e melhores propriedades mecânicas (JUNIOR; NUNES e ORMANJI, 2002).

De acordo com o estudo realizado para avaliar os efeitos do nano compósito de PEAD/PEBDL $\mathrm{Com} \mathrm{CaCO}_{3}$ nas propriedades morfológicas, mecânicas e reológicas de chapas de polietileno, os resultados mostraram que o módulo de tração e a resistência ao impacto $I Z O D$ aumentaram com o acréscimo do nano $\mathrm{CaCo}_{3}$, enquanto a tensão de ruptura diminuiu. Adicionalmente foi constatado que o índice de fluidez diminuiu com acréscimo do nano $\mathrm{CaCo}_{3}$, fato este que pode impactar significativamente no processamento do compósito (ZAMAN, 2014).

No passado, o uso de cargas em geral era normalmente voltado a redução de custos do material final, porém, atualmente os materiais carregados são usualmente utilizados para desempenhar papéis funcionais, como no incremento de propriedades térmicas ou mecânicas (IPPOLITO et al., 2019). 


\subsubsection{Dióxido de titânio}

O dióxido de titânio é um óxido metálico e semicondutor, encontrado nas formas alotrópicas, brookita, anatase e rutilo. Anatase e rutilo são as formas cristalinas mais utilizadas e comercializadas como forma de pigmento branco para as indústrias de plásticos, fibras sintéticas, papel, vidro, entre outros (VALLE, 2018).

Confere cobertura, brilho e alto poder de espalhamento de luz, é insolúvel e muito estável a altas temperaturas, o que permite as condições agressivas de processamento (JUNIOR; NUNES e ORMANJI, 2002).

O dióxido de titânio assim como outros pigmentos brancos conferem cor por meio de fenômenos de refração e difração da luz, ao contrário de outros pigmentos coloridos que conferem cor ao substrato por meio de fenômenos de absorção de parte do espectro de luz visível. Assim quanto maior o teor de pigmento branco maior será o seu índice de refração e maior será o grau de desvio da trajetória da luz, voltando para a superfície e tornando branco e opaco (JUNIOR, NUNES e ORMANJI, 2002).

$\mathrm{Na}$ Tabela 1 é apresentado o índice de refração de alguns minerais utilizados em plásticos. Pode-se observar que quanto maior o índice de refração, maior a eficiência do mineral quando utilizado como pigmento branco (JUNIOR; NUNES e ORMANJI, 2002).

Tabela 1 - Índice de refração de alguns minerais utilizados em plásticos

\begin{tabular}{|lc|}
\hline Mineral & Índice de refração \\
\hline Dióxido de titânio, rutilo & 2,73 \\
\hline Dióxido de titânio, anatase & 2,55 \\
\hline Óxido de antimônio & $2,09-2,29$ \\
\hline Óxido de zinco & 2,02 \\
\hline Carbonato básico de chumbo & $1,94-2,09$ \\
\hline Litopónio & 1,84 \\
\hline Caulim & 1,65 \\
\hline Silicato de magnésio & 1,65 \\
\hline Barita (sulfato de bário) & 1,64 \\
\hline Carbonato de cálcio & 1,63 \\
\hline Silica & $1,41-1,49$ \\
\hline PVC & 1,48 \\
\hline
\end{tabular}

Fonte: JUNIOR, NUNES e ORMANJI, 2002.

Diversos particulados rígidos são incorporados nos polietilenos para promover redução de custo, porém quando utilizados em escala nanométrica novas 
possibilidades podem ser conseguidas, uma vez que os nano particulados aumentam a superfície de contato, resultando em uma melhor adesão entre o polímero matriz e a carga utilizada (PANAITESCU et al., 2011).

PANAITESCU et al. (2011) estudaram a influência de nano partículas de $\mathrm{TiO}_{2}$ anatase e rutilo nas propriedades do PEAD, sendo que o estudo revelou uma melhor dispersão das nano partículas e um incremento nas propriedades mecânicas sob o método de masterbaches. Adicionalmente os resultados não mostraram mudanças significativas nas propriedades mecânicas e reológicas entre os compósitos de polietileno/anatase e polietileno/rutilo, exceto um aumento significativo no módulo elástico nos compósitos contendo anatase.

\subsubsection{Dióxido de silício}

A fase estável da sílica $\left(\mathrm{SiO}_{2}\right)$ à temperatura ambiente, conhecida como quartzo$\alpha$, é um dos minerais mais abundantes da crosta terrestre, cerca de $12 \%$. Ela ocorre na composição de rochas magmáticas, sedimentares e metamórficas, na forma monocristalina (quartzo hialino, ametista, citrino, entre outros), na forma poli cristalina (quartzito, calcedônia e ágata), e amorfa (opala) (LUZ e LINS, 2008).

A adição de sílica em polímeros é uma técnica bastante conhecida pela indústria, a fim de modificar as propriedades do polímero e torná-los mais compatíveis as suas aplicações. Como por exemplo adição de quartzo moído em resinas epóxi, o que melhora suas propriedades térmicas. Diversos trabalhos mostraram que este tipo de adição é capaz de fazer com que a resina apresente melhores propriedades mecânicas em temperaturas mais altas. A adição de sílica também é capaz de reduzir a condutividade elétrica, o que é interessante para aplicação de isolantes. Adicionalmente o estudo revelou que pode-se obter um aumento de condutibilidade térmica, propiciando no caso do poliuretano com adição de sílica, um resfriamento mais rápido das peças, gerando um ganho de produtividade (BMRC, 2014).

BATISTA e KIECKOW (2016), estudaram a aplicação de $\mathrm{SiO}_{2}$ na matriz polimérica PEUHMW (polietileno de ultra alto peso molecular) para colheitadeira de arroz. Com a fabricação deste material compósito conseguiu-se um aumento na 
resistência ao desgaste de 49,5\% em relação ao PEUHMW natural e diminuição nos custos de manutenção do equipamento de colheita, mostrando para esta aplicação uma melhora nas propriedades desejadas.

SIMENDIC et al. (2004) estudaram os efeitos de nucleantes no comportamento de cristalização de polipropileno isotático. Foram comparados diferentes teores mássicos de $\mathrm{SiO}_{2}$, variando de $0,5 \%$ a $3 \%$ adicionados ao polipropileno em diferentes temperaturas de cristalização, sendo $0^{\circ} \mathrm{C}, 100^{\circ} \mathrm{C}, 120^{\circ} \mathrm{C}$ e $140^{\circ} \mathrm{C}$. Os resultados mostraram que previsivelmente o grau de cristalinidade aumentou a medida que a temperatura de cristalização também aumentou, independentemente do tipo e do teor de nucleante utilizado. O grau máximo de cristalinidade foi obtido com concentração de $1 \%$ de nucleante, variando também o tamanho dos cristalitos observados por difração de Raios X.

Dentro desse contexto pode-se obter mudanças significativas nas propriedades dos materiais, uma vez que se consegue variar o grau de cristalinidade, o tamanho dos cristalitos, mudanças nas formas cristalinas e diferentes temperaturas de cristalização. Sendo assim, tais mudanças podem favorecer a aplicação de nucleantes para melhorar propriedades de barreira em embalagens como por exemplo, uma vez que para filmes finos a permeabilidade de vapores e oxigênio varia de acordo com a quantidade de frações amorfas na estrutura. Outras propriedades podem ser melhoradas regulando a cristalinidade dos materiais adicionando nucleantes, como tempo de ciclo de produção, propriedades ópticas melhoradas, propriedades mecânicas e também estabilidade dimensional (SIMENDIC et al., 2004), porém tais materiais quando misturados como é o caso dos resíduos plásticos a serem reciclados podem acabar atuando como contaminantes, concentradores de tensão e reduzindo o desempenho de longa duração. 


\subsection{FISSURAMENTO SOB TENSÃO}

O fissuramento sob tensão (stress cracking) é um processo de desprendimento das cadeias moleculares, onde prevalecem os escorregamentos entre as microfibrilas, em que as poliolefinas são mais sensíveis ao fenômeno, enquanto os polímeros mais complexos e com domínios interfibrilares mais resistentes são praticamente imunes (LAVOIE e BUENO, 2006).

Para avaliação dos tempos de falha dos materiais em anos são associados os mecanismos de formação de fissuras, a evolução da zona de defeito e a propagação ao restante do material em questão. Normalmente para esta avaliação utiliza-se da aplicação interna de pressão, mas o custo e a duração deste teste podem se tornar inviáveis para muitas aplicações. Nesse contexto outras formas de avaliar a propagação lenta de trincas de modo mais acelerado foram desenvolvidos, afim de simular a falha (ADIB, 2015).

Ensaios como o PENT (Pennsylvania Edge- Notch Tensile) e o FNCT (Full Notch Creep Tests) têm sido utilizados e aceitos para a avaliação da propagação lenta de trincas, porém com as novas gerações de PE que apresentam elevada resistência ao fissuramento sob tensão, o tempo de ensaio muitas vezes se torna demasiado, algumas vezes excedendo $10.000 \mathrm{~h}$ inviabilizando as avaliações, além de que a morfologia da fratura não se relaciona ao mecanismo de propagação lenta que ocorre quando aplicado em campo (ADIB, 2015).

Quando se deseja utilizar resíduos de materiais plásticos como por exemplo de PEAD reciclado, ensaios em ambientes muito agressivos como o PENT podem não representar resultados de forma compatível, inviabilizando comparações efetivas entre diferentes polímeros devido ao curto tempo de falha, pois tais materiais podem apresentar níveis de degradação em estágios acelerados conforme foram processados e inclusões de possíveis contaminantes. Para tanto existem dois métodos padronizados para avaliação quanto ao fissuramento sob tensão de polímeros: o ensaio de NCLS (Notched, Constant Ligament-Stress) e o NCTL (Notched Constant Tensile Load Test), os quais são padronizados pelas normas ASTM F2136-18 e ASTM D5397, respectivamente. As principais diferenças entre os ensaios de NCLS e NCTL são as cargas aplicadas nos corpos de prova (THOMAS e CUTTINO, 2011). 
O ensaio de UCLS (Un-notched, Constant Ligament-Stress), possui vantagens frente aos ensaios de NCLS e NCTL, pois os corpos de prova não possuem entalhe, de modo que a avaliação do fissuramento se dará em função dos diferentes contaminantes presentes nas amostras, e ainda os corpos de prova de UCLS apresentam maiores dimensões, de forma a aumentar a quantidade de partículas contaminantes na região analisada. Uma desvantagem é o tempo de ensaio demasiado inviabilizando em alguns casos o seu uso uma vez que os únicos concentradores de tensão serão os contaminantes dispersos nas amostras. $O$ ensaio de UCLS foi desenvolvido tendo como base o ensaio de NCLS e, da mesma forma os corpos de prova são imersos em um líquido aquecido e submetidos a um carregamento constante com posterior avaliação do tempo necessário para a falha do material e são baseados nos conceitos de mecânica da fratura.

Quando carregamentos constantes são aplicados no material de PEAD, duas são as causas principais das falhas: solda inadequada ou existência de pequenos defeitos internos que podem gerar o crescimento lento de trincas no material. Uma terceira possibilidade para a falha ocorrer é a rápida transição dúctil-frágil com propagação rápida de trincas em baixa temperatura, principalmente em países nórdicos (SCHOUWENAARS et al., 2007).

O crescimento lento de trincas é um fenômeno comum em PEAD, ocorre abaixo do ponto de escoamento, e apresenta morfologia frágil. Esse fenômeno tem origem em pontos concentradores de tensão e compreende vários estágios: após o início da trinca, a partir de entalhes, riscos ou imperfeições, micro vazios, se formam na ponta da trinca. Esses micro vazios crescem gradualmente, dando origem a vazios ainda maiores, originando fibrilas de material altamente orientado, processo esse conhecido como fissuração. Esse fenômeno é governado pela tensão global ao redor da fissura e a resistência a extensão dessas fibrilas governam o crescimento da trinca até a falha (ADIB et al., 2015).

Na Figura 12 é mostrada uma representação hipotética do tempo de vida em serviço de longo prazo do polietileno de alta densidade, em que são apresentadas três regiões distintas de envelhecimento. A primeira região representada pela designação Estágio I - dúctil se refere a carregamentos mecânicos expressivos (acima de $30 \%$ da tensão de escoamento) correspondente ao tempo de vida do material em serviço. A segunda região se refere aos carregamentos intermediários e envolve falhas por 
propagação lenta de trincas relacionadas ao fissuramento sob tensão, designada como Estágio II - frágil. A terceira região designada como Estágio III - químico se refere quando o material está submetido a uma baixa tensão, e a falha só irá aparecer quando os aditivos tiverem sido completamente consumidos e tiver ocorrido a degradação oxidativa (THOMAS e CUTTINO, 2011), em que o tempo de falha é definido pela Equação (1):

$$
t_{S C G}=t_{\mathrm{if}}+t_{\mathrm{pf}}
$$

em que:

$t_{S C G}=$ tempo total para a propagação lenta de fissuras

$t_{\text {if }}=$ tempo para o início da fissura

$t_{\mathrm{pf}}=$ tempo para a propagação da fissura

Figura 12 - Tempo de vida hipotético do PEAD

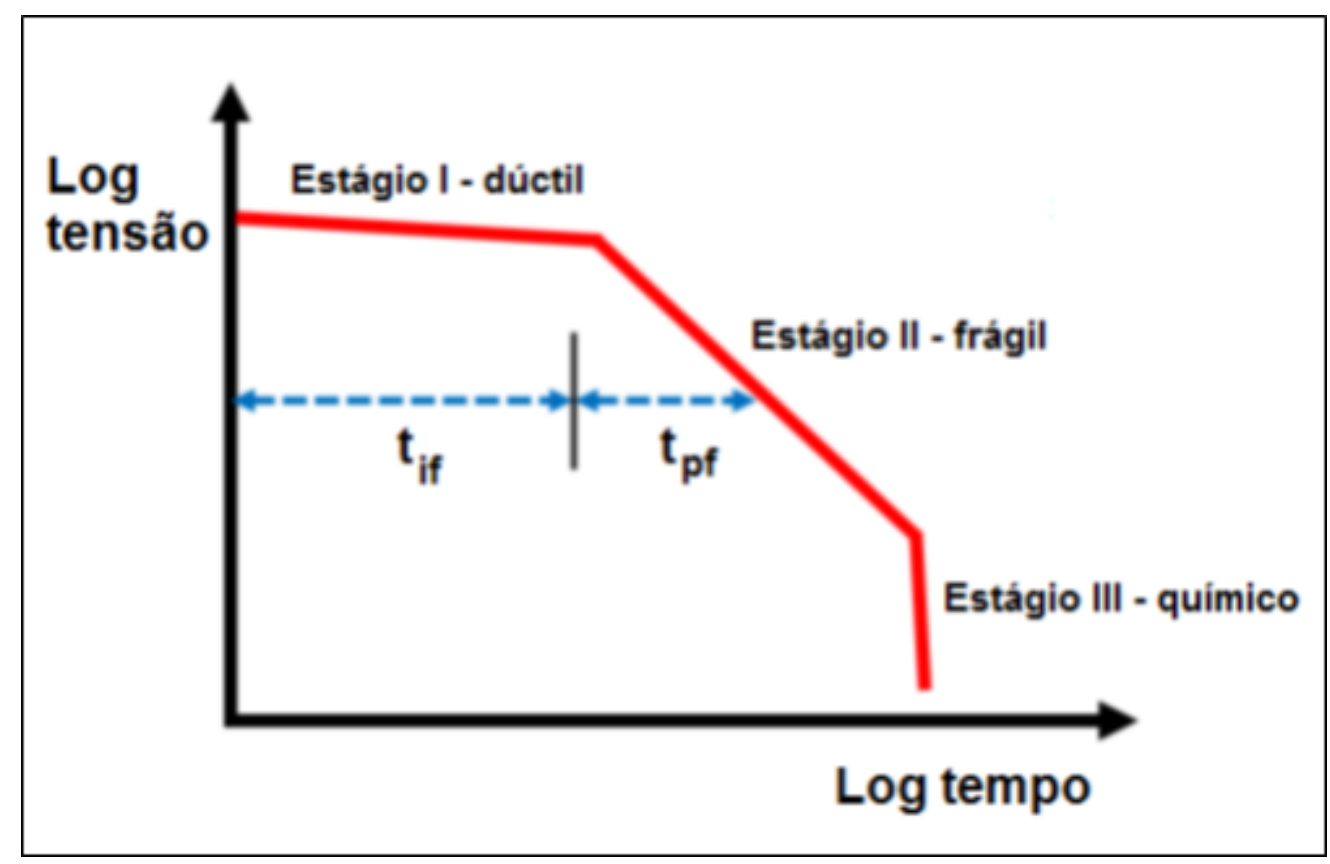

Fonte: Adaptado de THOMAS e CUTTINO, 2011.

LAVOIE E BUENO (2007), avaliaram a resistência ao fissuramento sob tensão em geomembranas fabricadas em PEAD virgem e degradada em laboratório por exposição à radiação ultravioleta e ao envelhecimento térmico. Foram realizados ensaios de fissuramento sob tensão de acordo com a norma ASTM D5397, e os 
resultados mostraram que os processos de degradação podem ser considerados catalisadores do fenômeno de fissuramento sob tensão, pois ocorreram reduções quanto ao fissuramento sob tensão da ordem de $50 \%$ a $60 \%$ nas amostras previamente degradadas. Os tempos de ruptura para os ensaios de fissuramento sob tensão estão apresentados na Tabela 2, em que as amostras degradadas previamente mostraram redução de $57 \%$ para amostra degradada com radiação ultravioleta e $48 \%$ para a amostra degradada termicamente.

Tabela 2 - Parâmetros obtidos dos resultados dos ensaios de fissuramento sob tensão

\begin{tabular}{ccccc}
\hline Amostra & $\begin{array}{c}\text { R. Dúctil } \\
(\% / \mathrm{h})\end{array}$ & $\begin{array}{c}\text { R. Frágil } \\
(\% / \mathrm{h})\end{array}$ & $\begin{array}{c}\mathrm{T}_{\mathrm{t}} \\
(\mathrm{h})\end{array}$ & $\begin{array}{c}\sigma_{\mathrm{t}} \\
(\%)\end{array}$ \\
\hline Virgem & $-0,038$ & $-0,23$ & 143 & 35 \\
UV & $-0,069$ & $-0,39$ & 62 & 32,5 \\
Térmica & $-0,060$ & $-0,19$ & 75 & 35 \\
\hline
\end{tabular}

Fonte: Adaptado de LAVOIE e BUENO, 2007.

Tal fato demonstra que degradações causadas por processamentos em condições adversas e degradação oxidativa podem influenciar significativamente no desempenho do PEAD para aplicações estruturais.

THOMAS e CUTTINO (2011), avaliaram as propriedades e o tempo de falha do PEAD reciclado. Diferentes misturas foram caracterizadas e analisadas, e os materiais que foram encontrados em teores significativos juntamente a matriz de PEAD foram o $\mathrm{PP}, \mathrm{CaCO}_{3}, \mathrm{SiO}_{2}$ e $\mathrm{TiO}_{2}$. Os resultados mostraram que materiais de diferentes grades, cores, cargas, aditivos, quando misturados podem atuar como contaminantes, proporcionando efeito deletério nas propriedades, podendo inviabilizar certas aplicações que demandam longo tempo de vida em serviço como tubos corrugados, tubos de drenagem pluvial, geomembranas e entre outras.

Desta forma existe um grande desafio em analisar os efeitos do PEAD reciclado nos tempos de falha. É possível conduzir os ensaios de fissuramento sob tensão para avaliar PEAD virgens e reciclados, caso o material apresente contaminantes que concentrem tensão de forma significativa, o tempo para a falha ocorrer será reduzido podendo inviabilizar o emprego do material para aplicações estruturais. Outra possibilidade de aplicação é quando um material que apresente baixa resistência ao fissuramento sob tensão possa ser misturado com um material que apresente alta 
resistência ao fissuramento sob tensão, resultando em uma mistura com uma média resistência que será compatível a sua aplicação (KRISHNASWAMY e SHIM, 2010).

Portanto o foco deste estudo é verificar o tempo de falha do PEAD reciclado mecanicamente por uma única etapa de extrusão por meio de ensaios de fissuramento sob tensão constante e entalhe NCLS para viabilização em aplicações estruturais. 


\section{MATERIAIS E MÉTODOS}

\subsection{MISTURAS DE PEAD VIRGEM/CONTAMINANTES}

\subsubsection{Composição das misturas}

Este trabalho propõe estudar de maneira aproximada o desempenho de longa duração do PEAD para aplicações estruturais, em comparação ao PEAD reprocessado mecanicamente por uma única etapa de extrusão visando simular os efeitos da reciclagem. Adicionalmente analisar os efeitos dos contaminantes mais encontrados no PEAD reciclado no desempenho de curta duração. Foram desenvolvidas misturas entre a matriz PEAD e as fases dispersas $\mathrm{PP}, \mathrm{CaCO}_{3}, \mathrm{SiO}_{2}$, $\mathrm{TiO}_{2}$, que neste estudo foram considerados contaminantes pois podem proporcionar efeito deletério nas propriedades de longo prazo.

A maior parte dos equipamentos e ensaios realizados foram no Instituto de Pesquisas Tecnológicas - IPT, Laboratório de Plásticos e Borrachas.

Na Tabela 3 são apresentadas as misturas realizadas, em que o PEAD é o polímero matriz, PEAD-R é o polímero matriz reprocessado mecanicamente por uma única etapa de extrusão e os demais materiais que aparecem em sequência são os contaminantes selecionados para avaliação das propriedades. 
Tabela 3 - Denominação das amostras e teores mássicos das misturas de PEAD/contaminantes

\begin{tabular}{|c|c|}
\hline Nomenclatura adotada & Fração mássica de contaminante (\%) \\
\hline PEAD & 0 \\
\hline PEAD-R & 0 \\
\hline \multirow{4}{*}{ PEAD/PP } & 2 \\
\hline & 4 \\
\hline & 6 \\
\hline & 8 \\
\hline \multirow{4}{*}{$\mathrm{PEAD} / \mathrm{CaCO}_{3}$} & 2 \\
\hline & 4 \\
\hline & 6 \\
\hline & 8 \\
\hline \multirow{4}{*}{$\mathrm{PEAD} / \mathrm{TiO}_{2}$} & 2 \\
\hline & 4 \\
\hline & 6 \\
\hline & 8 \\
\hline \multirow{4}{*}{$\mathrm{PEAD} / \mathrm{SiO}_{2}$} & 2 \\
\hline & 4 \\
\hline & 6 \\
\hline & 8 \\
\hline
\end{tabular}

\subsubsection{Especificação dos polímeros}

O PEAD utilizado neste estudo foi o GP 5550 da empresa Braskem. De acordo com o fabricante o mesmo apresenta alta massa molar, alta resistência ao fissuramento sob tensão, densidade de $0,949 \mathrm{~g} / \mathrm{cm}^{3}$, índice de fluidez de $0,3 \mathrm{~g} / 10 \mathrm{~min}$ e excelentes propriedades mecânicas, o que permite sua aplicação em produtos estruturais como tubos de drenagem pluvial, tubos de irrigação, geomembranas, dormentes, entre outros. O PP utilizado foi o HP 500D da empresa Braskem, sendo este um homopolímero de densidade de $0,905 \mathrm{~g} / \mathrm{cm}^{3}$, baixo índice de fluidez de 0,7 $\mathrm{g} / 10 \mathrm{~min}$, alta resistência ao impacto e alta rigidez. Ambos os polímeros apresentam baixo índice de fluidez. O PP foi selecionado como contaminante neste estudo devido as diversas aparições no PEAD reciclado, muitas aplicações são feitas em conjunto, como por exemplo frascos em PEAD e tampas e rótulos em PP. O $\mathrm{CaCO}_{3}$ utilizado foi o 031583 da empresa Unilever, o $\mathrm{TiO}_{2}$ foi o KB-2 da empresa Cristal Global e o $\mathrm{SiO}_{2}$ fornecido pela empresa Auriquímica. 


\subsubsection{Preparo das misturas: PEAD virgem/contaminantes}

$\mathrm{Na}$ busca por uma boa homogeneização das misturas, anteriormente ao processo de extrusão, foi verificado um melhor resultado quando os polímeros de PEAD e PP foram pulverizados separadamente em moinho de facas, tipo Willye modelo TE-680, fabricante Yechal, com auxílio de nitrogênio líquido, evitando aquecimento excessivo e empelotamento dos polímeros no equipamento, conforme mostrado na Figura 13.

Figura 13 - Moinho de facas utilizado na pulverização dos polímeros PEAD e PP

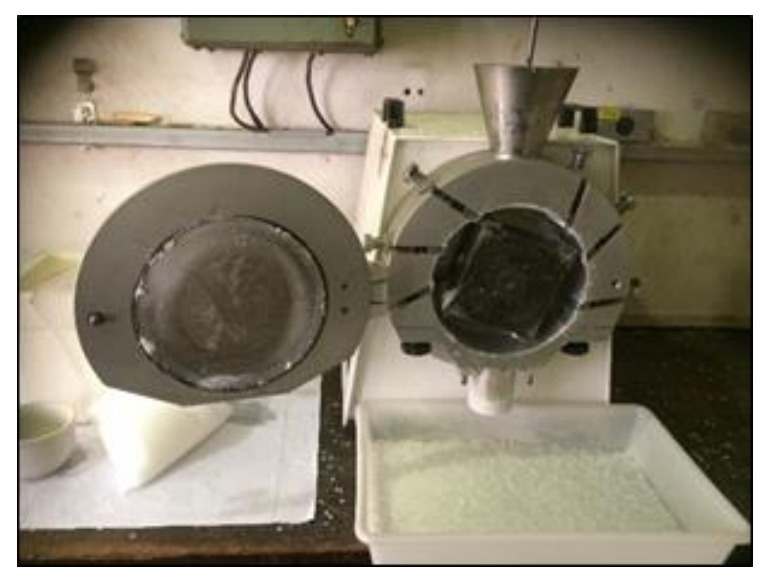

Fonte: Autoria própria.

Após a etapa de moagem os materiais em forma de pó foram homogeneizados em um misturador da marca Kotobuki, modelo Mixwheel Blender VL-10, durante 15 minutos para cada tipo de mistura conforme mostrado na Figura 14, seguindo as concentrações já anteriormente apresentadas na Tabela 3.

Figura 14 - Misturador tipo V Kotobuki utilizado para homogeneização das misturas

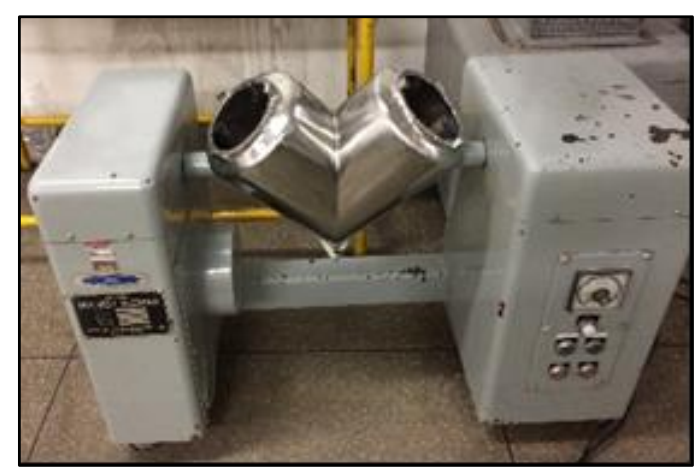

Fonte: Autoria própria. 


\subsubsection{Processo de extrusão}

Após as misturas terem sido homogeneizadas no misturador, as mesmas foram adicionadas em uma máquina extrusora do tipo dupla rosca corrotante da marca $A X$ Plásticos, modelo AX 16-DR, que apresenta uma relação L/D 40:1, a fim de obter os materiais na forma de grânulos simulando o PEAD reciclado por uma única etapa de extrusão, e promover uma melhor dispersão dos contaminantes no PEAD, conforme mostrada na Figura 15.

Figura 15 - Extrusora dupla rosca AX 16-DR usada na granulação das misturas

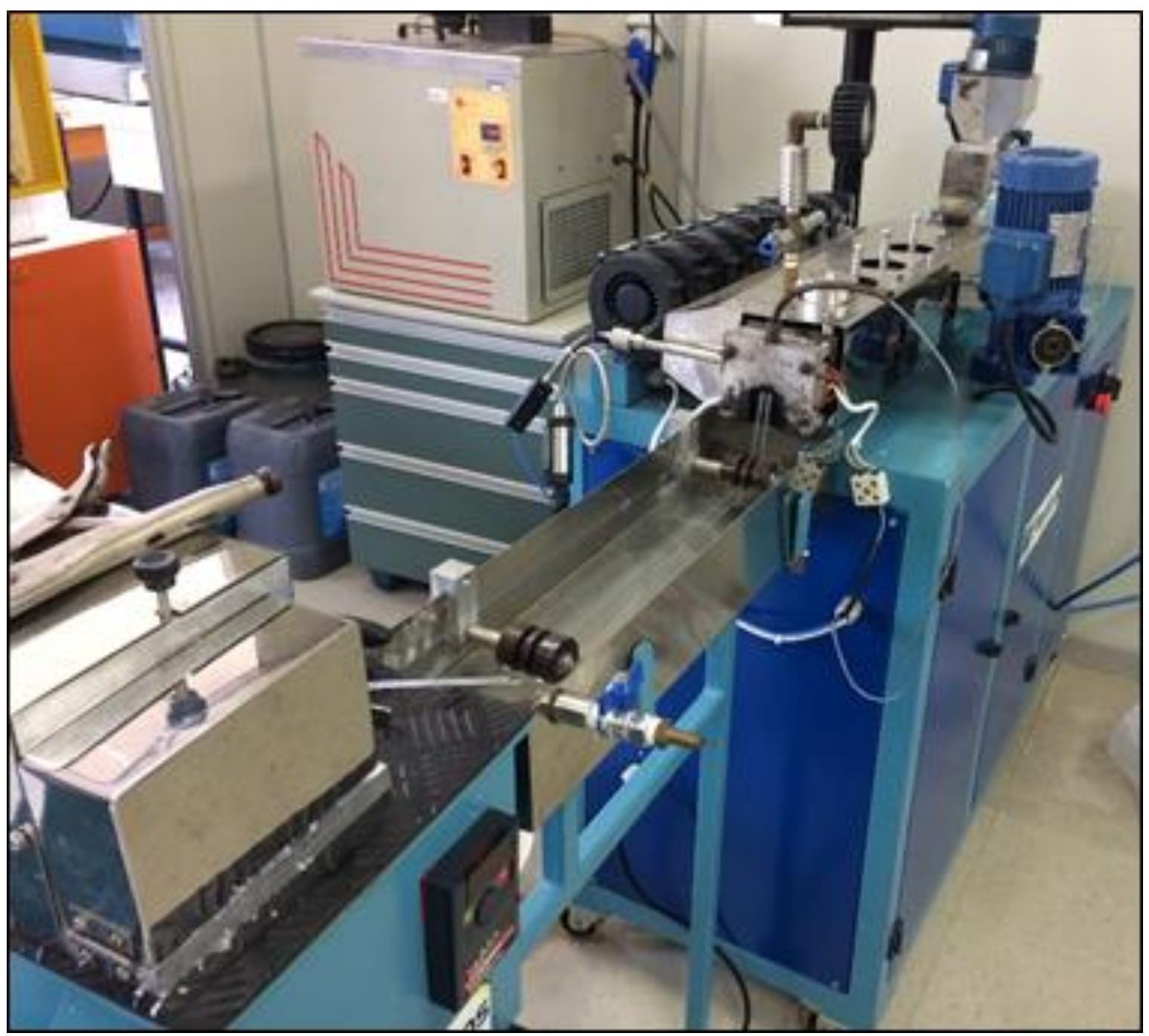

Fonte: Autoria própria. 
Parâmetros utilizados no processo de extrusão:

- Perfil de temperaturas nas zonas de extrusão (alimentação, compressão e dosagem): $140^{\circ} \mathrm{C} / 170^{\circ} \mathrm{C} / 175^{\circ} \mathrm{C} / 180^{\circ} \mathrm{C} / 185^{\circ} \mathrm{C} / 185^{\circ} \mathrm{C} / 170^{\circ} \mathrm{C} / 165^{\circ} \mathrm{C} / 160^{\circ} \mathrm{C}$.

- Velocidade de alimentação: 10 rpm a 12 rpm

- Velocidade de rotação das roscas: 105 rpm

\subsection{OBTENÇÃO DOS CORPOS DE PROVA}

\subsubsection{Obtenção dos corpos de prova para o ensaio de fissuramento sob tensão constante e entalhe NCLS}

Os corpos de prova para ensaios de NCLS (Notched Constant Ligament Stress) foram obtidos de acordo com a norma ASTM F2136-18, por meio de prensagem e posteriormente por meio de estampagem. Na Figura 16 é mostrada a prensa vertical da marca Crespi utilizada na prensagem e obtenção das plaquetas de PEAD virgem e as misturas de PEAD/contaminante. Na Figura 17 são mostradas as plaquetas obtidas para posterior estampagem dos corpos de prova. Foram obtidas plaquetas com medidas de $20 \mathrm{~cm} \times 20 \mathrm{~cm}$ a uma temperatura de $200^{\circ} \mathrm{C}$ e a uma pressão de 80 a $120 \mathrm{kgf} / \mathrm{cm}^{2}$.

Figura 16 - Prensa hidráulica utilizada para confecção das plaquetas

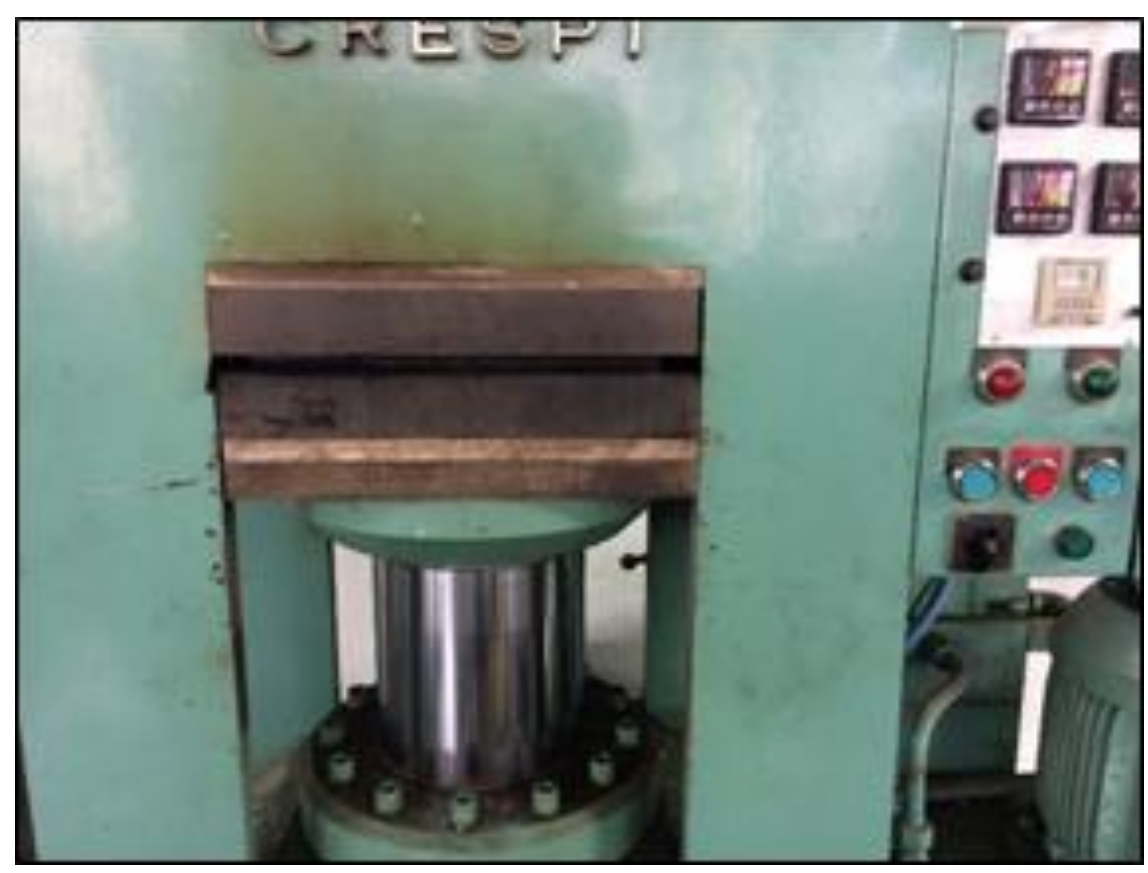

Fonte: Autoria própria. 
Figura 17 - Plaqueta para obtenção dos corpos de prova para ensaio de NCLS

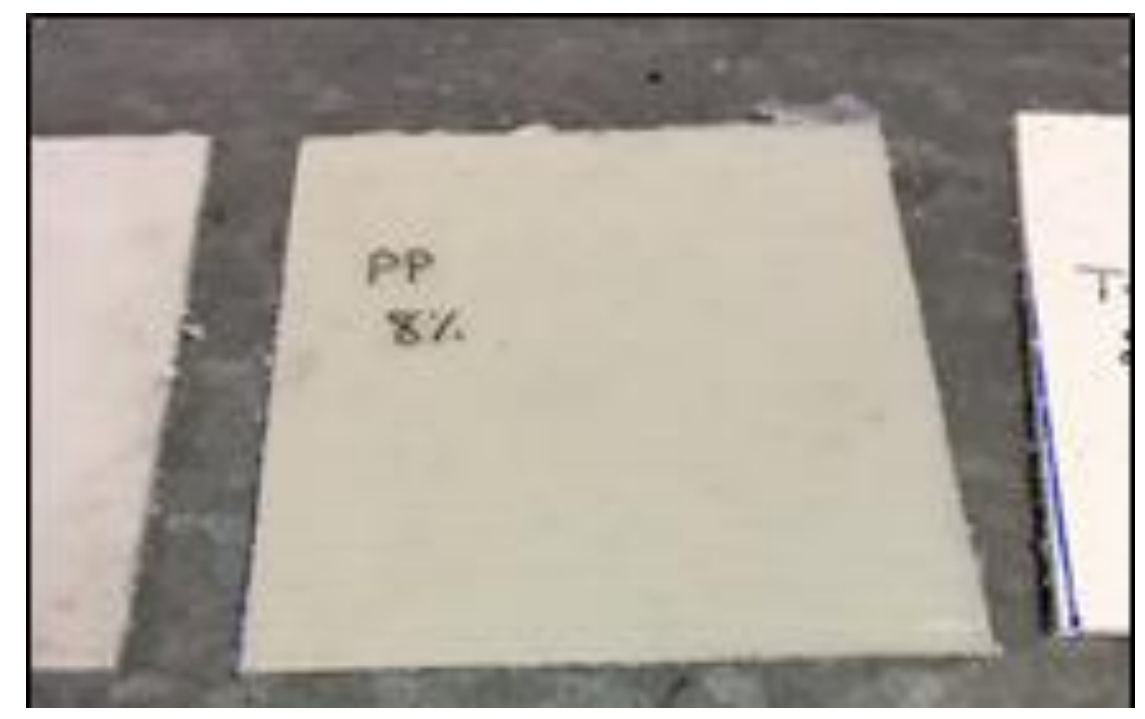

Fonte: Autoria própria.

Após o processo de prensagem e obtenção das placas foi realizado o processo de estampagem dos corpos de prova. A prensa pneumática da marca Zwick utilizada no processo estampagem para obtenção dos corpos de prova é mostrada na Figura 18. Posteriormente também foi necessária a furação dos corpos de prova para fixação no dispositivo de ensaio, em uma furadeira de bancada como mostrada na Figura 19, e por fim os corpos de prova são mostrados na Figura 20, conforme a norma ASTM F2136-18.

Figura 18 - Prensa Pneumática, fabricante Zwick, para estampagem dos corpos de prova

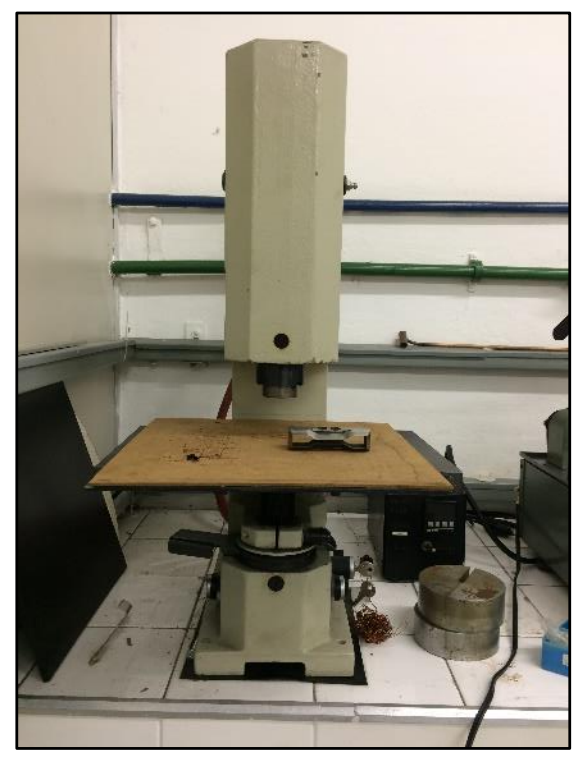

Fonte: Autoria própria. 
Figura 19 - Furadeira de bancada usada para furar os corpos de prova

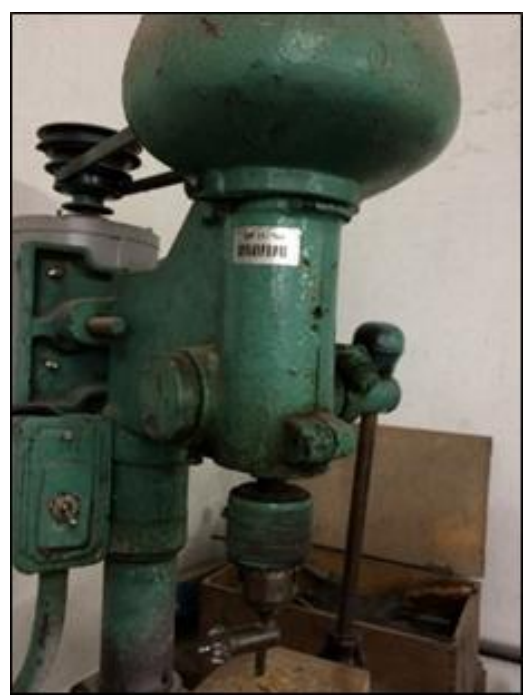

Fonte: Autoria própria.

Figura 20 - Imagem dos corpos de prova usados para ensaio de NCLS

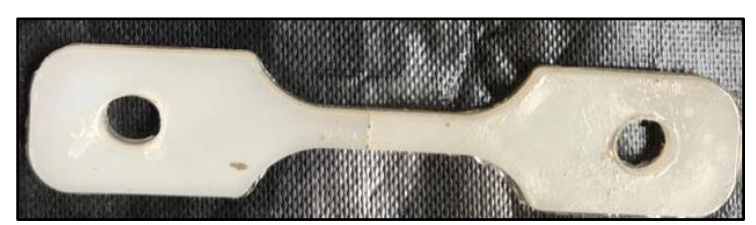

Fonte: Autoria própria.

Nas Figuras 21 a 23 são mostradas as máquinas entalhadoras utilizadas de acordo com os requisitos exigidos pela norma ASTM F2136-18 para realização dos entalhes nos corpos de prova. Três diferentes métodos foram utilizados para a realização dos entalhes. O primeiro método utilizado foi o processo cíclico com a máquina entalhadora Ceast da fabricante Instron, em que uma lâmina realiza movimentos perpendiculares ao plano do corpo de prova e gradualmente o entalhe é realizado com o auxílio de um micrômetro acoplado ao equipamento. O segundo método utilizado foi o processo estático em que a lâmina que realiza o entalhe atua como uma guilhotina. $O$ terceiro método realizado foi por meio de entalhe estático com limitadores metálicos de profundidade, em que a lâmina realiza o entalhe com um final curso estipulado. Os métodos de entalhe foram denominados como apresentados na Tabela 4. 
Figura 21 - Máquina entalhadora - Entalhe [1] - a) vista lateral e b) vista superior

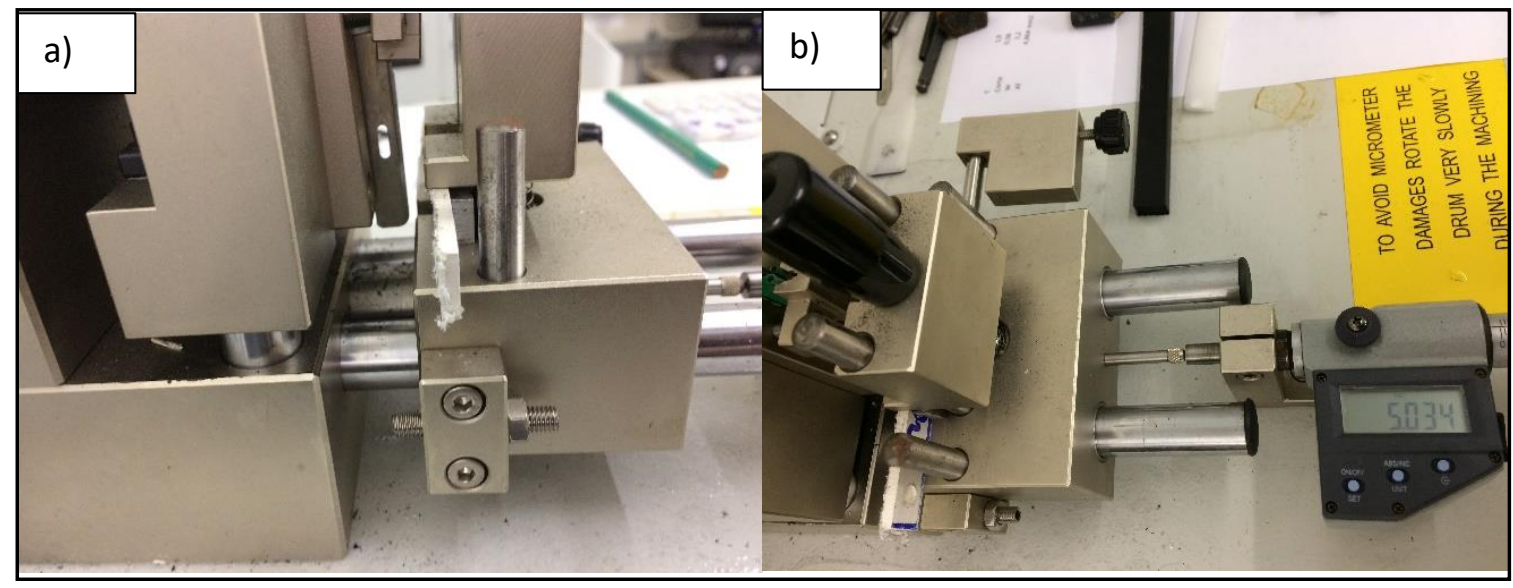

Fonte: Autoria própria.

Figura 22 - Máquina entalhadora - Entalhe [2]

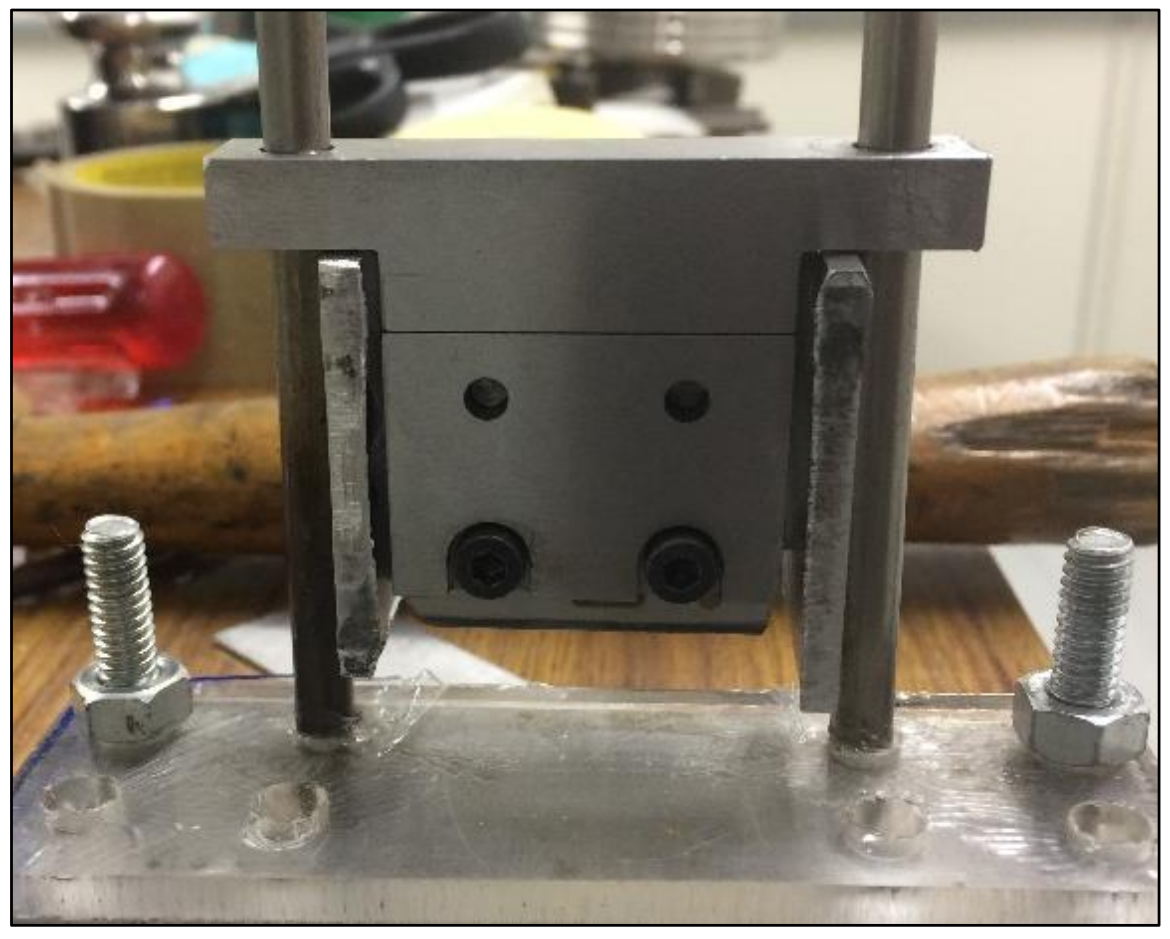

Fonte: Autoria própria. 
Figura 23 - Máquina entalhadora - Entalhe [3]

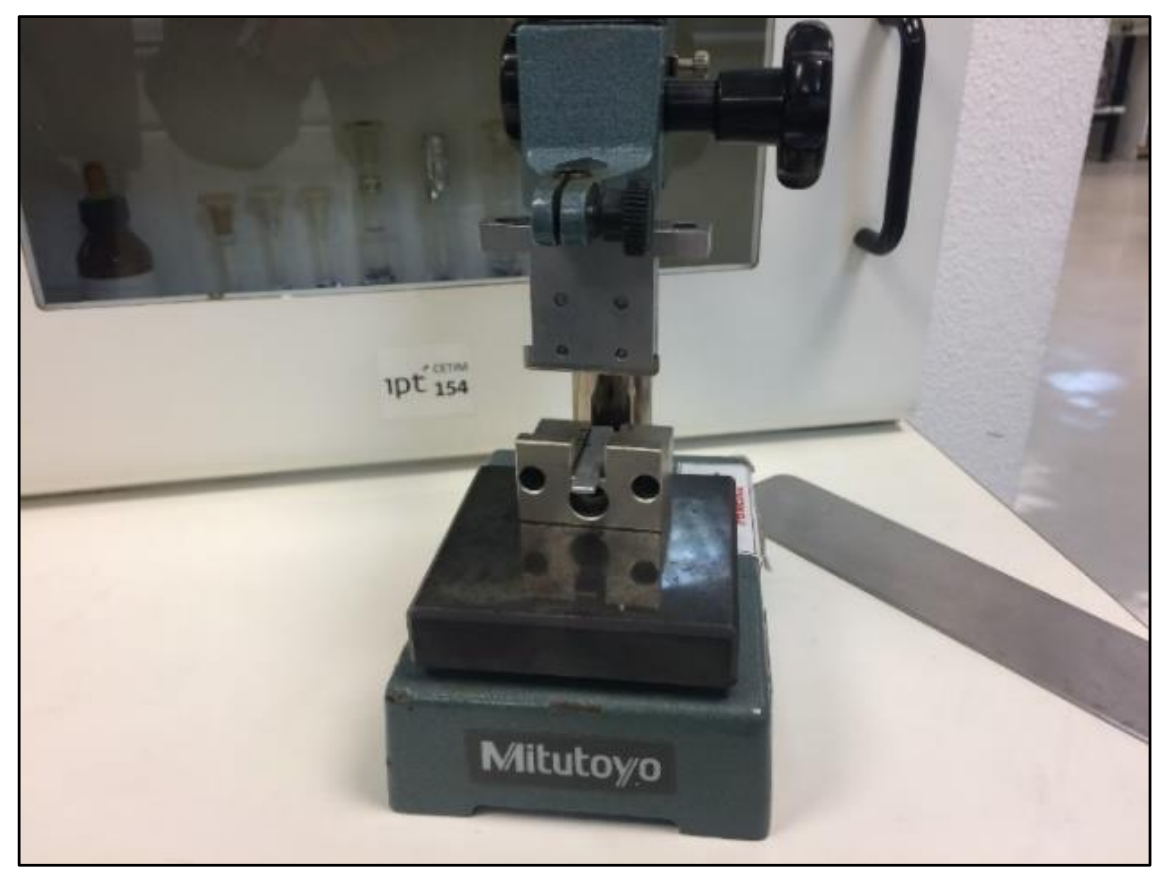

Fonte: Autoria própria.

Tabela 4 - Denominação das máquinas entalhadoras e os métodos utilizados para realização do processo de entalhamento dos corpos de prova

\begin{tabular}{|c|c|}
\hline Denominação & $\begin{array}{c}\text { Descrição } \\
\text { Entalhe [1] }\end{array}$ \\
\hline $\begin{array}{c}\text { Máquina entalhadora CEAST em que a lâmina realiza movimentos cíclicos } \\
\text { de subida e descida, e com auxílio de um micrometro acoplado ao } \\
\text { equipamento realiza-se o entalhe. }\end{array}$ \\
\hline Entalhe [2] & Máquina entalhadora tipo guilhotina. \\
\hline Entalhe [3] & $\begin{array}{c}\text { Máquina entalhadora tipo guilhotina com limitador metálico, com final de } \\
\text { curso para limitar a profundidade de entalhamento máximo realizado pela } \\
\text { lâmina. }\end{array}$ \\
\hline
\end{tabular}

Fonte: Autoria própria.

Os corpos de prova entalhados foram submetidos a microscopia óptica como mostrado na Figura 24, visando a obtenção da média da profundidade dos entalhes, pois as tensões aplicadas durante o ensaio variaram conforme a relação de área e profundidade dos entalhes descritos na norma ASTM F2136-18. 
Figura 24 - Exemplo de entalhe e medição no estéreo microscópio para validação do processo de entalhamento

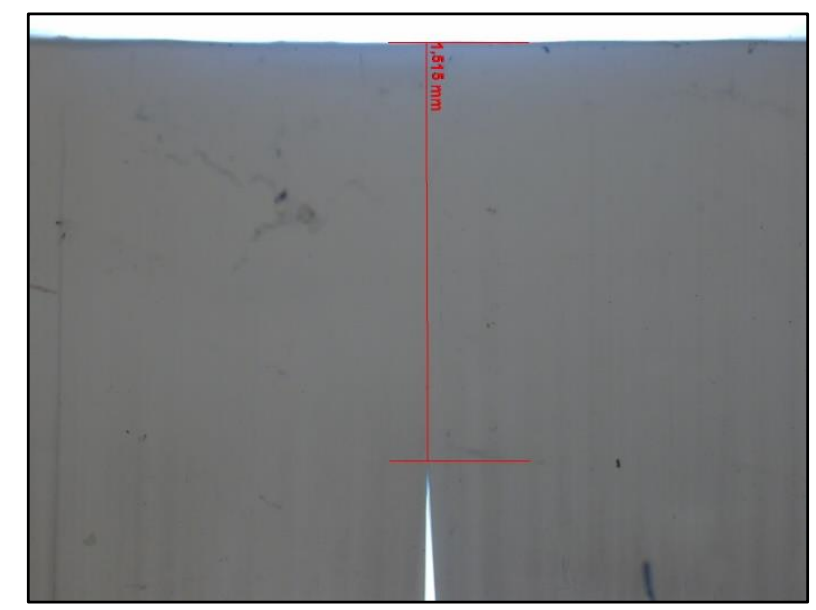

Fonte: Autoria própria.

A fim de corroborar com o estudo outro método de obtenção dos corpos de prova foi conduzido. Embora a norma ASTM F2136-18 preconize a obtenção por meio de processo de prensagem e posterior estampagem, os corpos de prova também foram obtidos por meio do processo de injeção. Um postiço com os requisitos dimensionais preconizados pela norma foi confeccionado e posteriormente os corpos de prova foram injetados como mostrado na Figura 25.

Figura 25 - Corpo de prova injetado para realização do ensaio NCLS

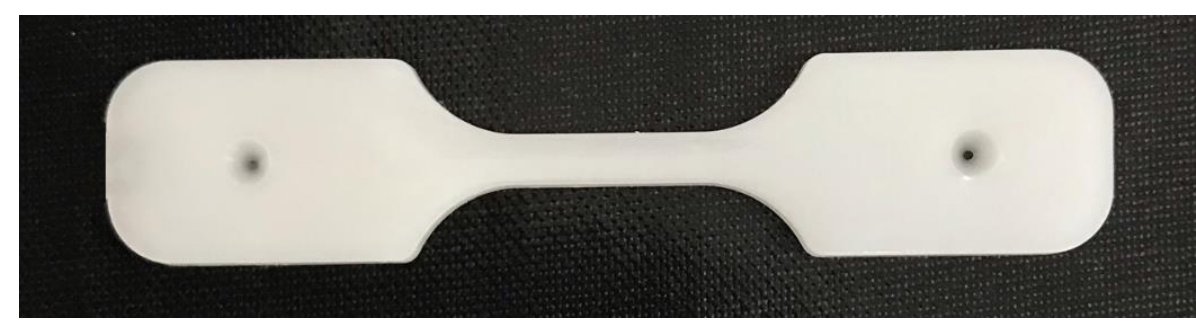

Fonte: Autoria própria.

Na Figura 26 é mostrada a balança do fabricante Yamato, marca Accu-Weight, modelo PPC-200W, utilizada na calibração das massas, uma vez que os corpos de prova apresentaram uma pequena variação em relação a largura, espessura e média da profundidade dos entalhes para realização do ensaio de NCLS. 
Figura 26 - Balança usada para validação das massas em função da área, da profundidade dos entalhes e a tensão aplicada em cada corpo de prova

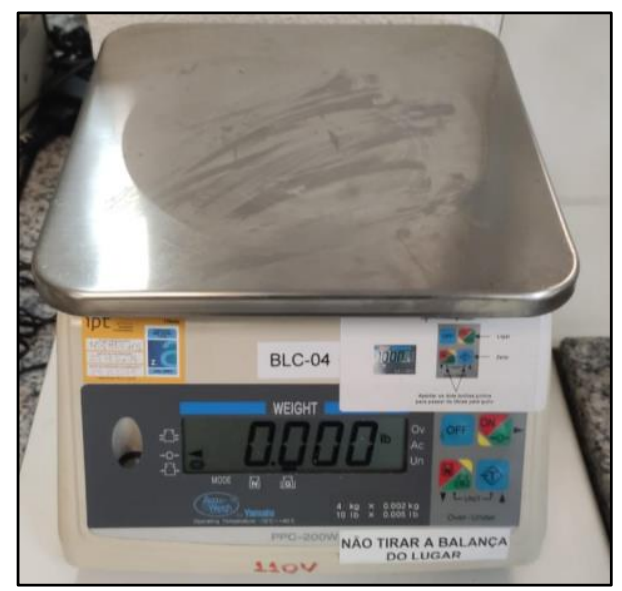

Fonte: Autoria própria.

Para a realização do ensaio de NCLS são necessários os ajustes das massas que realizam o ligamento constante nos corpos de prova como mostrado na Figura 27.

Figura 27 - Dispositivo de ensaio de fissuramento sob tensão constante e entalhe

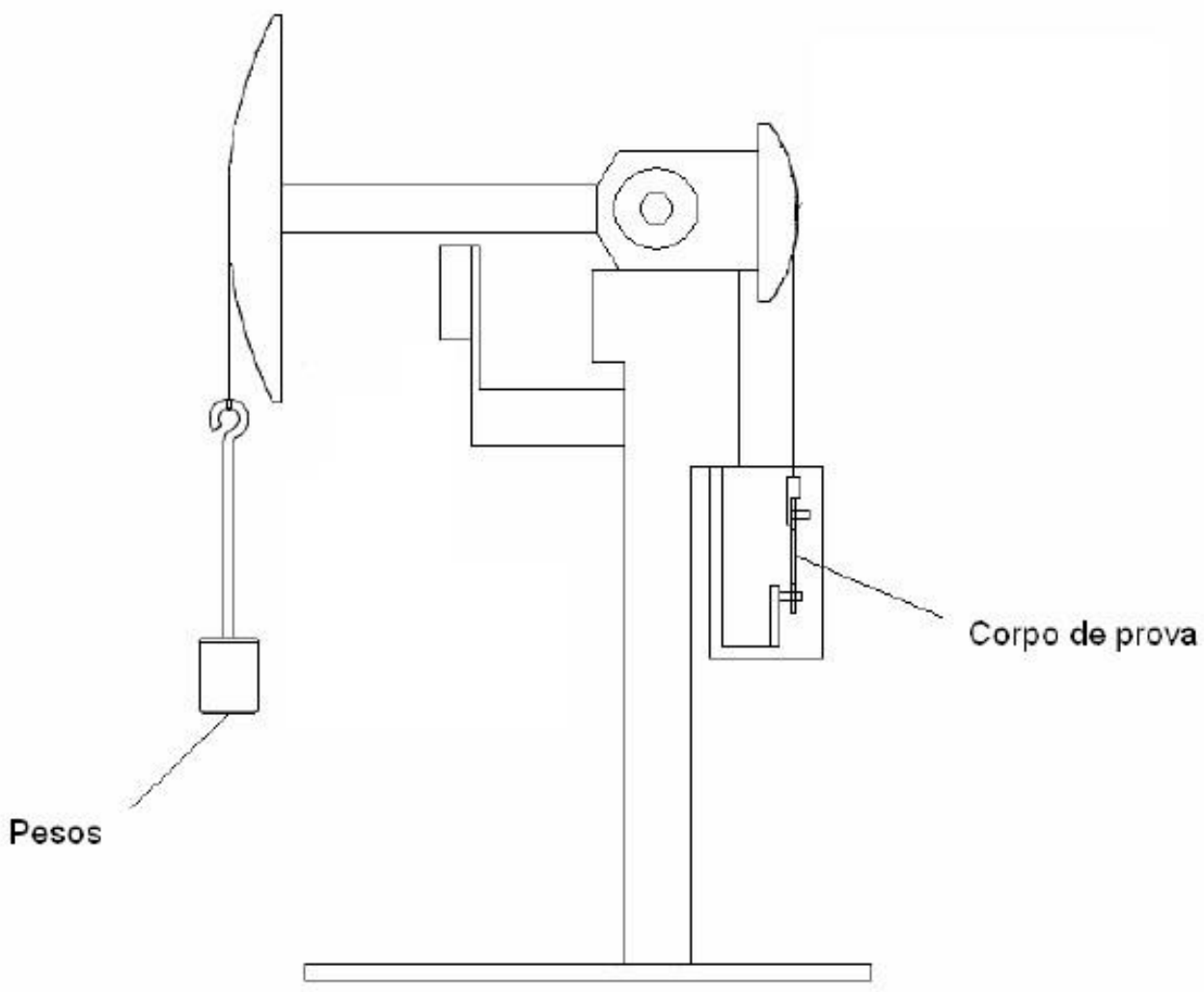

Fonte: Adaptado de LAVOIE e BUENO, 2007. 
De acordo com a norma ASTM F2136-18 o ajuste das massas para os corpos de prova segue a equação (2):

$P(g)=(T-a) W S$

em que:

$\mathbf{P}=$ o peso a ser aplicado à alavanca na estação de carregamento para produzir a tensão necessária para cada corpo de prova.

$\mathbf{T}=$ espessura do corpo de prova

$\mathbf{a}=$ profundidade do entalhe

W = largura da seção transversal do corpo de prova.

$\mathbf{S}=$ estresse específico do ligamento, psi (MPa).

Seguindo a norma ASTM F2136-18 para a realização do ensaio de NCLS sugere-se aplicar apenas uma porcentagem da tensão de escoamento 27,5 MPa nos corpos de prova dispostos no equipamento, porém esta tensão pode ser alterada a fim de encontrar a melhor condição para realização do ensaio, uma vez que se possa obter uma diferença mínima significativa no desempenho de longa duração entre as diferentes misturas.

De acordo com estudo realizado na produção de materiais estruturais com PEAD (THOMAS e CUTTINO, 2011) onde tubos corrugados para drenagem pluvial enterrados em condições normais de trabalho ficaram expostos a uma tensão de aproximadamente $4,125 \mathrm{MPa}$, o que corresponde a $15 \%$ da tensão sugerida pela norma ASTM F2136-18, os ensaios deram início seguindo estes valores.

Após calculadas as massas os corpos de prova foram montados no dispositivo construído para realização do ensaio de NCLS, como mostrado na imagem a, e b da Figura 28. 
Figura 28 - Dispositivo para realização de ensaio de fissuramento sob tensão constante e entalhe NCLS
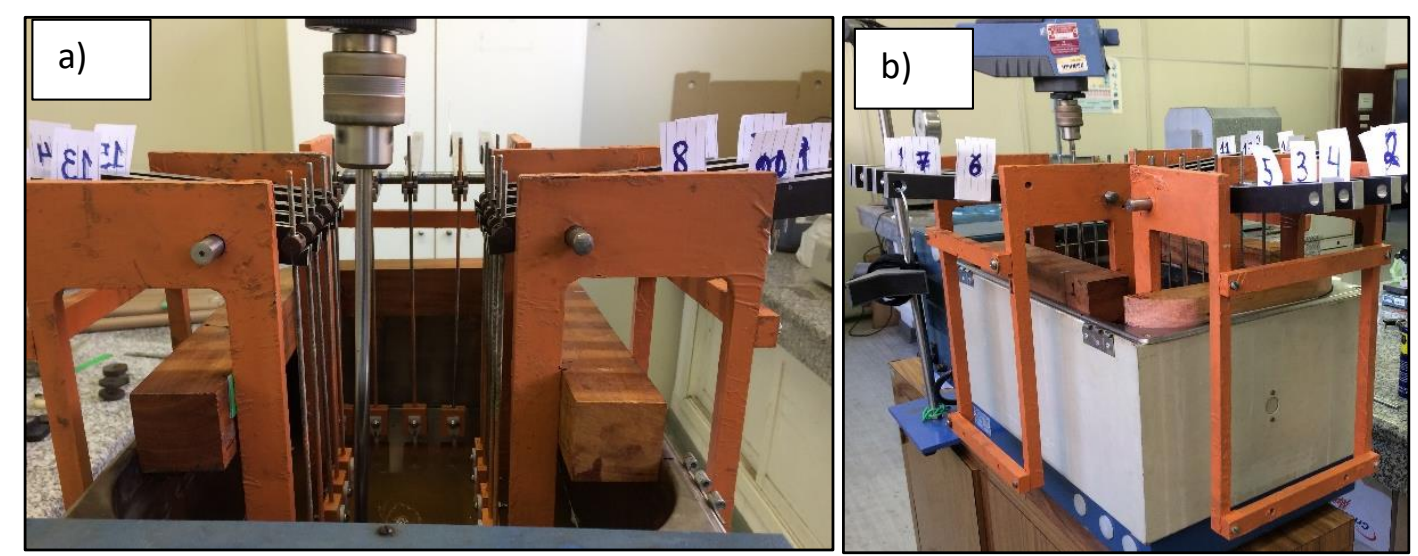

Fonte: Autoria própria.

\subsubsection{Injeção dos corpos de prova para os ensaios de curta duração}

Após a extrusão das misturas apresentadas na Tabela 3, foram obtidos os corpos de prova por meio do processo de injeção, para realização dos ensaios de resistência à tração, flexão e impacto pois representam o desempenho de curta duração. Na Figura 29 é mostrada a injetora de bancada modelo RAY-RAN Test Sample Injection Moulding Press, utilizada para confecção dos corpos de prova. Os parâmetros utilizados no processo de injeção dos corpos de prova foram temperatura do cilindro de plastificação $210^{\circ} \mathrm{C}$ e temperatura do molde $60^{\circ} \mathrm{C}$.

Figura 29 - Injetora de bancada usada para confecção dos corpos de prova para os ensaios de tração, flexão e impacto

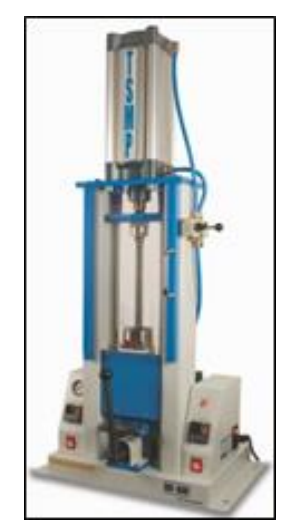

Fonte: INSTITUTE, 2021. 


\subsection{CARACTERIZAÇÕES}

As caracterizações de resistência à tração, resistência à flexão e resistência ao impacto foram escolhidas pois representam o desempenho de curta duração. Uma vez que os corpos de prova rompem em uma falha, estes ensaios podem fornecer informações significativas entre o material virgem e o material reprocessado que simula os efeitos da reciclagem (THOMAS e CUTTINO, 2011).

\subsubsection{Ensaio de resistência à tração}

Os tubos de irrigação bem como tubos para drenagem pluvial quando aplicados em campo estão susceptíveis a solicitações de tração, dessa forma as propriedades avaliadas neste ensaio foram: resistência à tração no escoamento, módulo de rigidez e alongamento na ruptura. Os ensaios seguiram as especificações descritas na norma ASTM D638-14 - Standard Test Method for Tensile Properties of Plastics. As condições de ensaio seguiram acondicionamento de $23 \pm 2^{\circ} \mathrm{C}$ e $50 \pm 5 \%$ de umidade relativa, durante 40 horas. A velocidade utilizada para o ensaio foi de $50 \mathrm{~mm} / \mathrm{min}$, e os corpos de prova utilizados foram Tipo I.

\subsubsection{Ensaio de resistência à flexão}

Os tubos para drenagem pluvial, tubos de irrigação aplicados em campo estão susceptíveis a esforços de flexão, portanto as propriedades de resistência à flexão e módulo sob flexão foram avaliadas. Os ensaios foram realizados seguindo as especificações da norma ASTM D790-17 - Standard Test Methods for Flexural Properties of Unreinforced and Reinforced Plastics and Eletrical Insulating Materials. As condições de ensaio seguiram acondicionamento de $23 \pm 2^{\circ} \mathrm{C}$ e $50 \pm$ $5 \%$ de umidade relativa, durante 40 horas. A velocidade do ensaio utilizada foi de 1,40 $\mathrm{mm} / \mathrm{min}$, e a distância entre apoios foi de $52,48 \mathrm{~mm}$.

\subsubsection{Ensaio de resistência ao impacto}

Os materiais estruturais como tubos de irrigação e drenagem pluvial quando aplicados em campo estão susceptíveis a solicitações de impacto. Dessa forma ensaios de impacto foram realizados e seguiram os critérios da norma ASTM D25618 - Standard Test Methods for Determining the Izod Pendulum Impact 
Resistence of Plastics. As condições de ensaio utilizadas foram martelo de $1 \mathrm{~J} \mathrm{e}$ velocidade do impacto de $3,8 \mathrm{~m} / \mathrm{s}$.

\subsubsection{Ensaio de fissuramento sob tensão por ligamento constante e entalhe (NCLS)}

Os ensaios de fissuramento sob tensão por ligamento constante e entalhe (NCLS) foram realizados com o propósito de avaliar o desempenho de longa duração do PEAD. Os ensaios foram baseados na norma ASTM F2136-18 - Standard Test Method for Notched, Constant Ligament-Stress (NCLS) Test to Determine SlowCrack-Growth Resistance of HDPE Resins or HDPE Corrugated Pipe1.

Condições de ensaio:

- Tensões aplicadas aos corpos de prova: 15\%, 30\% e 40\% de 27,5 MPa (tensão de escoamento de materiais especificados para fabricação de tubos de drenagem);

- Temperatura da incubação: $50 \pm 1^{\circ} \mathrm{C}$;

- Meio de imersão: água deionizada (90\%) e nonilfenol etoxilado (10\%).

Inicialmente o PEAD virgem foi avaliado quanto ao desempenho de longa duração por meio do ensaio de fissuramento sob tensão constante e entalhe, a fim de validar o dispositivo projetado e confeccionado para este estudo seguindo os requisitos dimensionais das normas ASTM D5397-20 e ASTM F2136-18. O dispositivo projetado e construído para este estudo é mostrado nas imagens (a e b) da Figura 30. 
Figura 30 - Dispositivo para realização dos ensaios de fissuramento sob tensão constante e entalhe NCLS

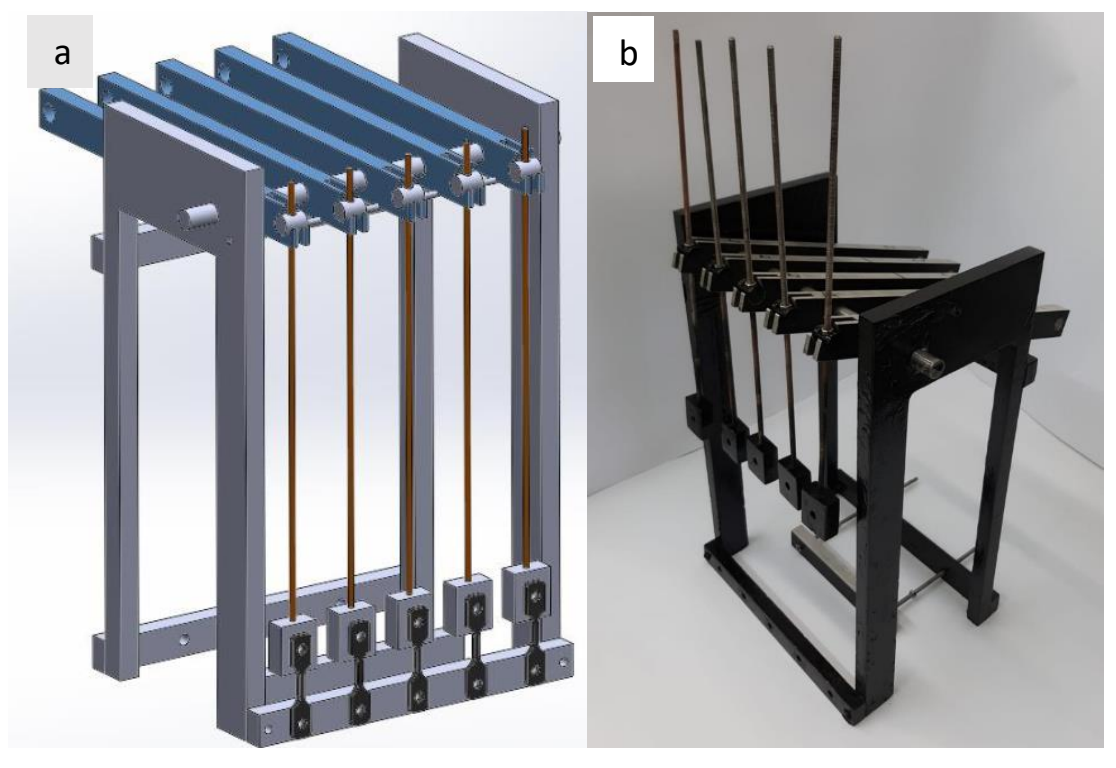

Fonte: Autoria própria.

Os principais parâmetros especificados na norma são com relação a proporção entre as cargas utilizadas e as aplicadas nos corpos de prova, as quais devem estar entre $2: 1$ e 5:1. Adicionalmente, os dispositivos foram dimensionados para suportar níveis de tensão de até 13,8 MPa. O processo utilizado para fabricação do dispositivo foi o de usinagem mecânica por meio de fresamento. Também foram utilizadas as técnicas de torneamento e furação. O dispositivo foi construído em liga de alumínio anodizado, visando proteção contra corrosão. Os métodos e as principais variáveis apresentadas na norma ASTM F2136-18 estão descritos a seguir:

1) Dimensões e tolerâncias dos corpos de prova: uma vez que o ensaio é baseado em uma porcentagem do valor da tensão de escoamento, variações na espessura e largura podem causar diferenças na tensão aplicada e, portanto, nos tempos de falha. A norma descreve as seguintes dimensões:

Comprimento $=60,00 \pm 0,25 \mathrm{~mm}$

Largura $=3,20 \pm 0,02 \mathrm{~mm}$

Espessura $=1,90 \pm 0,08 \mathrm{~mm}$

2) Entalhe: este deve ser perpendicular ao plano definido pela amostra na largura e comprimento, e alinhado ao ângulo correto e a direção da aplicação 
da carga. A taxa máxima de corte é $2,5 \mathrm{~mm} / \mathrm{min}$, e o entalhe deve ter um comprimento de $20 \%$ da espessura total, com uma variação máxima de $\pm 0,25$ $\mathrm{mm}$, que deve ser checada por meio de microscopia. A espessura aproximada da lâmina deve ser 0,2 a 0,3 mm e uma única lâmina não deve ser usada para mais de 10 amostras.

3) Vantagem mecânica das alavancas: deve ter uma proporção de 2:1 a 5:1. Alternativamente a tensão pode ser aplicada diretamente usando pesos ou outro método para produzir o ligamento e tensão constantes. A carga aplicada nas amostras deve ter precisão de $0,5 \%$. A carga aplicada por meio do ligamento constante obtidas das massas deve produzir uma variação entre $15 \%$ a $60 \%$ da tensão de escoamento.

4) Solução do banho: a temperatura deve estar ajustada em (50 $\left.\pm 1^{\circ} \mathrm{C}\right)$, e a solução deve consistir em $10 \%$ de nonilfenol etoxilado por volume em $90 \%$ de água deionizada. O nível da solução deve ser checado diariamente e a água deionizada usada para manter o nível da solução constante. Uma vez que a norma ASTM F2136-18 recomenda apenas a reposição da água destilada, entende-se que o efeito de arraste do tensoativo pela evaporação da água é desprezível. No entanto, como os tempos de falha podem variar de forma significativa de acordo com a grade de PEAD e as cargas aplicadas, o efeito do arraste foi verificado, visando avaliar se em longos períodos de ensaio, o efeito de arraste de tensoativo pode se tornar significativo. Nesse contexto a avaliação da concentração versus tempo de teste foram avaliados por meio do uso do índice de refração BRIX. As quantificações foram realizadas por meio de uma curva de calibração, que foi construída utilizandose diferentes concentrações de surfactante. As concentrações realizadas foram de 0, 5, 10, 15 e $20 \%$.

5) Corpos de prova: A norma afirma que os corpos de prova devem ser obtidos por meio da moldagem por compressão de acordo com o procedimento $C$ da norma ASTM D4703. A taxa de resfriamento deve ser de $15 \pm 2^{\circ} \mathrm{C} / \mathrm{min}$ e os corpos de prova devem ser obtidos por meio de estampagem da placa obtida.

Inicialmente os ensaios foram conduzidos com a matriz de PEAD a fim de validar o dispositivo e o método de ensaio NCLS. 


\subsubsection{Microscopia Eletrônica de Varredura (MEV), Emissão por Efeito de Campo (FEG)}

Imagens de MEV foram realizadas nos corpos de prova de PEAD para ensaios de fissuramento sob tensão após a realização dos diferentes métodos de entalhe, a fim de validar o processo de entalhamento e os requisitos dimensionais especificados na norma ASTM F2136-18. As imagens foram obtidas em equipamento da marca FEl, modelo Quanta 3D, com Espectrômetro por Dispersão de Energia de Raios-X (EDS), EDAX, do Instituto de Pesquisas Tecnológicas - IPT. 


\section{RESULTADOS E DISCUSSÃO}

\subsection{RESULTADOS DOS ENSAIOS DE CURTA DURAÇÃO PARA A MATRIZ DE PEAD E DE PEAD-R}

\subsubsection{Resultados dos ensaios de resistência à tração}

Para a realização do ensaio de fissuramento sob tensão constante e entalhe NCLS, deve-se obter os valores médios da tensão de escoamento da matriz de PEAD. Dessa forma os ensaios de curta duração foram conduzidos inicialmente para o PEAD, em que estão representados os valores médios para pelo menos cinco corpos de prova para os parâmetros de resistência à tração no escoamento, alongamento e módulo de rigidez, que estão apresentados na Tabela 5.

Tabela 5 - Resultados dos ensaios de resistência à tração das amostras de PEAD

\begin{tabular}{|c|c|c|c|}
\hline Amostra & $\begin{array}{c}\text { Resistência à tração no } \\
\text { escoamento }(\mathrm{MPa}) \pm \\
\text { intervalo de } 95 \% \text { de } \\
\text { confiança }\end{array}$ & $\begin{array}{c}\text { Alongamento } \pm \\
\text { intervalo de } 95 \% \text { de } \\
\text { confiança (\%) }\end{array}$ & $\begin{array}{c}\text { Módulo de rigidez (MPa) } \\
\text { intervalo de 95\% de } \\
\text { confiança (\%) }\end{array}$ \\
\hline PEAD & $30 \pm 2$ & $10 \pm 2$ & $314 \pm 34$ \\
\hline PEAD-R & $27 \pm 2$ & $9 \pm 1$ & $308 \pm 25$ \\
\hline
\end{tabular}

Fonte: Autoria própria.

De acordo com THOMAS E CUTTINO (2011) diversas misturas de PEAD reciclado foram analisadas e, aquelas que continham diferentes cores misturadas apresentaram uma significativa redução quanto a resistência à tração. $A$ análise dos resultados da Tabela 5 mostra que o PEAD e o PEAD-R apresentaram uma resistência à tração no escoamento e um alongamento compatível e ligeiramente superior aos valores descritos na norma ASTM F2136-18 que especifica 27,5 MPa para as resinas apropriadas a fabricação de tubos corrugados de irrigação e drenagem pluvial, corroborando para a reutilização do PEAD reciclado, uma vez que as barras de erro se sobrepõem em um intervalo de confiança de 95\%, como mostrado nas Figuras 31 e 32 respectivamente. Portanto para os parâmetros avaliados, os resultados mostram oportunidades para o uso do PEAD reciclado em aplicações estruturais, ou seja, que demandam um longo de vida em serviço. 
Figura 31 - Resistência à tração do PEAD e do PEAD-R

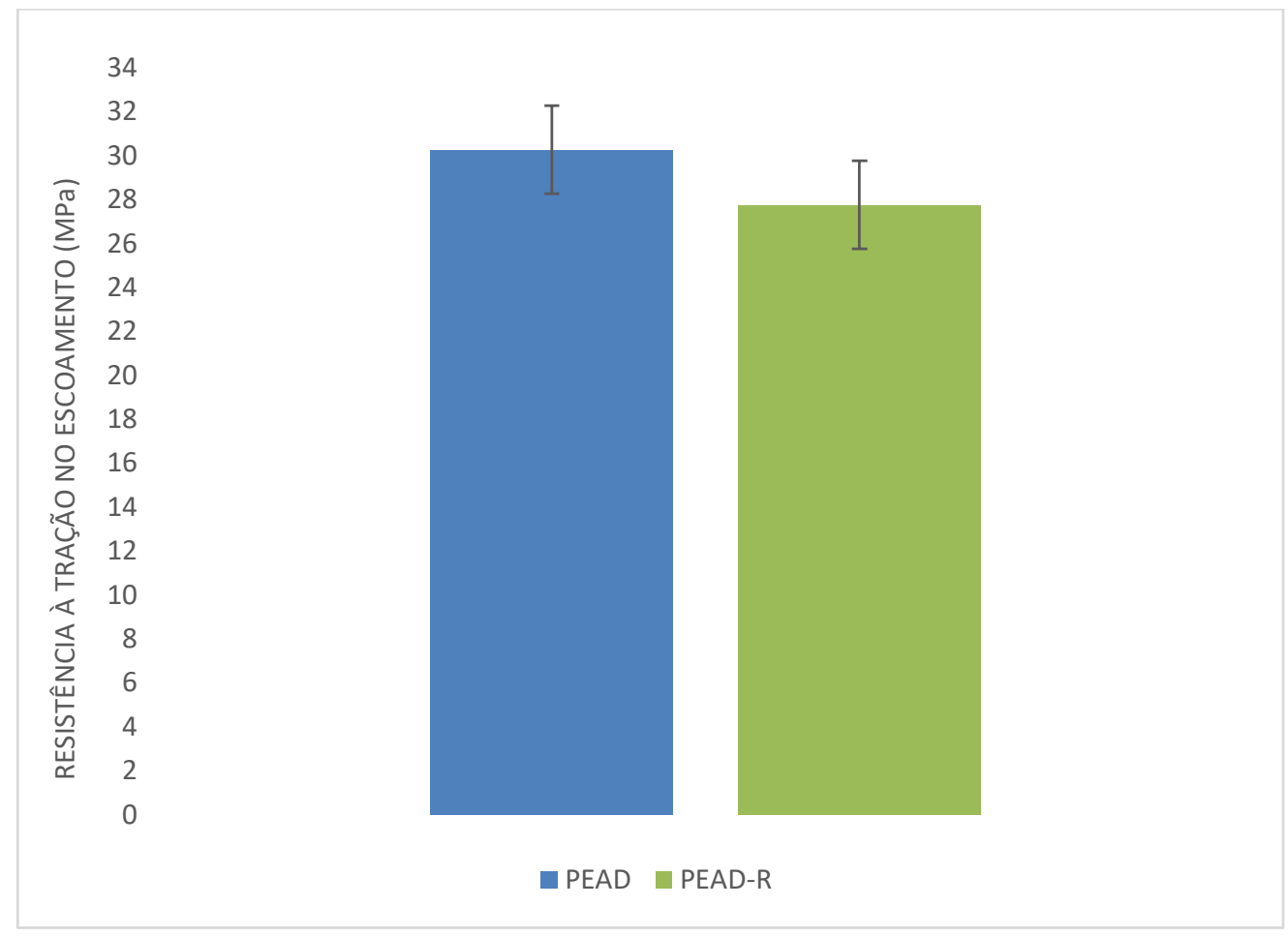

Fonte: Autoria própria.

Figura 32 - Alongamento do PEAD e do PEAD-R

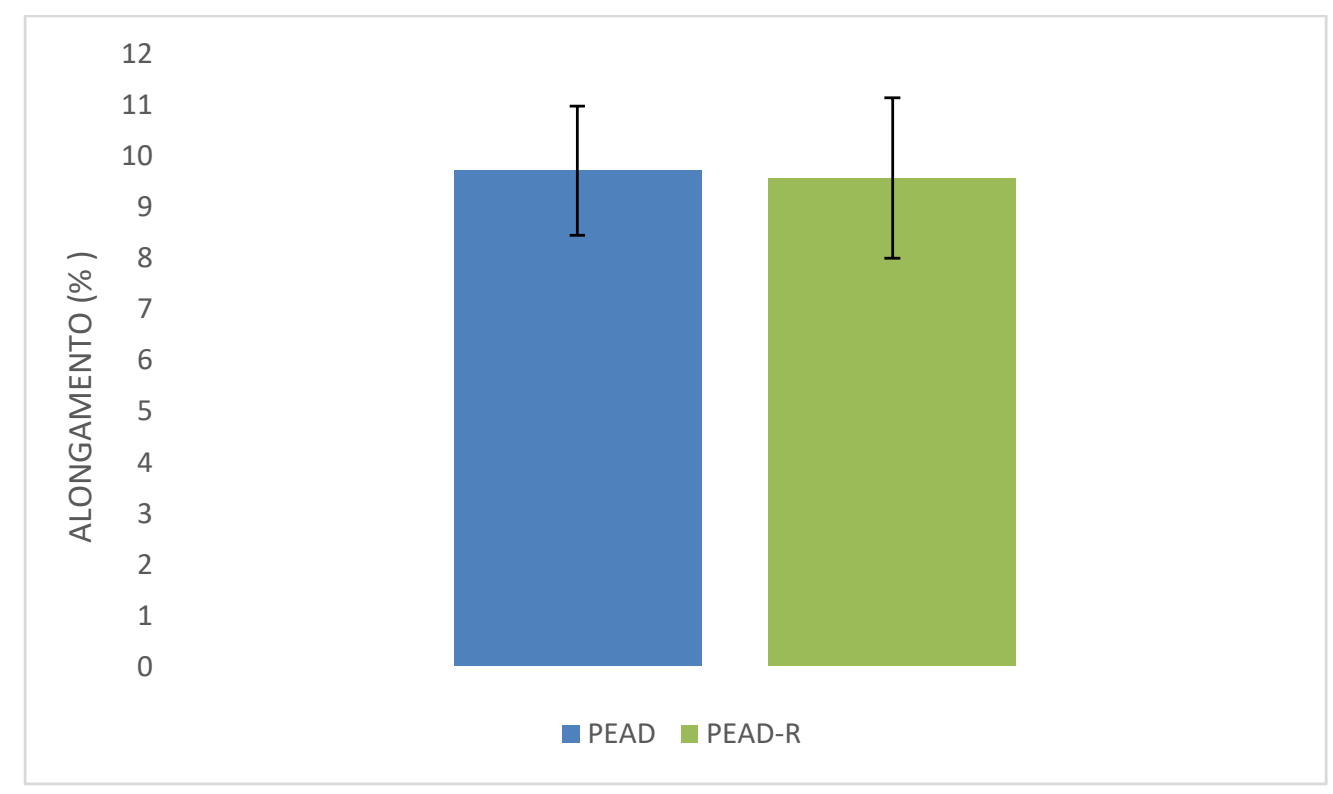

Fonte: Autoria própria. 


\subsubsection{Resultados dos ensaios de resistência à flexão}

Os resultados dos ensaios de resistência à flexão são apresentados na Tabela 6.

Tabela 6 - Resultados de resistência à flexão das amostras de PEAD e de PEAD-R

\begin{tabular}{|c|c|c|}
\hline Amostra & $\begin{array}{c}\text { Resistência à flexão a 2\% }(\mathbf{M P a}) \pm \\
\text { intervalo de } \mathbf{9 5 \%} \text { de confiança }\end{array}$ & $\begin{array}{c}\text { Módulo sob flexão }(\mathbf{M P a}) \mathbf{\pm} \\
\text { intervalo de 95\% de confiança }\end{array}$ \\
\hline PEAD & $9,2 \pm 0,2$ & $1016 \pm 31$ \\
\hline PEAD-R & $8,8 \pm 0,1$ & $988 \pm 27$ \\
\hline
\end{tabular}

Fonte: Autoria própria.

Comparando os resultados de resistência à flexão da amostra de PEAD e da amostra de PEAD-R, foi verificado que a resistência à flexão e o módulo sob flexão estão compatíveis com os valores nominais das resinas especificadas para a fabricação de tubos corrugados e tubos para drenagem pluvial, uma vez que as barras de erro se sobrepõem em um intervalo de confiança de 95\%, como mostrados nas Figuras 33 e 34, respectivamente. ALZERRECA et al. (2015) avaliaram o uso de PEAD reciclado pós-consumo e pós-industrial na fabricação de tubos para sistemas de esgoto gravitacional, e os resultados mostraram que o PEAD reciclado apresentou propriedades inferiores ao material virgem, uma vez que a taxa de cisalhamento e temperatura durante o processamento podem provocar diminuição das massas molares, e ainda proporcionar ligações cruzadas. Portanto neste estudo o PEAD reciclado mecanicamente por uma única etapa de extrusão, embora os resultados apresentados na Tabela 6 mostraram uma pequena variação em relação ao PEAD virgem, apresenta oportunidades para aplicações que exijam um tempo de falha significativo, como tubos corrugados, tubos para drenagem pluvial entre outras, 
Figura 33 - Resultados de resistência à flexão do PEAD e do PEAD-R

10
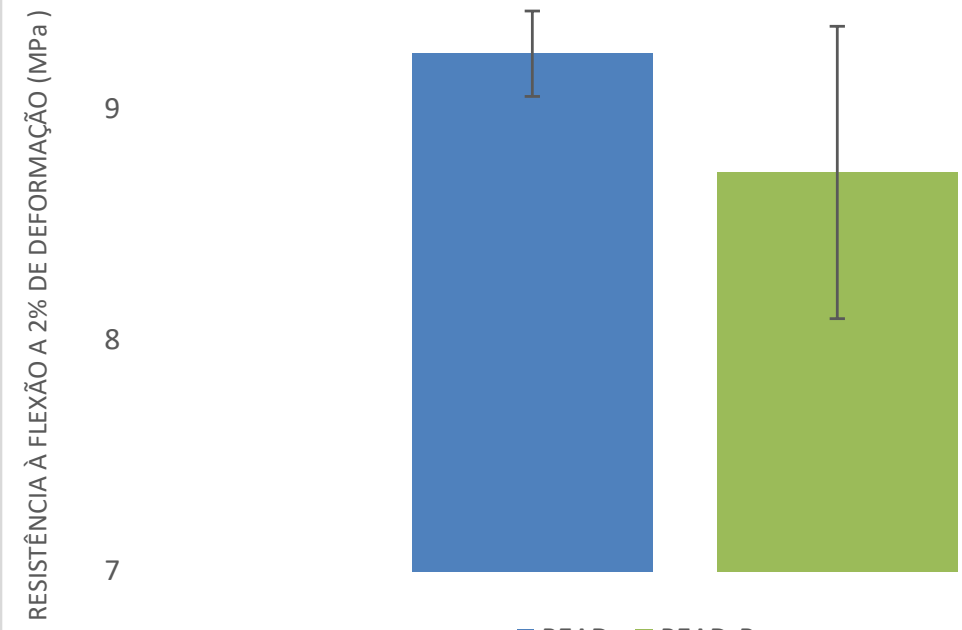

- PEAD $\square$ PEAD-R

Fonte: Autoria própria.

Figura 34 - Resultados dos módulos sob flexão do PEAD e do PEAD-R
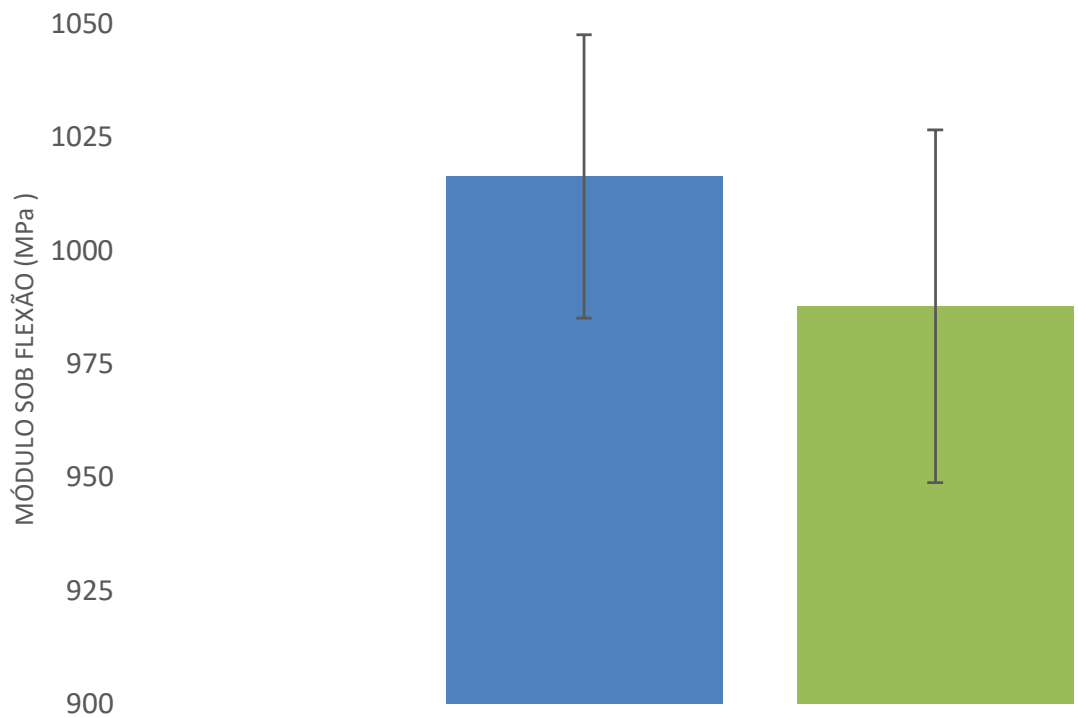

- PEAD PEAD-R

Fonte: Autoria própria. 


\subsubsection{Resultados dos ensaios de resistência ao impacto}

Os resultados dos ensaios de resistência ao impacto para o PEAD e o PEAD-R são apresentados na Tabela 7.

Tabela 7 - Resultados de resistência ao impacto das amostras de PEAD e de PEAD-R

\begin{tabular}{|c|c|}
\hline Amostra & Resistência ao impacto IZOD (J/m) \\
\hline PEAD & $333 \pm 10$ \\
\hline PEAD-R & $297 \pm 10$ \\
\hline
\end{tabular}

Fonte: Autoria própria.

Analisando os resultados obtidos para o PEAD e o PEAD-R quanto a resistência ao impacto notou-se que não há diferença mínima significativa, uma vez que as barras de erro se sobrepõem em um intervalo de confiança de $95 \%$, e não devem afetar as propriedades de curta duração do material, conforme mostrado na Figura 35.

Dessa forma os resultados dos parâmetros de curta duração como resistência à tração, resistência à flexão e resistência ao impacto, embora mostraram uma leve tendência de redução nas propriedades, uma vez que a taxa de cisalhamento, tempos de residência durante o processamento e temperatura excessiva podem provocar diminuição das massas molares, e ainda proporcionar ligações cruzadas, estão correlacionadas com as propriedades de fluência e fadiga que são propriedades relacionadas ao desempenho de longa duração, o PEAD reciclado mecanicamente por uma única etapa de extrusão se mostrou compatível para aplicações estruturais, gerando assim oportunidades significativas para o emprego do uso de PEAD reciclado mitigando o uso de resina virgem, e contribuindo assim com a redução do descarte diretamente no meio ambiente, reduzindo assim os impactos ambientais. 
Figura 35 - Resultados de resistência ao impacto do PEAD e do PEAD-R

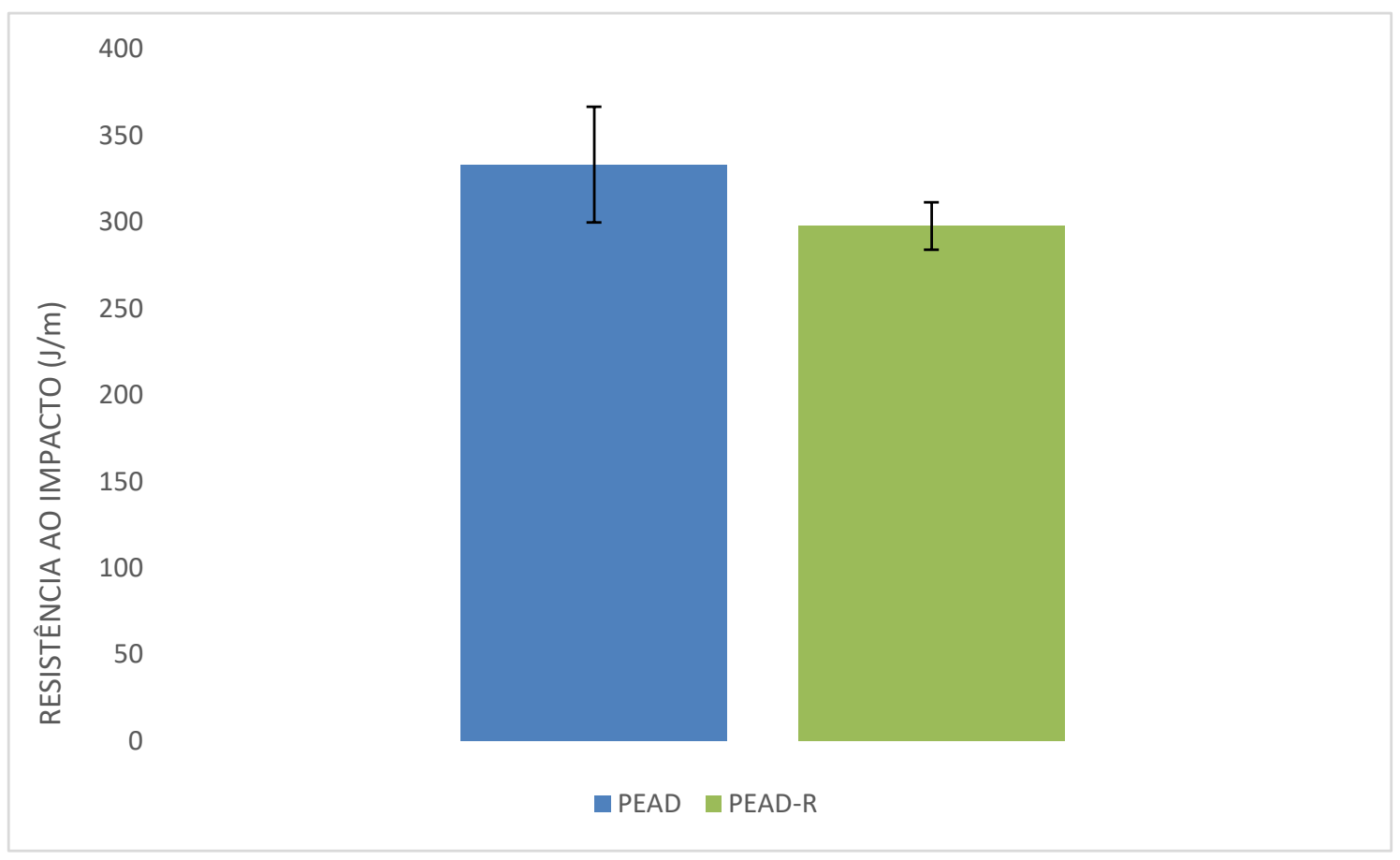

Fonte: Autoria própria.

\subsection{RESULTADOS DE NCLS PARA O PEAD}

Os resultados obtidos para os ensaios de fissuramento sob tensão constante e entalhe NCLS para o PEAD virgem a fim de primeiramente validar o dispositivo e o método de ensaio são apresentados na Tabela 8.

Tabela 8 - Resultados de fissuramento sob tensão e entalhe NCLS para a matriz de PEAD a fim de validar o dispositivo construído e o método de ensaio

\begin{tabular}{|c|c|c|c|c|}
\hline \multirow{3}{*}{ Amostra } & $\begin{array}{c}\text { Carga aplicada } \\
\text { (MPa) }\end{array}$ & $\begin{array}{c}\text { Tempo de falha } \\
\text { (h) }\end{array}$ & $\begin{array}{c}\text { Desvio } \\
\text { padrão (h) }\end{array}$ & $\begin{array}{c}\text { Coeficiente } \\
\text { de variação } \\
\text { (\%) }\end{array}$ \\
\hline \multirow{4}{*}{ PEAD } & 4,125 & Maior que 700 & - & - \\
\cline { 2 - 5 } & 8,25 & 228 & 64 & 28,1 \\
\cline { 2 - 5 } & 11,00 & 18 & 58 & 322,2 \\
\cline { 2 - 5 } & 13,75 & Menor que 0,08 & 7 & - \\
\hline
\end{tabular}

Fonte: Autoria própria.

A análise dos resultados mostra que a dispersão nos tempos de falha é significativa, mesmo em níveis diferentes de tensão. De acordo com os resultados dos tempos de falha foi verificado que para aplicação de cargas com $30 \%$ da tensão de escoamento 
ou menos, o tempo de ensaio se tornaria demasiado e inviável para realização dos estudos. A norma ASTM F2136-18 recomenda um desvio máximo para os tempos de falha de $10 \%$, portanto os desvios apresentados na Tabela 8 são maiores que o máximo permitido. Para determinar a influência dos principais parâmetros de teste na dispersão dos resultados e validar o dispositivo construído, outros ensaios foram realizados no PEAD virgem com a avaliação dos tempos de falha em diferentes condições.

Na Tabela 9 são apresentados os resultados de NCLS para os parâmetros de homogeneidade do banho - Entalhe [1], Entalhe [2], reposição do banho, homogeneidade do banho - Entalhe [3] e ajustes das cargas aplicadas.

Tabela 9 - Resultados de NCLS - parâmetros avaliados: homogeneidade do banho - Entalhe [1], Entalhe [2], reposição do banho, homogeneidade do banho - Entalhe [3] e ajustes das cargas aplicadas

\begin{tabular}{|c|c|c|c|c|}
\hline \multirow[b]{2}{*}{ Amostra } & \multicolumn{4}{|c|}{ Homogeneidade do banho - Entalhe [1] } \\
\hline & $\begin{array}{c}\text { Carga aplicada } \\
\text { (MPa) }\end{array}$ & $\begin{array}{c}\text { Tempo de falha } \\
\text { (h) }\end{array}$ & $\begin{array}{l}\text { Desvio } \\
\text { padrão }\end{array}$ & $\begin{array}{c}\text { Coeficiente } \\
\text { de variação } \\
(\%)\end{array}$ \\
\hline \multirow{14}{*}{ PEAD } & 8,25 & 204 & 142 & 69,6 \\
\hline & 11,00 & 43 & 12 & 27,9 \\
\hline & \multicolumn{4}{|c|}{ Entalhe [2] } \\
\hline & 8,25 & 261 & 64 & 24,5 \\
\hline & 11,00 & 67 & 22 & 32,8 \\
\hline & \multicolumn{4}{|c|}{ Reposição do banho } \\
\hline & 8,25 & 305 & 58 & 19 \\
\hline & 11,00 & 74 & 35 & 47,3 \\
\hline & \multicolumn{4}{|c|}{ Homogeneidade do banho e Entalhe [3] } \\
\hline & 8,25 & 327 & 89 & 27,2 \\
\hline & 11,00 & 63 & 13 & 20,6 \\
\hline & \multicolumn{4}{|c|}{ Ajuste das cargas } \\
\hline & 8,25 & 283 & 43 & 15,2 \\
\hline & 11,00 & 59 & 37 & 67,2 \\
\hline
\end{tabular}

Fonte: Autoria própria.

De acordo com os resultados apresentados na Tabela 9 algumas comparações podem ser realizadas: 
- Homogeneidade do banho e entalhe [1] cíclico - os corpos de prova avaliados nesta etapa foram entalhados por meio de processo cíclico. Nota-se um tempo de falha de $204 \mathrm{~h}$ e $43 \mathrm{~h}$ para as cargas de $8,25 \mathrm{MPa}$ e 11,00 MPa respectivamente, que correspondem a $30 \%$ e $40 \%$ da tensão de escoamento do material especificado na norma ASTM F 2136-18. Foram verificadas dispersões elevadas acima do que a norma preconiza. Imagens por meio de MEV foram realizadas nos corpos de prova entalhados. Na Figura 36 a e b são mostradas as micrografias dos corpos de prova de PEAD e nota-se que há uma grande quantidade de material plastificado na ponta da trinca e uma quantidade significativa de microfissuras. E nas regiões abaixo da trinca gerando pontos de concentração de tensão que podem causar redução nos tempos de falha esperados para o material, uma vez que o surfactante atua nesta região. $O$ processo de entalhamento cíclico pode ter induzido a formação excessiva de microfissuras e uma deformação plástica também excessiva, causando significativa dispersão nos tempos de falha e, portanto, modificações foram realizadas e novos ensaios foram conduzidos.

Figura 36 - Micrografias obtidas por MEV das amostras de PEAD destacando: a) a presença significativa de material plastificado na ponta da trinca e b) microfissuras na ponta da trinca

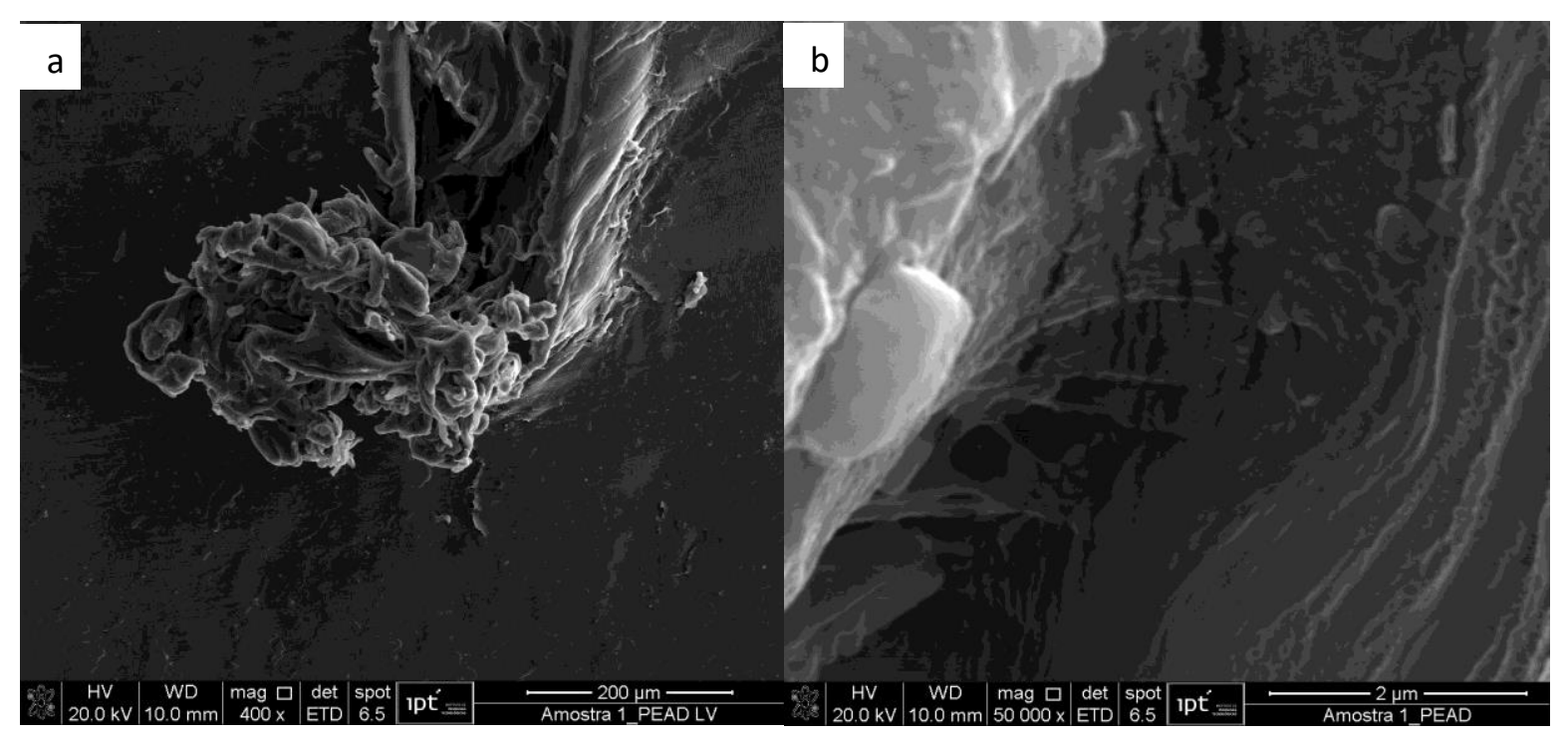

Fonte: Autoria própria.

- Entalhe [2]: os corpos de prova passaram a ser preparados e entalhados de forma estática por processo tipo guilhotina. Pôde-se verificar que as dispersões foram reduzidas para as cargas de $11 \mathrm{MPa}$ e aumentaram para as cargas de 
8,25 $\mathrm{MPa}$, porém ainda permaneceram acima da recomendação da norma ASTM F2136-18. Na Figura 37 a e b são mostrados o entalhe e a ponta da trinca respectivamente, e notou-se que a quantidade de material plastificado na ponta da trinca reduziu significativamente, menores quantidades de fissuras foram observadas, embora ainda presentes nas micrografias, e os requisitos dimensionais de profundidade do entalhe exigidos pela norma foram alcançados e, portanto, esse processo de entalhamento estático foi adotado para os demais ensaios.

Figura 37 - Micrografias obtidas por MEV das amostras de PEAD destacando: a) redução significativa de material plastificado na ponta da trinca e b) redução na quantidade de microfissuras na ponta da trinca

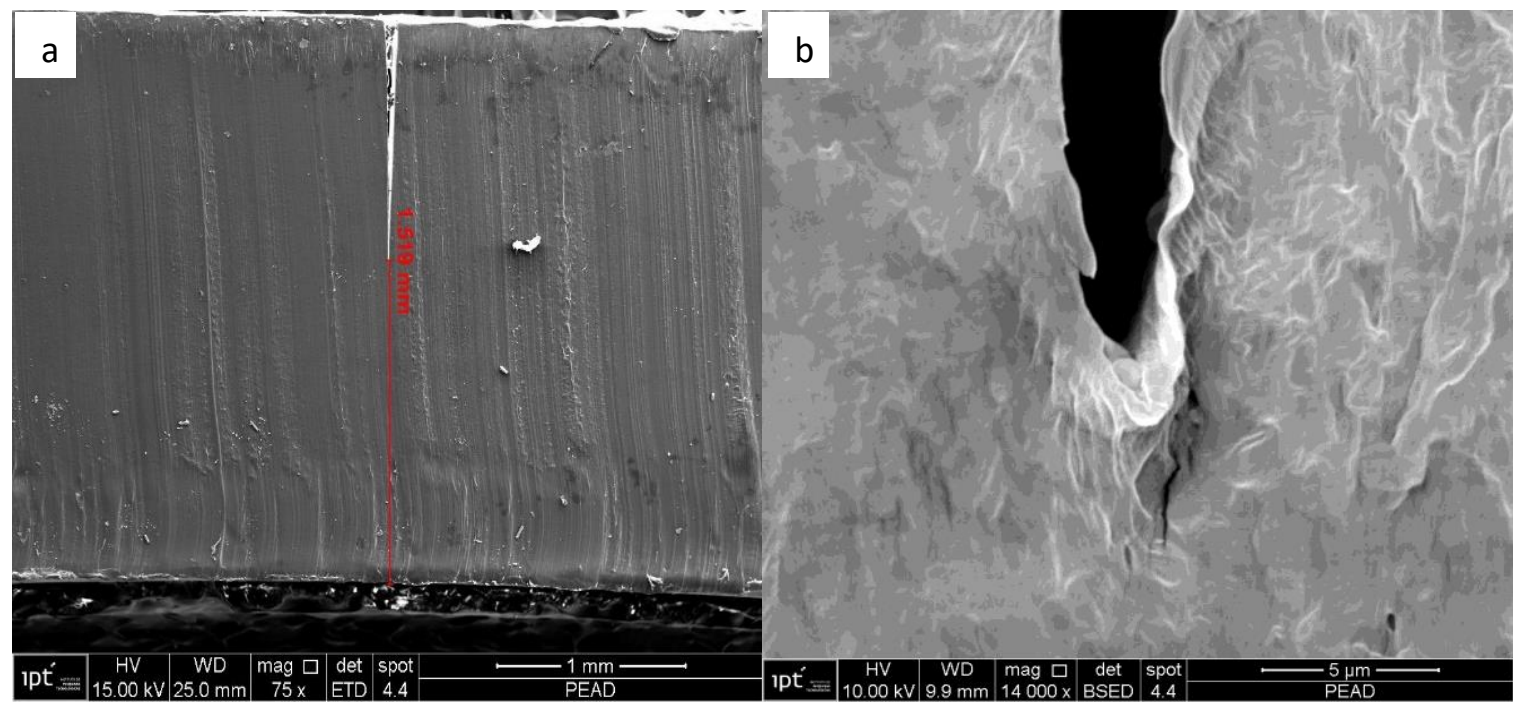

Fonte: Autoria Própria.

Reposição do banho: Ensaios de índice de refração BRIX foram conduzidos e os resultados estão apresentados na Tabela 10 e mostrados na Figura 38. 
Tabela 10 - Diferentes concentrações de surfactante versus índice de refração BRIX para criação da curva de calibração e validação da concentração, perda e reposição do banho

\begin{tabular}{|c|c|}
\hline $\begin{array}{c}\text { Concentração de } \\
\text { surfactante (\%) }\end{array}$ & Índice de refração BRIX (\%) \\
\hline 0 & 0,26 \\
\hline 5 & 6,22 \\
\hline 10 & 11,69 \\
\hline 15 & 16,40 \\
\hline 20 & 21,50 \\
\hline
\end{tabular}

Fonte: Autoria Própria.

A curva de calibração e a equação para quantificação da concentração de surfactante usando regressão linear estão mostradas na Figura 38.

Figura 38 - Curva de calibração - Índice de refração BRIX versus concentração de surfactante usando regressão linear para análise quantitativa

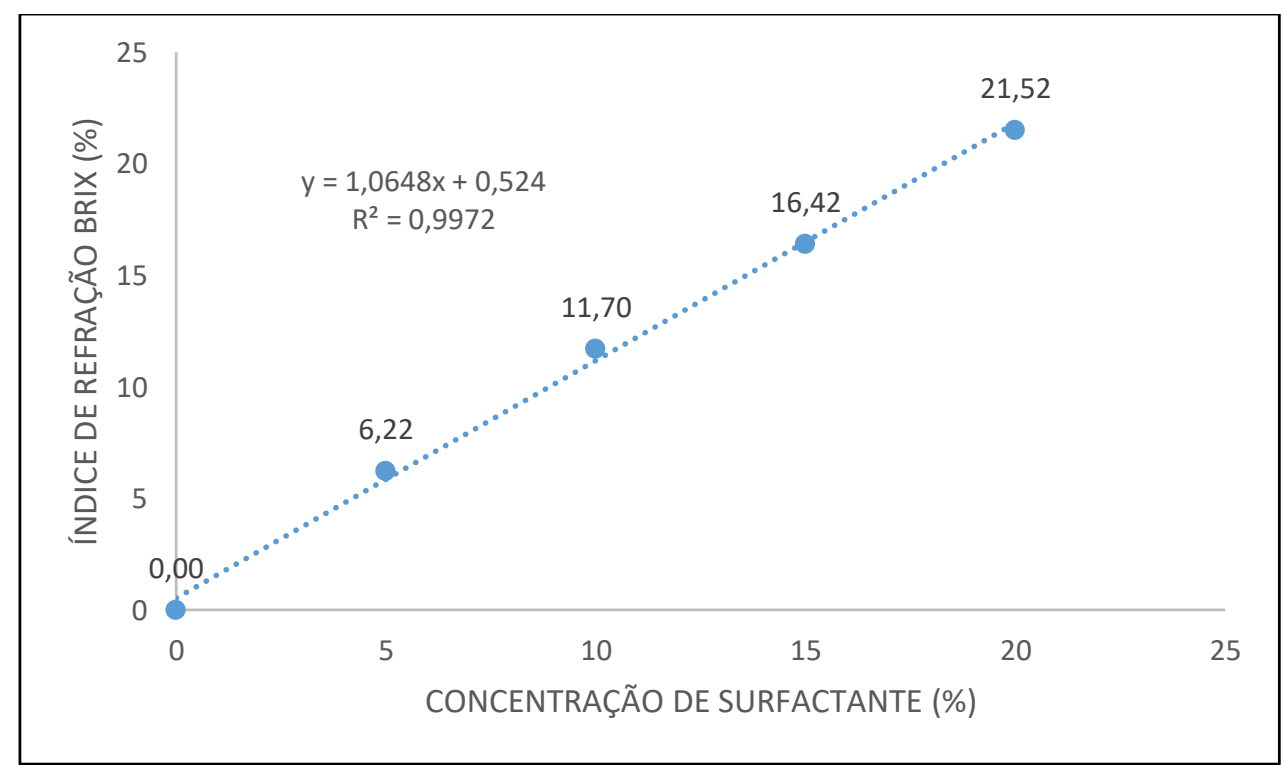

Fonte: Autoria Própria.

Comparando os resultados verificou-se que devido ser possível obter uma relação linear entre o índice de refração BRIX e a concentração do banho, a concentração de uma solução desconhecida pode ser medida por meio de regressão linear pelo 
Método dos Mínimos Quadrados (MMQ). Dessa forma tornou-se possível a validação da concentração e reposição do banho, uma vez que em $10 \%$ de concentração de surfactante o índice de refração BRIX é 11,68\%.

Após a criação da curva de calibração novos ensaios foram realizados. Foram analisados seis dias consecutivos sem reposição da água deionizada para verificar os níveis de concentração do banho. O preparo foi realizado de acordo com os requisitos especificados na norma ASTM F2136-18 com 90\% de água deionizada e 10\% de surfactante. O nível inicial do banho ou altura remanescente do mesmo registrado foi de $180 \mathrm{~mm}$ em relação ao fundo da incubação. Novas amostras foram coletadas nos dias subsequentes em níveis de $164 \mathrm{~mm}, 148 \mathrm{~mm}, 132 \mathrm{~mm}, 116 \mathrm{~mm}$ e $100 \mathrm{~mm}$, que correspondem a um intervalo de 24 horas, a medida em que a evaporação ocorria. Novos índices de refração BRIX foram conduzidos e os resultados estão apresentados na Tabela 11.

Tabela 11 - Índices de refração BRIX sem reposição de água deionizada por seis dias consecutivos em intervalos de 24 horas

\begin{tabular}{|c|c|c|c|}
\hline Dia & $\begin{array}{c}\text { Altura remanescente do } \\
\text { banho }(\mathrm{mm})\end{array}$ & $\begin{array}{c}\text { Índice de refração } \\
\text { BRIX (\%) }\end{array}$ & $\begin{array}{c}\text { Concentração de } \\
\text { surfactante (\%) }\end{array}$ \\
\hline 1 & $\mathbf{1 8 0}$ & $\mathbf{1 2 , 3 8}$ & $\mathbf{1 0 , 5 9}$ \\
\hline 2 & $\mathbf{1 6 4}$ & $\mathbf{1 3 , 6 6}$ & 13,12 \\
\hline 3 & 148 & 15,34 & 14,82 \\
\hline 4 & 132 & 17,32 & 17,47 \\
\hline 5 & 116 & 20,42 & 19,50 \\
\hline 6 & 100 & 22,80 & $\mathbf{1 0 , 6 0}$ \\
\hline $\mathbf{7}$ & $\mathbf{1 8 0}$ & $\mathbf{1 2 , 4 2}$ & \\
\hline
\end{tabular}

Fonte: Autoria Própria.

Correlacionando os valores de refração BRIX, pôde-se observar que o nível do banho em $180 \mathrm{~mm}$ havia uma concentração de aproximadamente 10,5\% de surfactante e após 24 horas, com o banho a um nível de $164 \mathrm{~mm}$, havia aproximadamente uma concentração de $11,68 \%$, mostrando que a reposição de água deionizada deve ser 
conduzida a cada 24 horas, corroborando a recomendação da norma ASTM F213618. Após a reposição do banho ao nível inicial de $180 \mathrm{~mm}$ com água deionizada, nova medição do índice de refração BRIX foi realizada e a concentração do banho retornou ao valor inicial de $10,60 \%$. O Índice de refração BRIX versus a concentração de surfactante e o nível do banho versus concentração de surfactante após os seis dias consecutivos com evaporação da água deionizada estão mostrados nas Figuras 39 e 40 , respectivamente. 
Figura 39 - Índices de refração BRIX versus concentração de surfactante

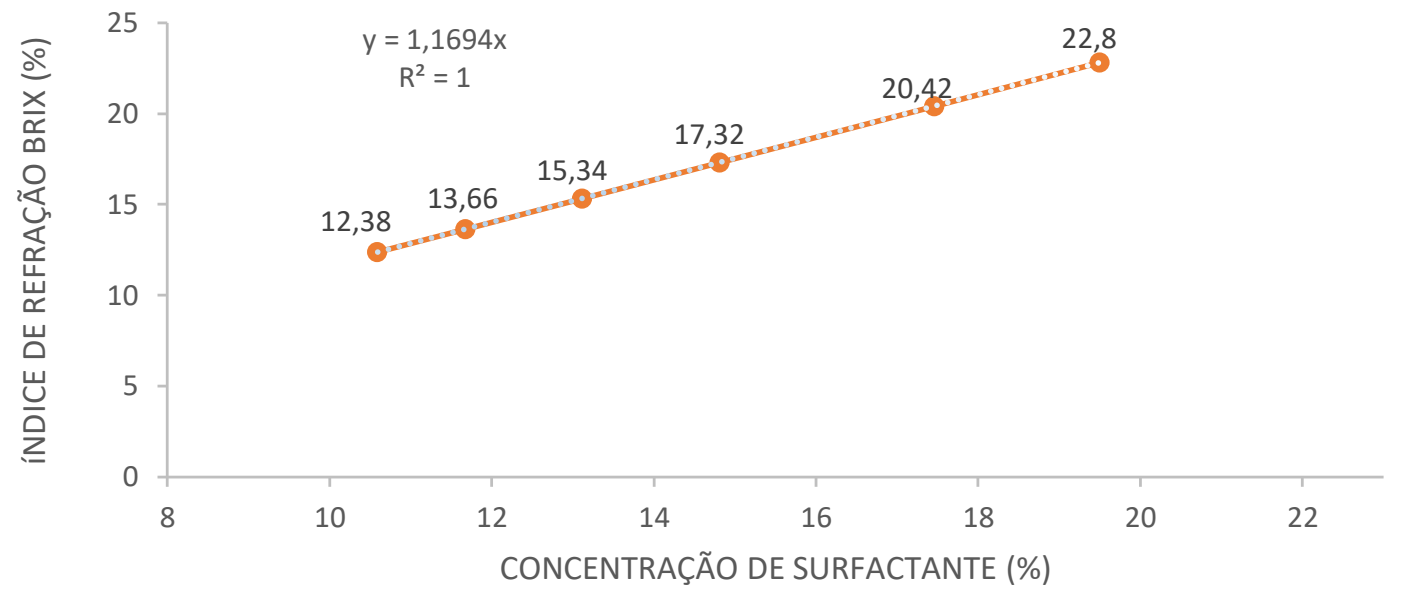

Fonte: Autoria Própria.

Figura 40 - Altura remanescente do banho versus concentração de surfactante com os respectivos índices de refração BRIX

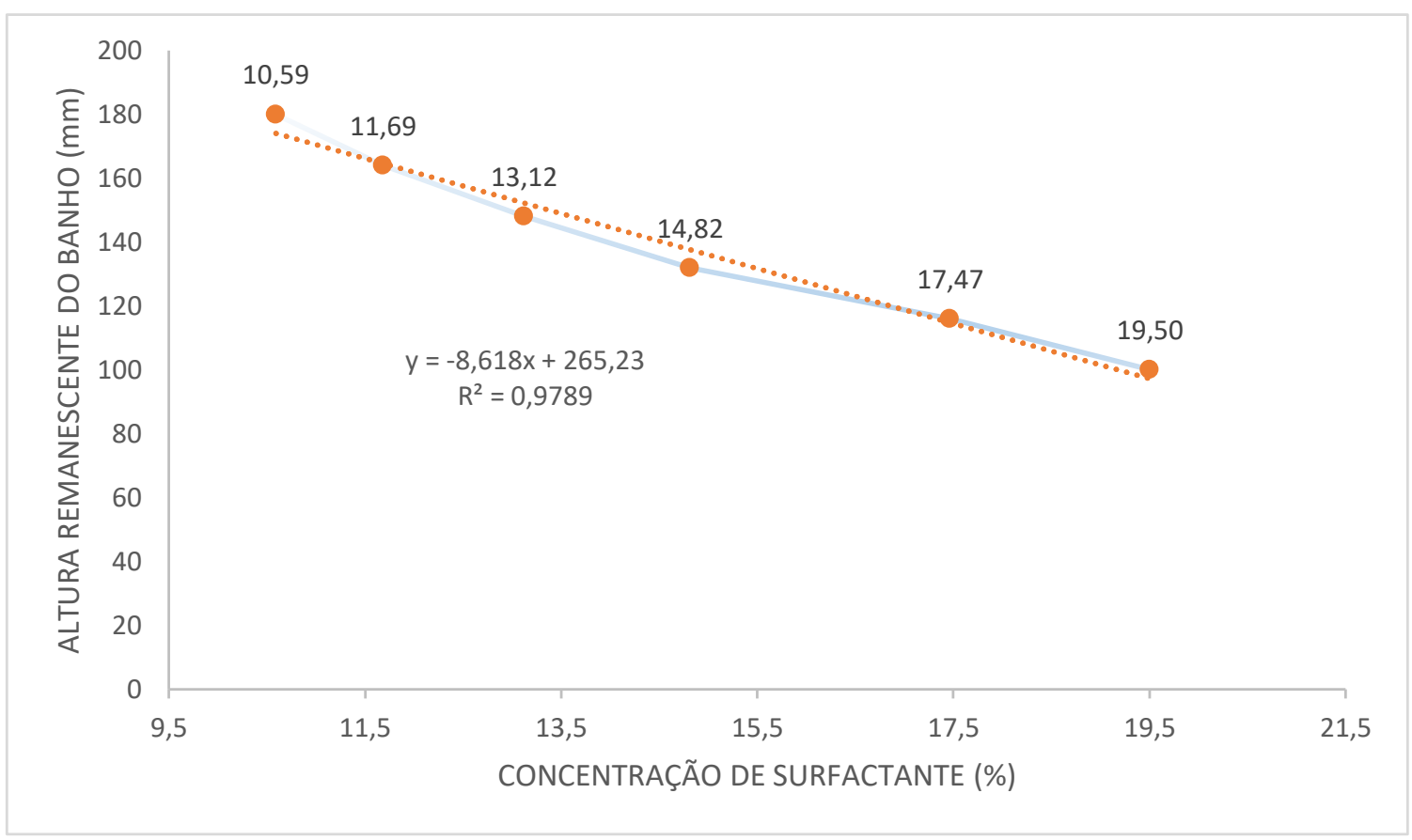

Fonte: Autoria Própria.

Analisando os resultados notou-se um significativo aumento na concentração de surfactante, que pode induzir a uma elevada dispersão nos tempos de falha. Portanto foi adotada a reposição de água deionizada diariamente mantendo o nível inicial corroborando com a norma ASTM F2136-18. 
- Homogeneidade do banho e entalhe [3]: foram realizados ajustes na máquina entalhadora afim de reduzir a variabilidade dos dimensionais dos entalhes preconizados pela norma ASTM F2136-18. Foi mudada a estrutura do dispositivo, e adicionalmente inserido o limitador metálico de curso de entalhamento. Novos corpos de prova foram produzidos e entalhados, e novas imagens de MEV foram realizadas e as micrografias são mostradas nas imagens (a, b, c e d) da Figura 41.

Figura 41 - Micrografias obtidas por MEV das amostras de PEAD destacando: a) e b) redução significativa de material plastificado na ponta da trinca e redução na quantidade e extensão de microfissuras na ponta da trinca; c) e d) trincas encontradas em regiões distantes ao entalhe
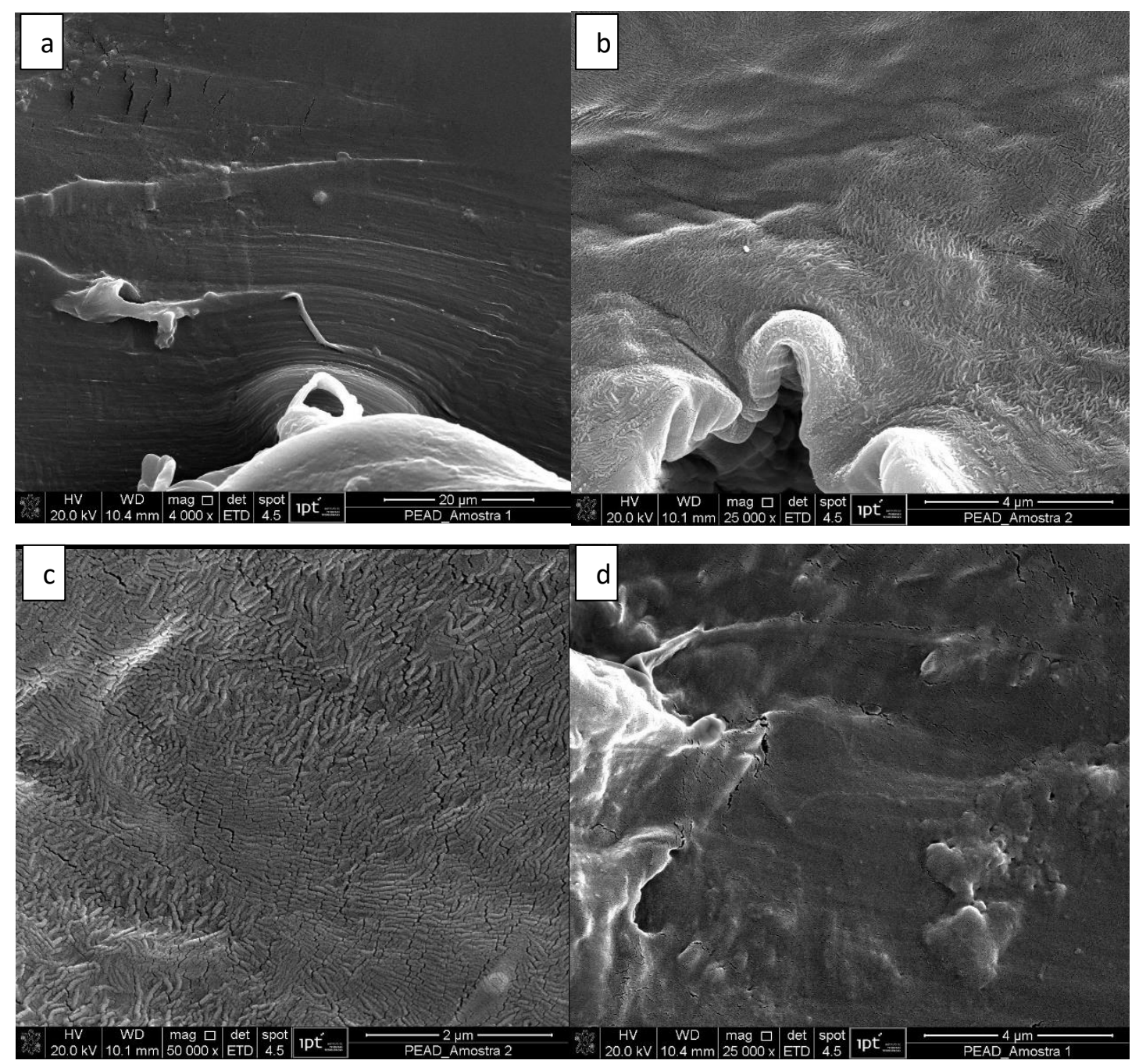

Fonte: Autoria própria.

Analisando as micrografias 41a e 41b notou-se uma redução significativa de regiões com microfissuras na ponta da trinca e redução na quantidade de 
material plastificado, mostrando que o processo de entalhamento foi evoluído significativamente. Na micrografia 41a notou-se uma região superior esquerda com microfissuras e adicionalmente foram realizadas micrografias em regiões aleatórias distantes ao entalhe como mostradas nas imagens $41 \mathrm{c}$ e $41 \mathrm{~d}$, em que com o aumento gradativo da ampliação favorece a degradação do polímero e o surgimento de microfissuras. Dessa forma pôde-se verificar a degradação do material e a formação de fissuras no momento da ampliação para realização das micrografias.

A fim de melhorar a homogeneidade do banho foi adicionado um agitador contínuo com controle de velocidade. Pôde-se verificar que as temperaturas em diferentes pontos do banho se mantem dentro dos requisitos de variação da norma ASTM F2136-18. Porém observou-se que os resultados permaneceram com uma dispersão elevada e, novos parâmetros foram analisados.

- Ajuste das cargas: a vantagem mecânica que a norma preconiza para o ligamento constante nos corpos de prova é de 2:1 a 5:1. As cargas aplicadas nas amostras devem apresentar uma variação de no máximo 0,5\% dos valores calculados. Os resultados obtidos foram medidos por meio de um dinamômetro acoplado ao dispositivo colocando-se uma massa certificada de $1 \mathrm{~kg}$ na extremidade das alavancas. Pode-se notar que durante o ensaio há uma acomodação dos corpos de prova e do dispositivo causando dispersão nos resultados. Após o nivelamento do dispositivo utilizando um inclinômetro digital de precisão e o dinamômetro, observou-se uma redução dos desvios para $15,2 \%$, muito próximos aos requisitos da norma ASTM F2136-18. 
Analisando os resultados da Tabela 09, notou-se uma significativa dispersão nos tempos de falha. A medida em que cada parâmetro foi corrigido conforme as especificações, observou-se o aumento significativo dos tempos de falha para ambas as tensões aplicadas, corroborando para a diminuição das dispersões e possibilidade de validação do dispositivo.

Na Figura 42 estão mostrados os parâmetros avaliados para o ensaio de NCLS com os respectivos resultados dos tempos de falha e a redução dos coeficientes de variação até $15,2 \%$.

Figura 422 - Principais variáveis descritas na norma ASTM F2136-18 em função da redução dos respectivos coeficientes de variação com $30 \%$ da tensão de escoamento

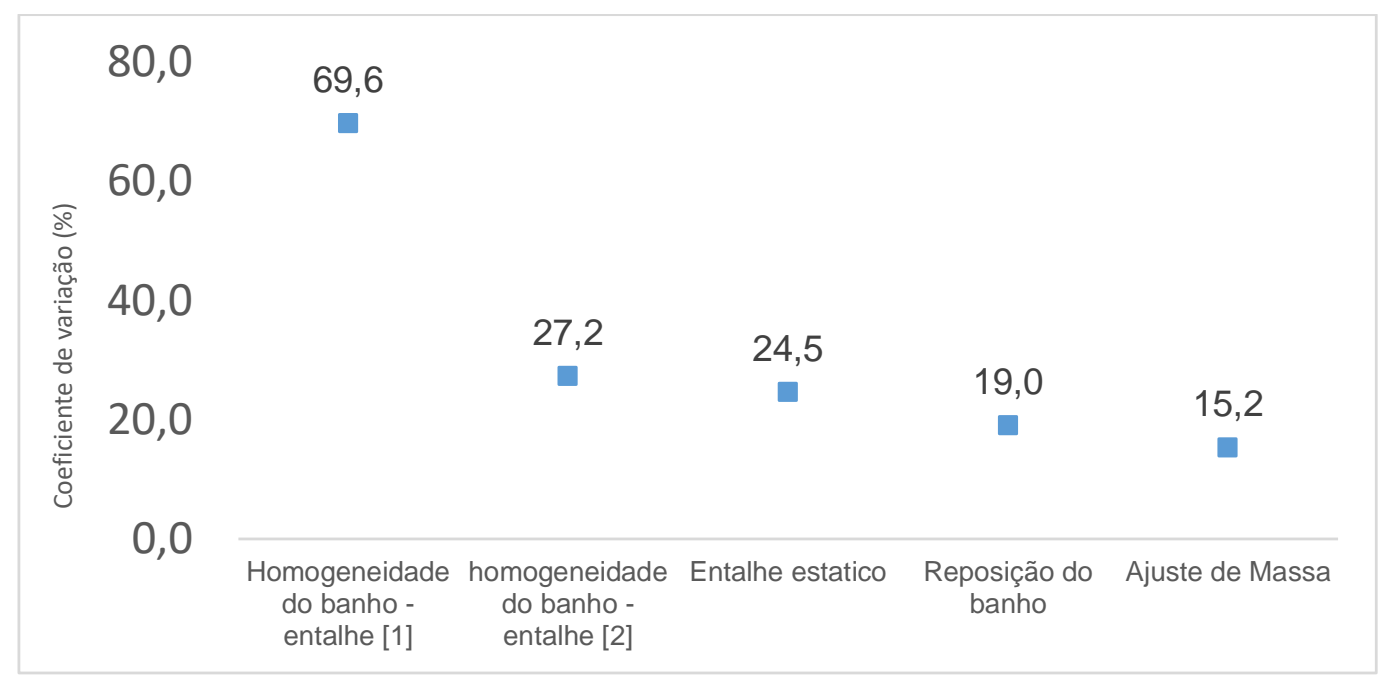

Fonte: Autoria Própria.

Analisando os resultados com os respectivos coeficientes de variação, observou-se uma significativa redução nas dispersões dos tempos de falha entre as amostras, de $69,6 \%$ para $15,2 \%$, porém os resultados permanecem $5 \%$ acima do permitido. A norma ASTM F2136-18 preconiza uma variação máxima de 10\%. Dessa forma um novo método de obtenção dos corpos de prova foi conduzido. Novos corpos de prova foram produzidos por meio do processo de injeção para o ensaio de fissuramento sob tensão constante e entalhe NCLS e os resultados são apresentados na Tabela 12. 
Tabela 12 - Resultados de NCLS para os corpos de prova injetados de PEAD

\begin{tabular}{|c|c|c|c|c|}
\hline \multirow{2}{*}{ Amostra } & $\begin{array}{c}\text { Carga aplicada (MPa) } \\
{[1]}\end{array}$ & $\begin{array}{c}\text { Tempo de falha (h) } \\
\text { [2] }\end{array}$ & Desvio padrão & $\begin{array}{c}\text { Coeficiente de } \\
\text { variação (\%) }\end{array}$ \\
\hline \multirow{3}{*}{ PEAD } & 4,12 & $>500$ & - & - \\
\cline { 2 - 5 } & 8,25 & 329,5 & 29,6 & $\mathbf{8 , 9}$ \\
\cline { 2 - 5 } & 11,00 & 282,5 & 21,3 & $\mathbf{7 , 5}$ \\
\hline
\end{tabular}

Fonte: Autoria própria.

Analisando os resultados de NCLS para o PEAD verificou-se um tempo de falha compatível com os requisitos das resinas próprias para aplicações estruturais, o coeficiente de variação compatível com a norma ASTM F2136-18, abaixo de 10\%, e dessa forma os ensaios de NCLS também foram realizados para o PEAD reciclado mecanicamente por uma única etapa de extrusão.

Os resultados dos ensaios de NCLS para o PEAD reciclado por uma única etapa de extrusão são apresentados na Tabela 13.

Tabela 13 - Resultados de NCLS para os corpos de prova injetados de PEAD-R

\begin{tabular}{|c|c|c|c|c|}
\hline \multirow{2}{*}{ Amostra } & $\begin{array}{c}\text { Carga aplicada (MPa) } \\
{[1]}\end{array}$ & $\begin{array}{c}\text { Tempo de falha (h) } \\
{[\mathbf{2}]}\end{array}$ & Desvio padrão & $\begin{array}{c}\text { Coeficiente de } \\
\text { variação (\%) }\end{array}$ \\
\hline \multirow{2}{*}{ PEAD R } & 4,12 & $>500$ & - & - \\
\cline { 2 - 5 } & 8,25 & 312,3 & 27,3 & $\mathbf{8 , 7}$ \\
\cline { 2 - 5 } & 11,00 & 279,2 & 26,9 & $\mathbf{9 , 6}$ \\
\hline
\end{tabular}

Fonte: Autoria própria.

Analisando os resultados dos ensaios de fissuramento sob tensão constante e entalhe NCLS para os corpos de prova injetados de PEAD-R, com cargas de 15\%, 30\% e $40 \%$ da tensão de escoamento, verificou-se que os materiais apresentaram tempo de falha compatível para as aplicações estruturais. Adicionalmente os valores dos coeficientes de variação se mostraram compatíveis com os requisitos exigidos pela norma ASTM F2136-18. Dessa forma o PEAD-R reciclado mecanicamente por uma única etapa de extrusão apresentou oportunidades significativas para aplicações que demandam um longo tempo de vida em serviço como tubos de irrigação, geomembranas, tubos de drenagem pluvial, dormentes, entre outras, em relação ao parâmetro de fissuramento sob tensão constante e entalhe avaliado neste estudo. Dessa forma, afim de verificar se há diferenças mínimas significativas para a matriz de PEAD com os contaminantes dispersos nos ensaios de curta duração novos ensaios de resistência à tração, flexão e impacto foram conduzidos. 


\subsection{RESULTADOS DOS ENSAIOS DE CURTA DURAÇÃO PARA AS MISTURAS DE PEAD/CONTAMINANTE}

\subsubsection{Resultados dos ensaios de resistência à tração para as misturas de PEAD/contaminante}

Ensaios de resistência à tração foram realizados a fim de verificar o efeito dos contaminantes dispersos na matriz de PEAD.

Os resultados obtidos para os ensaios de resistência à tração das amostras de PEAD e das misturas de PEAD/PP, PEAD/TiO $, \mathrm{PEAD} / \mathrm{CaCO}_{3}, \mathrm{PEAD} / \mathrm{SiO}_{2}$ em frações mássicas de contaminante variando de $2 \%$ a $8 \%$, em que estão representados os valores médios para pelo menos cinco corpos de prova para os parâmetros de resistência à tração no escoamento, alongamento e módulo de rigidez, são apresentados na Tabela 14 e mostrados Figuras 45 e 46, respectivamente. Para avaliar se as diferenças entre as misturas são significativas, foi realizado um teste estatístico, método Tukey, em que por meio de comparações múltiplas em conjunto com uma ANOVA (Analysis of Variance) pôde-se observar se as medianas são diferentes entre si em um nível de confiança (TECHNOLOGY, 2013). 
Tabela 14 - Resultados de resistência à tração no escoamento, alongamento e módulo de rigidez das amostras de PEAD e misturas de PEAD/PP, PEAD/CaCO $3, \mathrm{PEAD} / \mathrm{SiO}_{2}, \mathrm{PEAD} / \mathrm{TiO}_{2}$ para as frações mássicas de $2 \%$ a $8 \%$ de cada contaminante

\begin{tabular}{|c|c|c|c|}
\hline Amostra & $\begin{array}{c}\text { Resistência à tração no } \\
\text { escoamento (MPa) } \pm \\
\text { intervalo de } 95 \% \text { de } \\
\text { confiança }\end{array}$ & $\begin{array}{c}\text { Alongamento } \pm \\
\text { intervalo de } 95 \% \text { de } \\
\text { confiança }(\%)\end{array}$ & $\begin{array}{c}\text { Módulo de rigidez (MPa) } \\
\text { intervalo de } 95 \% \text { de } \\
\text { confiança (\%) }\end{array}$ \\
\hline PEAD & $30 \pm 2$ & $10 \pm 2$ & $314 \pm 34$ \\
\hline PEAD/PP2\% & $31,5 \pm 0,6$ & $12 \pm 4$ & $280 \pm 97$ \\
\hline PEAD/PP4\% & $28 \pm 2$ & $10 \pm 3$ & $282 \pm 73$ \\
\hline PEAD/PP6\% & $29 \pm 2$ & $13 \pm 2$ & $228 \pm 43$ \\
\hline PEAD/PP8\% & $30 \pm 3$ & $12 \pm 4$ & $281 \pm 116$ \\
\hline $\mathrm{PEAD} / \mathrm{CaCO}_{3} 2 \%$ & $31,5 \pm 0,8$ & $9,7 \pm 0,9$ & $327 \pm 52$ \\
\hline $\mathrm{PEAD} / \mathrm{CaCO}_{3} 4 \%$ & $30,8 \pm 1$ & $9,7 \pm 1$ & $319 \pm 43$ \\
\hline $\mathrm{PEAD} / \mathrm{CaCO}_{3} 6 \%$ & $29,4 \pm 1,3$ & $10,6 \pm 1,4$ & $282 \pm 63$ \\
\hline $\mathrm{PEAD} / \mathrm{CaCO}_{3} 8 \%$ & $30 \pm 0,9$ & $10,2 \pm 0,6$ & $293 \pm 21$ \\
\hline $\mathrm{PEAD} / \mathrm{SiO}_{2} 2 \%$ & $30,4 \pm 1,1$ & $11,8 \pm 2,3$ & $263 \pm 55$ \\
\hline $\mathrm{PEAD} / \mathrm{SiO}_{2} 4 \%$ & $29,2 \pm 1,4$ & $10,4 \pm 0,6$ & $282 \pm 40$ \\
\hline $\mathrm{PEAD} / \mathrm{SiO}_{2} 6 \%$ & $30,1 \pm 1,5$ & $12,5 \pm 1,3$ & $242 \pm 36$ \\
\hline $\mathrm{PEAD} / \mathrm{SiO}_{2} 8 \%$ & $30,7 \pm 2$ & $11,45 \pm 1,70$ & $277 \pm 88$ \\
\hline $\mathrm{PEAD} / \mathrm{TiO}_{2} 2 \%$ & $29,6 \pm 0,9$ & $10,2 \pm 0,9$ & $292 \pm 40$ \\
\hline $\mathrm{PEAD} / \mathrm{TiO}_{2} 4 \%$ & $29,2 \pm 0,5$ & $9,8 \pm 0,8$ & $301 \pm 45$ \\
\hline $\mathrm{PEAD} / \mathrm{TiO}_{2} 6 \%$ & $30,6 \pm 0,6$ & $9,2 \pm 0,7$ & $333 \pm 33$ \\
\hline $\mathrm{PEAD} / \mathrm{TiO}_{2} 8 \%$ & $30,2 \pm 1,9$ & $8,9 \pm 1,1$ & $343 \pm 83$ \\
\hline
\end{tabular}

Fonte: Autoria própria.

Pôde-se observar que aumentando os teores dos contaminantes $\mathrm{PP}, \mathrm{CaCO}_{3}$, $\mathrm{SiO}_{2}$ e $\mathrm{TiO}_{2}$ em frações mássicas variando de $2 \%$ a $8 \%$, não houveram variações significativas no desempenho de curta duração, pode-se observar que para todas as misturas ensaiadas as barras de erro se sobrepõem quando comparadas ao material PEAD. Dessa forma para os parâmetros de resistência à tração, alongamento e módulo de rigidez, para as frações mássicas de $2 \%$ a $8 \%$ o PEAD/PP, PEAD/CaCO $\mathrm{CO}_{3}$, $\mathrm{PEAD} / \mathrm{SiO}_{2}$ e o $\mathrm{PEAD} / \mathrm{TiO}_{2}$ se mostraram compatíveis para aplicações estruturais que demandam longo tempo de vida em serviço. Embora os resultados mostraram uma certa igualdade em um intervalo de confiança de 95\% a mistura PEAD/PP mostra uma pequena redução nos valores de resistência à tração, evidenciando uma baixa miscibilidade entre os polímeros, resultando numa interface pobre e proporcionando um efeito deletério nas propriedades da mistura, corroborando com os estudos realizados por (THOMAS e CUTTINO, 2011). Na Figura 43 estão mostrados os valores médios dos resultados de resistência à tração no escoamento. 
Figura 433 - Gráfico dos resultados de resistência à tração no escoamento das amostras de PEAD e misturas de PEAD/PP, PEAD/CaCO $3, \mathrm{PEAD} / \mathrm{SiO}_{2}$ e $\mathrm{PEAD} / \mathrm{TiO}_{2}$ para frações mássicas de $2 \%$ a $8 \%$ de contaminante

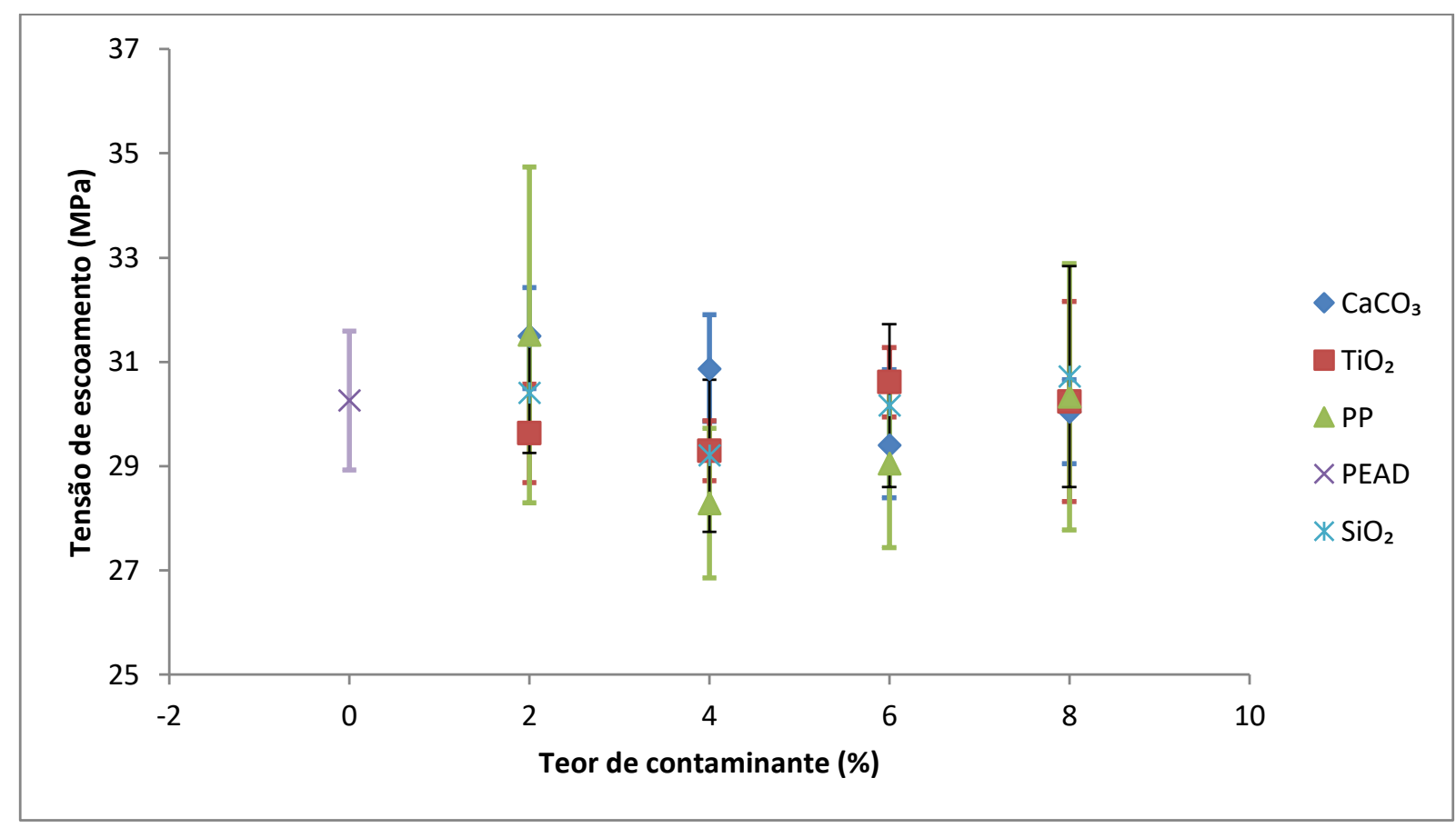

Fonte: Autoria própria.

Na Figura 44 é mostrado o gráfico de resistência à tração quanto ao alongamento para as mesmas amostras analisadas quanto ao parâmetro de resistência à tração no escoamento. Pôde-se observar que para todas as misturas ensaiadas as barras de erro se sobrepõem quando comparadas ao material de PEAD, não apresentando variações significativas no desempenho de curta duração. 
Figura 444 - Gráfico dos resultados de resistência à tração quanto ao alongamento das amostras de $\mathrm{PEAD}$ e misturas de $\mathrm{PEAD} / \mathrm{PP}, \mathrm{PEAD} / \mathrm{CaCO}_{3}, \mathrm{PEAD} / \mathrm{SiO}_{2}$ e $\mathrm{PEAD} / \mathrm{TiO}{ }_{2}$ para frações mássicas de $2 \%$ a $8 \%$ de contaminante

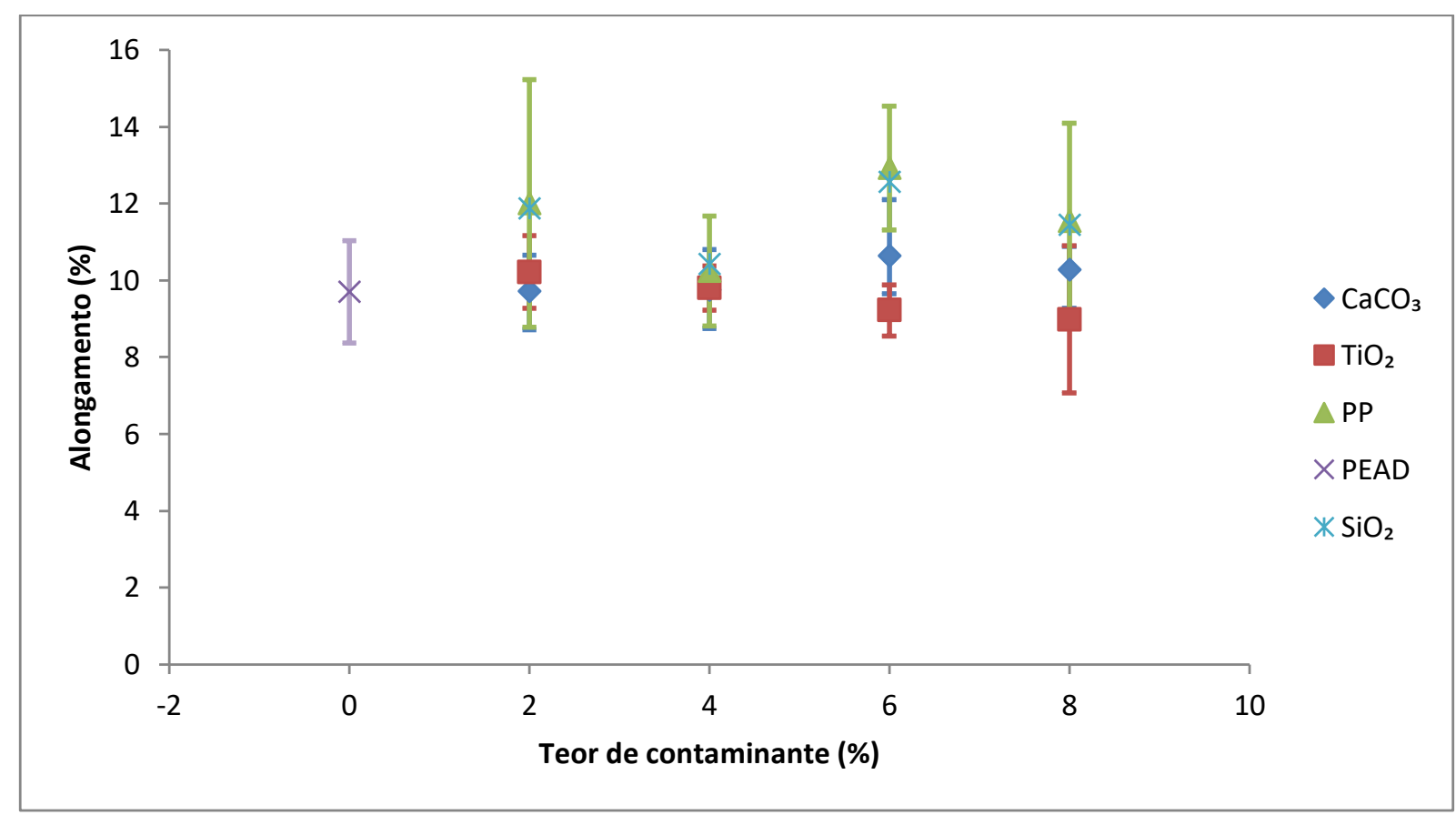

Fonte: Autoria própria. 


\subsubsection{Resultados dos ensaios de resistência à flexão para as misturas de PEAD/contaminante}

A fim de corroborar e avaliar se os teores de contaminantes dispersos na matriz de PEAD são significativos, foram realizados ensaios de resistência à flexão nas demais misturas. Os resultados obtidos para os ensaios de resistência à flexão das amostras de PEAD e das misturas de PEAD/PP, PEAD/TiO, 2 PEAD/CaCO ${ }_{3}$, $\mathrm{PEAD} / \mathrm{SiO}_{2}$ em frações mássicas de contaminante variando de $2 \%$ a $8 \%$, em que estão representados os valores médios para pelo menos cinco corpos de prova para os parâmetros de resistência à flexão e o módulo sob flexão analisados são apresentados na Tabela 15. Para avaliar se as diferenças entre as misturas são significativas, foi realizado um teste estatístico, método Tukey, em que por meio de comparações múltiplas em conjunto com uma ANOVA (Analysis of Variance) pôdese observar se as medianas são diferentes entre si em um nível de confiança (TECHNOLOGY, 2013).

Tabela 15 - Resultados de resistência à flexão das amostras de PEAD e misturas de PEAD/PP, $\mathrm{PEAD} / \mathrm{CaCO}_{3}, \mathrm{PEAD} / \mathrm{SiO}_{2}$ e $\mathrm{PEAD} / \mathrm{TiO}_{2}$ para as frações mássicas de $2 \%$ a $8 \%$ de cada contaminante

\begin{tabular}{|c|c|c|}
\hline Amostra & $\begin{array}{c}\text { Resistência à flexão (MPa) } \pm \\
\text { intervalo de } 95 \% \text { de confiança }\end{array}$ & $\begin{array}{l}\text { Módulo sob flexão (MPa) } \pm \\
\text { intervalo de } 95 \% \text { de confiança }\end{array}$ \\
\hline PEAD & $9,2 \pm 0,2$ & $1016 \pm 31$ \\
\hline PEAD/PP2\% & $9,7 \pm 0,1$ & $951 \pm 67$ \\
\hline PEAD/PP4\% & $10,3 \pm 0,6$ & $1050 \pm 85$ \\
\hline PEAD/PP6\% & $9,8 \pm 0,3$ & $1081 \pm 68$ \\
\hline PEAD/PP8\% & $10,2 \pm 0,2$ & $948 \pm 95$ \\
\hline $\mathrm{PEAD} / \mathrm{CaCO}_{3} 2 \%$ & $9,2 \pm 0,9$ & $1010 \pm 52$ \\
\hline $\mathrm{PEAD} / \mathrm{CaCO}_{3} 4 \%$ & $10,0 \pm 0,4$ & $960 \pm 58$ \\
\hline $\mathrm{PEAD} / \mathrm{CaCO}_{3} 6 \%$ & $10,7 \pm 0,5$ & $1030 \pm 64$ \\
\hline $\mathrm{PEAD} / \mathrm{CaCO}_{3} 8 \%$ & $9,7 \pm 0,5$ & $911 \pm 21$ \\
\hline $\mathrm{PEAD} / \mathrm{SiO}_{2} 2 \%$ & $10,2 \pm 0,6$ & $943 \pm 58$ \\
\hline $\mathrm{PEAD} / \mathrm{SiO}_{2} 4 \%$ & $10,0 \pm 0,4$ & $968 \pm 63$ \\
\hline $\mathrm{PEAD} / \mathrm{SiO}_{2} 6 \%$ & $10,7 \pm 0,5$ & $1031 \pm 60$ \\
\hline $\mathrm{PEAD} / \mathrm{SiO}_{2} 8 \%$ & $9,8 \pm 0,5$ & $912 \pm 59$ \\
\hline $\mathrm{PEAD} / \mathrm{TiO}_{2} 2 \%$ & $10,3 \pm 0,4$ & $980 \pm 32$ \\
\hline $\mathrm{PEAD} / \mathrm{TiO}_{2} 4 \%$ & $9,4 \pm 0,5$ & $966 \pm 43$ \\
\hline $\mathrm{PEAD} / \mathrm{TiO}_{2} 6 \%$ & $9,3 \pm 0,7$ & $968 \pm 66$ \\
\hline $\mathrm{PEAD} / \mathrm{TiO}_{2} 8 \%$ & $9,7 \pm 0,8$ & $930 \pm 57$ \\
\hline
\end{tabular}

Fonte: Autoria própria. 
Pôde-se observar que aumentando os teores dos contaminantes de $2 \%$ a $8 \%$ de $\mathrm{PP}, \mathrm{CaCO}_{3}, \mathrm{SiO}_{2}$ e $\mathrm{TiO}_{2}$, na matriz de PEAD não houveram variações significativas no desempenho de curta duração. Na Figura 45, são mostrados os valores médios dos resultados de resistência à flexão, e observou-se que as barras de erro se sobrepõem em quase todas as misturas quando comparados ao material de PEAD. Somente as amostras de PEAD $/ \mathrm{CaCO}_{3} 6 \%$ e de $\mathrm{PEAD} / \mathrm{SiO}_{2} 6 \%$ mostraram diferença mínima significativa em relação ao PEAD que representou $14 \%$, que no desempenho de curta duração não devem representar diferença significativa. Os resultados também mostraram uma leve tendência ao aumento nos valores de resistência à flexão para a mistura PEAD/PP uma vez que a matriz de polipropileno apresenta um módulo de flexão superior a matriz de PEAD de acordo com os valores caracterizados pelo fabricante das resinas apresentados nos respectivos data sheets, e também um pequeno aumento para as demais misturas $\mathrm{PEAD} / \mathrm{CaCO}_{3}, \mathrm{PEAD} / \mathrm{TiO} \mathrm{O}_{2}$ e $\mathrm{PEAD} / \mathrm{SiO}_{2}$.

Figura 455 - Gráfico dos resultados de resistência à flexão para o PEAD e as misturas de PEAD/PP, $\mathrm{PEAD} / \mathrm{CaCO}_{3}, \mathrm{PEAD} / \mathrm{SiO}_{2}$ e $\mathrm{PEAD} / \mathrm{TiO}_{2}$ variando de $2 \%$ a $8 \%$ em concentração mássica de contaminante

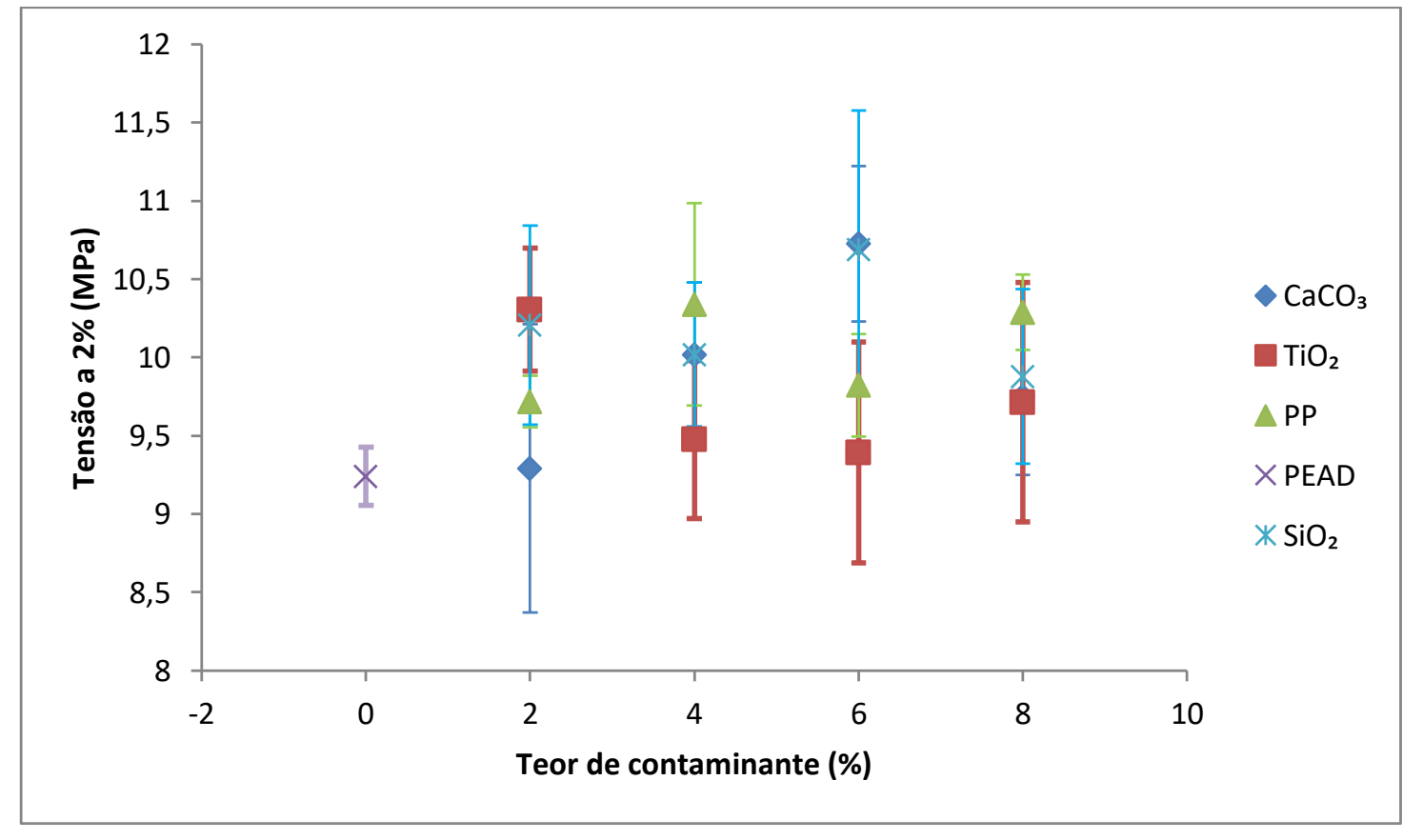

Fonte: Autoria própria.

$\mathrm{Na}$ Figura 46, são mostrados os resultados dos módulos sob flexão para as mesmas amostras analisadas para o parâmetro de resistência à flexão, em que as barras de erro de quase todas as misturas se sobrepõem quando comparadas ao material de PEAD, não apresentando diferença mínima significativa no desempenho 
de curta duração. Somente duas amostras de $\mathrm{PEAD} / \mathrm{CaCO}_{3} 8 \%$ e de $\mathrm{PEAD} / \mathrm{SiO}_{2} 8 \%$ apresentaram uma variação mínima em relação ao PEAD que representou $16 \%$ aproximadamente, que no desempenho de curta duração não deve representar variação significativa.

Figura 466 - Gráfico dos resultados quanto ao módulo sob flexão para o PEAD e as misturas de $\mathrm{PEAD} / \mathrm{PP}, \mathrm{PEAD} / \mathrm{CaCO}_{3}, \mathrm{PEAD} / \mathrm{SiO}_{2}$ e $\mathrm{PEAD} / \mathrm{TiO}_{2}$ variando de $2 \%$ a $8 \%$ em concentração mássica de contaminante

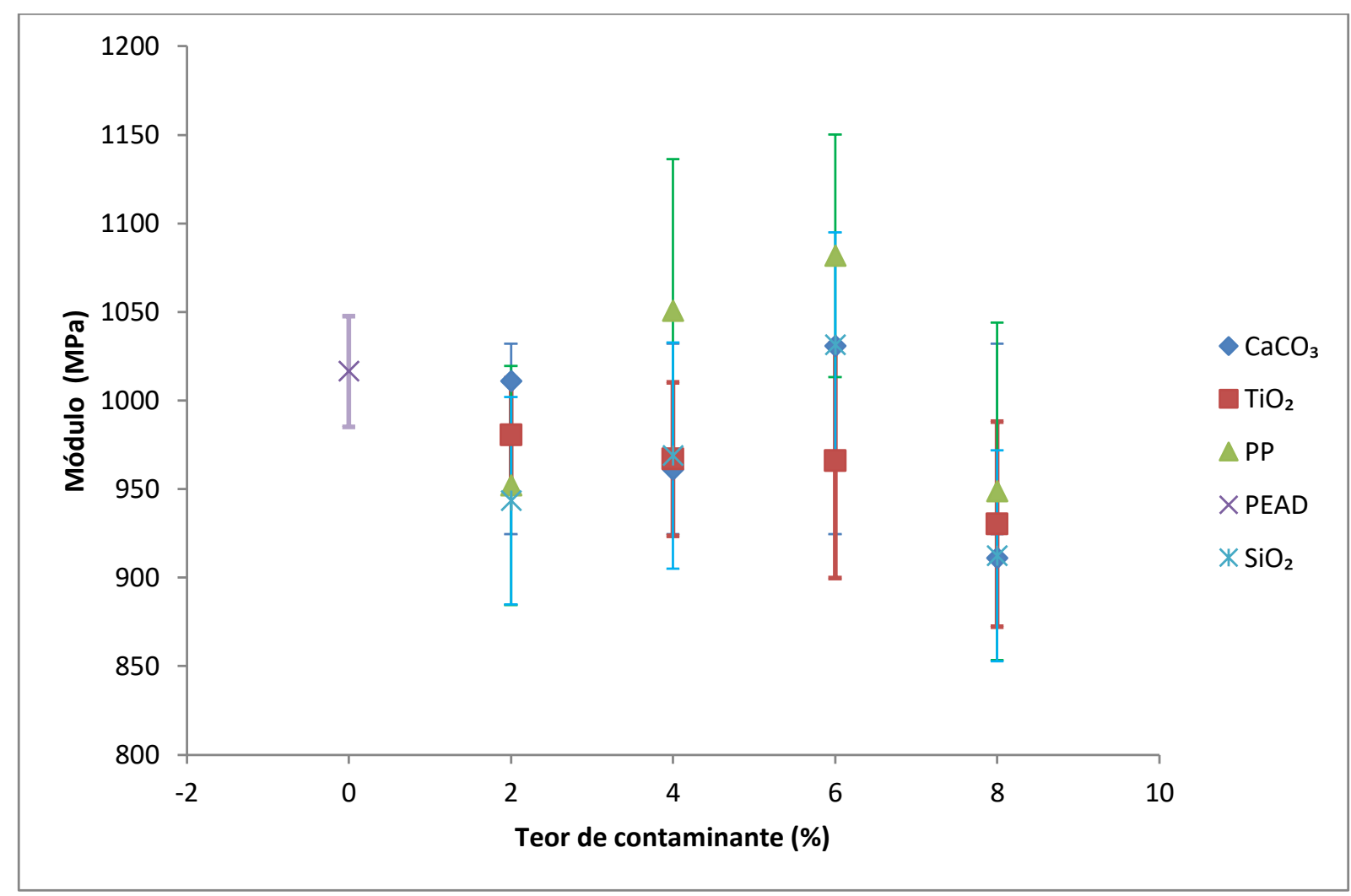

Fonte: Autoria própria. 


\subsubsection{Resultados de resistência ao impacto de PEAD/contaminante}

Os resultados de resistência ao impacto para o PEAD e as demais misturas de $\mathrm{PEAD} / \mathrm{PP}, \mathrm{PEAD} / \mathrm{CaCO}_{3}, \mathrm{PEAD} / \mathrm{SiO}_{2}$ e $\mathrm{PEAD} / \mathrm{TiO}_{2}$ variando de $2 \%$ a $8 \%$ em concentração mássica de contaminante estão apresentados na Tabela 16 e mostrados na Figura 47, respectivamente.

Tabela 16 - Resultados de resistência ao impacto para o PEAD e as demais misturas de PEAD/PP, $\mathrm{PEAD} / \mathrm{CaCO}_{3}, \mathrm{PEAD} / \mathrm{SiO}_{2}$ e $\mathrm{PEAD} / \mathrm{TiO}_{2}$ variando de $2 \%$ a $8 \%$ em concentração mássica de contaminante

\begin{tabular}{|c|c|}
\hline Amostra & $\begin{array}{l}\text { Resistência ao impacto IZOD } \\
(\mathrm{J} / \mathrm{m})\end{array}$ \\
\hline PEAD & $333 \pm 25$ \\
\hline PEAD/PP2\% & $292 \pm 33$ \\
\hline PEAD/PP4\% & $293 \pm 46$ \\
\hline PEAD/PP6\% & $266 \pm 41$ \\
\hline PEAD/PP8\% & $260 \pm 31$ \\
\hline $\mathrm{PEAD} / \mathrm{CaCO}_{3} 2 \%$ & $282 \pm 26$ \\
\hline $\mathrm{PEAD} / \mathrm{CaCO}_{3} 4 \%$ & $259 \pm 50$ \\
\hline $\mathrm{PEAD} / \mathrm{CaCO}_{3} 6 \%$ & $278 \pm 30$ \\
\hline $\mathrm{PEAD} / \mathrm{CaCO}_{3} 8 \%$ & $282 \pm 27$ \\
\hline $\mathrm{PEAD} / \mathrm{SiO}_{2} 2 \%$ & $306 \pm 28$ \\
\hline $\mathrm{PEAD} / \mathrm{SiO}_{2} 4 \%$ & $305 \pm 33$ \\
\hline $\mathrm{PEAD} / \mathrm{SiO}_{2} 6 \%$ & $299 \pm 45$ \\
\hline $\mathrm{PEAD} / \mathrm{SiO}_{2} 8 \%$ & $277 \pm 14$ \\
\hline $\mathrm{PEAD} / \mathrm{TiO}_{2} 2 \%$ & $325 \pm 23$ \\
\hline $\mathrm{PEAD} / \mathrm{TiO}_{2} 4 \%$ & $318 \pm 51$ \\
\hline $\mathrm{PEAD} / \mathrm{TiO}_{2} 6 \%$ & $313 \pm 50$ \\
\hline $\mathrm{PEAD} / \mathrm{TiO}_{2} 8 \%$ & $281 \pm 19$ \\
\hline
\end{tabular}

Fonte: Autoria própria. 
Figura 477 - Gráfico dos resultados de resistência ao impacto para o PEAD e as demais misturas de $\mathrm{PEAD} / \mathrm{PP}, \mathrm{PEAD} / \mathrm{CaCO}_{3}, \mathrm{PEAD} / \mathrm{SiO}_{2}$ e $\mathrm{PEAD} / \mathrm{TiO}_{2}$ variando de $2 \%$ a $8 \%$ em concentração mássica de contaminante

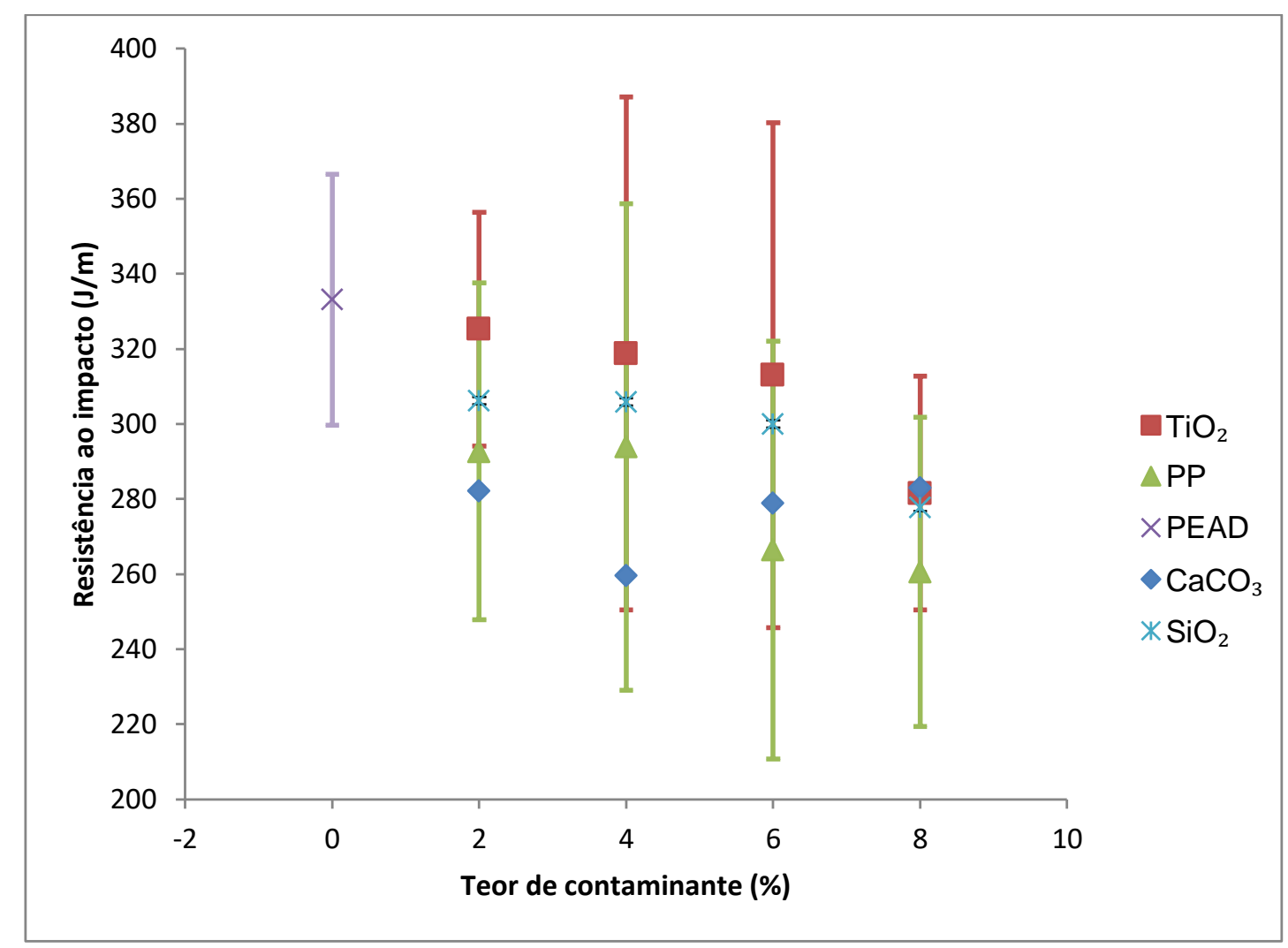

Fonte: Autoria própria.

Os resultados obtidos para todas as amostras se mostraram ligeiramente inferiores a matriz de PEAD, em que são esperadas pequenas variações nas propriedades em razão das condições de processamento, diminuição da massa molar, taxas de cisalhamento ocasionado pelo reprocessamento do material, variações nos graus de cristalinidade (ALZERRECA et.al., 2015). Observou-se que as barras de erro de todas as misturas se sobrepõem quando comparadas ao material de PEAD, não apresentando diferença mínima significativa no desempenho de curta duração. Uma vez que os materiais aqui tratados como contaminantes podem elevar a rigidez das misturas, e também acabar atuando como concentradores de tensão principalmente em maiores concentrações como as de $8 \%$, embora os resultados mostraram uma certa igualdade em um intervalo de confiança de $95 \%$, notou-se uma tendência na redução da resistência ao impacto para todas as misturas em maiores concentrações quando comparadas a matriz de PEAD, corroborando com os estudos de (THOMAS e CUTTINO, 2011; ALZERRECA et.al., 2015; KURDIZIEL, 2014). 


\subsubsection{Análises estatísticas pelo método Tukey para os ensaios de tração, flexão e impacto de PEAD/contaminante}

Nas Tabelas 17 a 19 são apresentadas as análises estatísticas realizadas pelo método Tukey para os ensaios de resistência à tração, resistência à flexão e resistência ao impacto, na qual o caractere igual a 1 indica que há diferença das medianas significativa ao nível de 0,05 , que representa $95 \%$ de confiança, e o caractere 0 indica que não há diferença mínima significativa ao nível de 0,05. Podese observar que para os parâmetros de resistência à tração no escoamento e alongamento não houveram variações mínimas significativas. Os parâmetros de resistência à flexão e módulo sob flexão, somente quatro misturas reportaram uma pequena diferença, que representaram uma variação média entre $14 \%$ e $16 \%$, que para o desempenho de curto prazo não devem representar diferença significativa. Os resultados de resistência ao impacto não houveram variações mínimas significativas.

Tabela 17 - Análise estatística pelo método Tukey para os ensaios de resistência à tração no escoamento e alongamento do PEAD e das misturas de PEAD/PP PEAD/CaCO $3, \mathrm{PEAD} / \mathrm{SiO}_{2}$ e $\mathrm{PEAD} / \mathrm{TiO}_{2}$ para as frações mássicas de $2 \%$ a $8 \%$ de contaminante

\begin{tabular}{|c|c|c|c|c|c|c|c|c|c|c|c|c|c|c|c|c|c|}
\hline AMOSTRAS & $\begin{array}{l}\text { 啰 } \\
\text { 品 }\end{array}$ & 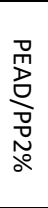 & $\begin{array}{l}\frac{0}{m} \\
\text { व } \\
\text { गे } \\
\text { के } \\
\text { do }\end{array}$ & 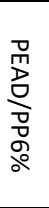 & 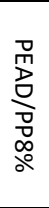 & 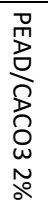 & 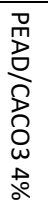 & 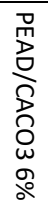 & 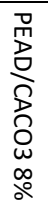 & 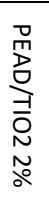 & 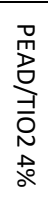 & 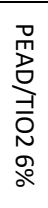 & 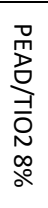 & 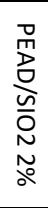 & 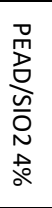 & 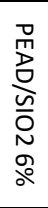 & 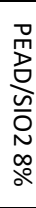 \\
\hline PEAD & & 0 & 0 & 0 & 0 & 0 & 0 & 0 & 0 & 0 & 0 & 0 & 0 & 0 & 0 & 0 & 0 \\
\hline PEAD/PP2\% & 0 & & 0 & 0 & 0 & 0 & 0 & 0 & 0 & 0 & 0 & 0 & 0 & 0 & 0 & 0 & 0 \\
\hline PEAD/PP4\% & 0 & 0 & & 0 & 0 & 0 & 0 & 0 & 0 & 0 & 0 & 0 & 0 & 0 & 0 & 0 & 0 \\
\hline PEAD/PP6\% & 0 & 0 & 0 & & 0 & 0 & 0 & 0 & 0 & 0 & 0 & 0 & 0 & 0 & 0 & 0 & 0 \\
\hline PEAD/PP8\% & 0 & 0 & 0 & 0 & & 0 & 0 & 0 & 0 & 0 & 0 & 0 & 0 & 0 & 0 & 0 & 0 \\
\hline PEAD/CACO3 2\% & 0 & 0 & 0 & 0 & 0 & & 0 & 0 & 0 & 0 & 0 & 0 & 0 & 0 & 0 & 0 & 0 \\
\hline PEAD/CACO3 4\% & 0 & 0 & 0 & 0 & 0 & 0 & & 0 & 0 & 0 & 0 & 0 & 0 & 0 & 0 & 0 & 0 \\
\hline PEAD/CACO3 6\% & 0 & 0 & 0 & 0 & 0 & 0 & 0 & & 0 & 0 & 0 & 0 & 0 & 0 & 0 & 0 & 0 \\
\hline PEAD/CACO3 8\% & 0 & 0 & 0 & 0 & 0 & 0 & 0 & 0 & & 0 & 0 & 0 & 0 & 0 & 0 & 0 & 0 \\
\hline PEAD/TIO2 2\% & 0 & 0 & 0 & 0 & 0 & 0 & 0 & 0 & 0 & & 0 & 0 & 0 & 0 & 0 & 0 & 0 \\
\hline PEAD/TIO2 4\% & 0 & 0 & 0 & 0 & 0 & 0 & 0 & 0 & 0 & 0 & & 0 & 0 & 0 & 0 & 0 & 0 \\
\hline PEAD/TIO2 6\% & 0 & 0 & 0 & 0 & 0 & 0 & 0 & 0 & 0 & 0 & 0 & & 0 & 0 & 0 & 0 & 0 \\
\hline PEAD/TIO2 8\% & 0 & 0 & 0 & 0 & 0 & 0 & 0 & 0 & 0 & 0 & 0 & 0 & & 0 & 0 & 0 & 0 \\
\hline PEAD/SIO2 2\% & 0 & 0 & 0 & 0 & 0 & 0 & 0 & 0 & 0 & 0 & 0 & 0 & 0 & & 0 & 0 & 0 \\
\hline $\mathrm{PEAD} / \mathrm{SIO} 24 \%$ & 0 & 0 & 0 & 0 & 0 & 0 & 0 & 0 & 0 & 0 & 0 & 0 & 0 & 0 & & 0 & 0 \\
\hline PEAD/SIO2 6\% & 0 & 0 & 0 & 0 & 0 & 0 & 0 & 0 & 0 & 0 & 0 & 0 & 0 & 0 & 0 & & 0 \\
\hline PEAD/SIO2 8\% & 0 & 0 & 0 & 0 & 0 & 0 & 0 & 0 & 0 & 0 & 0 & 0 & 0 & 0 & 0 & 0 & \\
\hline
\end{tabular}


Tabela 18 - Análise estatística pelo método Tukey para os ensaios de resistência à flexão e módulo sob flexão do PEAD e das misturas de PEAD/PP PEAD/CaCO ${ }_{3}, \mathrm{PEAD} / \mathrm{SiO}_{2}$ e PEAD/TiO ${ }_{2}$ para as frações mássicas de $2 \%$ a $8 \%$ de contaminante

\begin{tabular}{|c|c|c|c|c|c|c|c|c|c|c|c|c|c|c|c|c|c|}
\hline AMOSTRAS & $\begin{array}{l}\text { D } \\
\text { 罟 }\end{array}$ & $\begin{array}{l}\text { D } \\
\text { 竞 } \\
\text { गे } \\
\text { No }\end{array}$ & 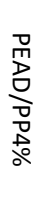 & 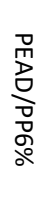 & 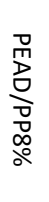 & 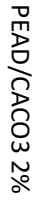 & 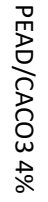 & 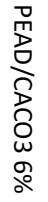 & 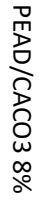 & 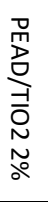 & 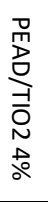 & 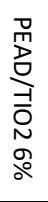 & 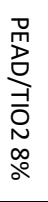 & 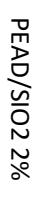 & 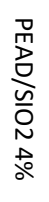 & $\begin{array}{l}0 \\
\text { 塄 } \\
\text { 心 } \\
\text { D } \\
\text { o } \\
\text { o }\end{array}$ & 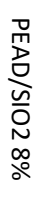 \\
\hline PEAD & & 0 & 0 & 0 & 0 & 0 & 0 & 1 & 0 & 0 & 0 & 0 & 0 & 0 & 0 & 1 & 0 \\
\hline PEAD/PP2\% & 0 & & 0 & 0 & 0 & 0 & 0 & 0 & 0 & 0 & 0 & 0 & 0 & 0 & 0 & 0 & 0 \\
\hline PEAD/PP4\% & 0 & 0 & & 0 & 0 & 0 & 0 & 0 & 0 & 0 & 0 & 0 & 0 & 0 & 0 & 0 & 0 \\
\hline PEAD/PP6\% & 0 & 0 & 0 & & 0 & 0 & 0 & 0 & 1 & 0 & 0 & 0 & 0 & 0 & 0 & 0 & 1 \\
\hline PEAD/PP8\% & 0 & 0 & 0 & 0 & & 0 & 0 & 0 & 0 & 0 & 0 & 0 & 0 & 0 & 0 & 0 & 0 \\
\hline PEAD/CACO3 2\% & 0 & 0 & 0 & 0 & 0 & & 0 & 0 & 0 & 0 & 0 & 0 & 0 & 0 & 0 & 0 & 0 \\
\hline PEAD/CACO3 4\% & 0 & 0 & 0 & 0 & 0 & 0 & & 0 & 0 & 0 & 0 & 0 & 0 & 0 & 0 & 0 & 0 \\
\hline PEAD/CACO3 6\% & 0 & 0 & 0 & 0 & 0 & 0 & 0 & & 0 & 0 & 0 & 0 & 0 & 0 & 0 & 0 & 0 \\
\hline PEAD/CACO3 8\% & 0 & 0 & 0 & 0 & 0 & 0 & 0 & 0 & & 0 & 0 & 0 & 0 & 0 & 0 & 0 & 0 \\
\hline PEAD/TIO2 2\% & 0 & 0 & 0 & 0 & 0 & 0 & 0 & 0 & 0 & & 0 & 0 & 0 & 0 & 0 & 0 & 0 \\
\hline PEAD/TIO2 4\% & 0 & 0 & 0 & 0 & 0 & 0 & 0 & 0 & 0 & 0 & & 0 & 0 & 0 & 0 & 0 & 0 \\
\hline PEAD/TIO2 6\% & 0 & 0 & 0 & 0 & 0 & 0 & 0 & 0 & 0 & 0 & 0 & & 0 & 0 & 0 & 0 & 0 \\
\hline PEAD/TIO2 8\% & 0 & 0 & 0 & 0 & 0 & 0 & 0 & 0 & 0 & 0 & 0 & 0 & & 0 & 0 & 0 & 0 \\
\hline PEAD/SIO2 2\% & 0 & 0 & 0 & 0 & 0 & 0 & 0 & 0 & 0 & 0 & 0 & 0 & 0 & & 0 & 0 & 0 \\
\hline PEAD/SIO2 4\% & 0 & 0 & 0 & 0 & 0 & 0 & 0 & 0 & 0 & 0 & 0 & 0 & 0 & 0 & & 0 & 0 \\
\hline PEAD/SIO2 6\% & 0 & 0 & 0 & 0 & 0 & 0 & 0 & 0 & 0 & 0 & 0 & 0 & 0 & 0 & 0 & & 0 \\
\hline PEAD/SIO2 8\% & 0 & 0 & 0 & 0 & 0 & 0 & 0 & 0 & 0 & 0 & 0 & 0 & 0 & 0 & 0 & 0 & \\
\hline
\end{tabular}

Fonte: Autoria própria. 
Tabela 19 - Análise estatística pelo método Tukey para os ensaios de resistência ao impacto do $\mathrm{PEAD}$ e das misturas de PEAD/PP PEAD/CaCO $3, \mathrm{PEAD} / \mathrm{SiO}_{2}$ e $\mathrm{PEAD} / \mathrm{TiO}_{2}$ para as frações mássicas de $2 \%$ a $8 \%$ de contaminante

\begin{tabular}{|c|c|c|c|c|c|c|c|c|c|c|c|c|c|c|c|c|c|}
\hline AMOSTRAS & $\begin{array}{l}\text { 啰 } \\
\text { 号 }\end{array}$ & 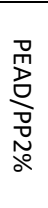 & 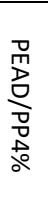 & $\begin{array}{l}\text { D } \\
\text { 咅 } \\
\text { गे } \\
\text { o } \\
\text { o }\end{array}$ & 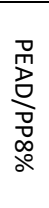 & 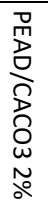 & 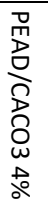 & 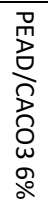 & 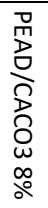 & 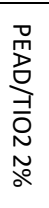 & 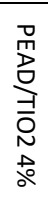 & $\begin{array}{l}0 \\
\text { 罗 } \\
\text { D. } \\
\text { D̄ } \\
\text { N } \\
\text { o } \\
\text { ○ }\end{array}$ & 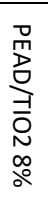 & 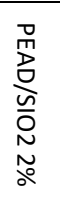 & 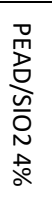 & 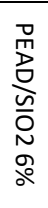 & 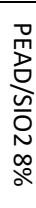 \\
\hline PEAD & & 0 & 0 & 0 & 0 & 0 & 0 & 0 & 0 & 0 & 0 & 0 & 0 & 0 & 0 & 0 & 0 \\
\hline PEAD/PP2\% & 0 & & 0 & 0 & 0 & 0 & 0 & 0 & 0 & 0 & 0 & 0 & 0 & 0 & 0 & 0 & 0 \\
\hline PEAD/PP4\% & 0 & 0 & & 0 & 0 & 0 & 0 & 0 & 0 & 0 & 0 & 0 & 0 & 0 & 0 & 0 & 0 \\
\hline PEAD/PP6\% & 0 & 0 & 0 & & 0 & 0 & 0 & 0 & 0 & 0 & 0 & 0 & 0 & 0 & 0 & 0 & 0 \\
\hline PEAD/PP8\% & 0 & 0 & 0 & 0 & & 0 & 0 & 0 & 0 & 0 & 0 & 0 & 0 & 0 & 0 & 0 & 0 \\
\hline PEAD/CACO3 2\% & 0 & 0 & 0 & 0 & 0 & & 0 & 0 & 0 & 0 & 0 & 0 & 0 & 0 & 0 & 0 & 0 \\
\hline PEAD/CACO3 4\% & 0 & 0 & 0 & 0 & 0 & 0 & & 0 & 0 & 0 & 0 & 0 & 0 & 0 & 0 & 0 & 0 \\
\hline PEAD/CACO3 6\% & 0 & 0 & 0 & 0 & 0 & 0 & 0 & & 0 & 0 & 0 & 0 & 0 & 0 & 0 & 0 & 0 \\
\hline PEAD/CACO3 8\% & 0 & 0 & 0 & 0 & 0 & 0 & 0 & 0 & & 0 & 0 & 0 & 0 & 0 & 0 & 0 & 0 \\
\hline PEAD/TIO2 2\% & 0 & 0 & 0 & 0 & 0 & 0 & 0 & 0 & 0 & & 0 & 0 & 0 & 0 & 0 & 0 & 0 \\
\hline PEAD/TIO2 4\% & 0 & 0 & 0 & 0 & 0 & 0 & 0 & 0 & 0 & 0 & & 0 & 0 & 0 & 0 & 0 & 0 \\
\hline PEAD/TIO2 6\% & 0 & 0 & 0 & 0 & 0 & 0 & 0 & 0 & 0 & 0 & 0 & & 0 & 0 & 0 & 0 & 0 \\
\hline PEAD/TIO2 8\% & 0 & 0 & 0 & 0 & 0 & 0 & 0 & 0 & 0 & 0 & 0 & 0 & & 0 & 0 & 0 & 0 \\
\hline PEAD/SIO2 2\% & 0 & 0 & 0 & 0 & 0 & 0 & 0 & 0 & 0 & 0 & 0 & 0 & 0 & & 0 & 0 & 0 \\
\hline PEAD/SIO2 4\% & 0 & 0 & 0 & 0 & 0 & 0 & 0 & 0 & 0 & 0 & 0 & 0 & 0 & 0 & & 0 & 0 \\
\hline $\mathrm{PEAD} / \mathrm{SIO} 26 \%$ & 0 & 0 & 0 & 0 & 0 & 0 & 0 & 0 & 0 & 0 & 0 & 0 & 0 & 0 & 0 & & 0 \\
\hline PEAD/SIO2 8\% & 0 & 0 & 0 & 0 & 0 & 0 & 0 & 0 & 0 & 0 & 0 & 0 & 0 & 0 & 0 & 0 & \\
\hline
\end{tabular}

Fonte: Autoria própria. 


\section{CONCLUSÕES}

O PEAD-R reprocessado mecanicamente por meio de uma única etapa de extrusão, sem contaminantes, pode ser utilizado para aplicações estruturais, pois se mostrou compatível com os requisitos de curta e longa duração.

Os resultados de curta duração para os parâmetros de resistência à tração, e resistência ao impacto não apresentaram diferenças mínimas significativas para as misturas preparadas entre a matriz de PEAD e os contaminantes dispersos em frações mássicas variando de $2 \%$ a $8 \%$. Somente para os parâmetros de resistência à flexão e módulo sob flexão em que quatro amostras mostraram uma variação mínima entre $14 \%$ e $16 \%$ que no desempenho de curta prazo não apresentou variação significativa.

Dentre os contaminantes preparados juntamente com a matriz de PEAD, a mistura de PEAD/PP embora os resultados tenham mostrado uma certa igualdade, uma tendência na redução das propriedades pôde ser observada uma vez que os diferentes polímeros apresentam uma baixa miscibilidade, uma interface pobre, resultando em um efeito deletério nas propriedades finais da mistura.

Os tempos de falha do PEAD-R em comparação ao do PEAD no ensaio de fissuramento sob tensão e entalhe NCLS com cargas de $15 \%, 30 \%$ e $40 \%$ da tensão de escoamento de $27,5 \mathrm{MPa}$, para os corpos de prova injetados se mostraram compatíveis para aplicações que demandam um longo tempo de vida em serviço. Portanto para esse parâmetro analisado o PEAD-R pode ser utilizado em aplicações estruturais como por exemplo tubos de drenagem, tubos de irrigação entre outras.

O PEAD se mostrou um material intrinsecamente sensível ao processo de entalhamento, apresentando regiões com microfissuras que resultaram em elevadas dispersões nos tempos de falha.

As variáveis mais significativas para os ensaios de fissuramento sob tensão constante e entalhe NCLS foram o método de obtenção dos corpos de prova, processo de entalhamento e ajustes das cargas.

O método de entalhamento 3 tipo guilhotina com limitador metálico com fim de curso da lâmina, se mostrou mais eficiente atingindo os requisitos dimensionais de entalhe nos corpos de prova, produziu menor quantidade de material plastificado na ponta da trinca, e reduziu a quantidade de microfissuras na região da ponta da trinca. 
Todas as variáveis como homogeneidade do banho, processo de entalhamento, método de obtenção dos corpos de prova, ajuste das cargas com a respectiva vantagem mecânica do dispositivo teve efeito significativo na dispersão dos resultados.

Neste trabalho destacou-se a avaliação do desempenho de longa duração do PEAD e do PEAD-R reprocessado mecanicamente por uma única etapa de extrusão por meio do ensaio de fissuramento sob tensão constante e entalhe NCLS para futuras aplicações estruturais. 


\section{REFERÊNCIAS ${ }^{3}$}

ABIPLAST. Associação Brasileira da Indústria do Plástico, 2017. Disponivel em: <http://www.abiplast.org.br/publicacoes/perfil-2016/>. Acesso em: 12 maio 2018.

ABIPLAST. Associação Brasileira da Indústria do Plástico, 2020. Disponível em: <http://www.abiplast.org.br/wpcontent/uploads/2021/08/Perfil2020_abiplast.pdf>. Acesso em: outubro 2021.

ACADEMY, P. P., 2017. Disponivel em: <http://www.packsys.com/blog/brevehistoria-del-polietileno/>. Acesso em: 23 maio 2018.

ADIB, A. et al. Influence of specimen geometry on the slow crack growth testing of. Polymer Testing, Madrid, n. 48, December 2015. 104-110.

ALZERRECA, M. et al. Mechanical properties and molecular structures of virgin and recycled HDPE polymers used in gravity sewer systems. Polymer Testing, Nantes, n. 46, p. 1-8, 2015.

ASTM. D256-18 Standard Test Methods for Determining the Izod Pendulum Impact Resistence of Plastics. ASTM. [S.I.]. 2018

ASTM. D638-14 - Standard Test Method for Tensile Properties of Plastics ASTM. [S.I.]. 2014

ASTM. D790-17 - Standard Test Methods for Flexural Properties of Unreinforced and Reinforced Plastics and Eletrical Insulating Materials. ASTM. [S.I.]. 2017

ASTM. D4976-12a - Standard Specification for Polyethylene Plastics Molding and Extrusion Materials1. ASTM. [S.I.]. 2012.

ASTM. D5397-19a - Standard Test Method for Evaluation of Stress Crack Resistance of Polyolefin Geomembranes Using Notched Constant Tensile Load Test. ASTM. [S.I.]. 2012.

ASTM. D2837-21 Standard Test Method for Obtaining Hydrostatic Design Basis for Thermoplastic Pipe Materials or Pressure Design Basis for Thermoplastic Pipe Products. ASTM. [S.I.]. 2013.

ASTM. F2136-18- Standard Test Method for Notched, Constant Ligament-Stress (NCLS) Test to Determine Slow-Crack-Growth Resistance of HDPE Resins or HDPE Corrugated Pipe1. ASTM. [S.I.]. 2018.

BARTOLOMEI, S. S. Estudo de nanocompósitos formados por PLA e nanopartículas de celulose. Escola Politécnica da Universidade de São Paulo USP. São Paulo, p. 134. 2016. (10.11606/D.3.2016.tde-04072016-152946).

BATISTA, P. B.; KIECKOW, F. Estudo das propriedades mecânicas do Polietileno UHMW aditivado com Sílica. Vivências - Revista Eletrônica de Extensão da URI, v. 12 , p. 144-153, maio 2016.

BMRC. BMRC- Beneficiamento de Minérios de Rio Claro, 2014. Disponivel em: <http://bmrc.com.br/blog/fillers-de-silica-em-polimeros/>. Acesso em: 21 jan. 2019.

\footnotetext{
${ }^{3}$ De acordo com a Associação Brasileira de Normas Técnicas (ABNT NBR 6023).
} 
BRASIL. Política Nacional de Resíduos Sólidos. LEI № 12.305, 2010. Disponivel em: <http://www.planalto.gov.br/ccivil_03/_ato2007-2010/2010/lei/l12305.htm>. Acesso em: 2 maio 2018.

CANDIAN, L. M. Estudo do Polietileno de Alta Densidade reciclado para uso em elementos estruturais. Universidade de São Paulo. São Carlos, p. 167. 2007.

CANEVAROLO, S. V. Técnicas de Caracterização de Polímeros. 3. ed. São Paulo: Artiliber, 2003.

CEMPRE. CEMPRE, 2014. Disponivel em: <http://cempre.org.br/cempre-

informa/id/19/reciclagem-quimica--destino-crescente-do-pet-pos-consumo>. Acesso em: 14 maio 2018.

CIMM. CIMM, 2019. Disponivel em:

$<$ https://www.cimm.com.br/portal/verbetes/exibir/99-contaminante>. Acesso em: 31 jan. 2019.

CORRÊA, L. C. - Alternativa para o Plástico: Reciclagem Energética. Alternativa para o Plástico: Reciclagem Energética. , 7 A 12 2012. 49-60.

DIKOBE, D. G.; LUYT, A. S. Thermal and mechanical properties of PP/HDPE/wood powder and MAPP/HDPE/wood powder polymer blend composities. Thermochimica Acta, v. 654, p. 40-50, September 2017. ISSN 10.1016/j.tca.2017.05.002.

DU, Y. J. et al. Earth Pressures on the Trenched HDPE Pipes in Fine-Grained Soils during Contruction Phase: Full-Scale Field Trial and Finite Element Modeling.

Transportation Geotechnics, Nanjing, v. 12, n. 129, p. 56-69, September 2017. ISSN 10.1016/j.trgeo.2017.08.002.

ENERGY, P., 2018. Disponivel em: <http://www.plasticenergy.net/>. Acesso em: 14 maio 2018.

FERNANDEZ, A. F. Análisis de la estrutura, movilidad molecular y propiedades de copolímeros de impacto de polipropileno. Rey Juan Carlos. Madrid, Espanha, p. 27-44. 2014.

FREITAS, E. L. Materiais Poliolefínicos. Escola Laurentino de Freitas. São Paulo, p. 2 a 5. 2008.

FREITAS, E. L. Cargas e Aditivos. Escola Laurentino de Freitas. São Paulo, p. 9. 2013.

FREITAS, R. L. M. Efeito da Temperatura de Resfriamento sobre as

Propriedades de Polímeros Amorfos e Semicristalinos. Universidade Federal do Rio de Janeiro. Rio de Janeiro. 2014.

GBI. GBI Research, 2011. Disponivel em: <http://www.gbiresearch.com/reportstore/market-reports/archive/high-density-polyethylene-hdpe-global-market-to-2020middle-east-expected-to-emerge-as-the-key-supplier/tables>. Acesso em: 2018.

Institute, M. (15 de junho de 2021).

http://www.masterinst.co.th/RayRanEquiptment.html. Fonte: Master Institute

IPPOLITO, F. et al. Influence of calcium carbonate on polyamide 12 regarding melting, formability and crystallization properties. Elsevier, v. 164, p. 158-167, maio 2019. ISSN 10.1016/j.compositesb.2018.11.079. 
ISO. 15270:2008 - Plastics - Guidelines for the recovery and recycling of plastics waste. ISO. [S.I.]. 2008.

JACQUES, L. Nosso futuro roubado, 2018. Disponivel em:

$<$ https://nossofuturoroubado.com.br/microplastico-poluicao-invisivel-ameacaoceanos/>. Acesso em: 02 maio 2018.

JUNIOR, A. R.; NUNES, L. R.; ORMANJI, W. Tecnologia do PVC. São Paulo: Pro Editores Associados Ltda, 2002.

KRISHNASWAMY, P.; SHIM, D. J. A review of service life prediction models for high density polyethylene piping for nuclear safety - related applications [PE]. Plastics Pipes, Columbus, September 2010.

KURDZIEL, J. M. Required Engineering Properties for High Density Polyethylene Pipe Utilizing Recycled Materials. Plastic Pipes Conference PPXVII. Chicago, p. [s.n.]. 2014.

LAVOIE, F. L.; BUENO, B. S. O Fenômeno de Fissuramento Sob Tensão (Stress Cracking): Mecanismos de Ocorrência e Ensaios em Geomembranas de polietileno (PE) virgens e degradadas. Universidade de São Paulo. São Carlos, p. 6. 2006. (10.11606/D.18.2006.tde-18082006-133723).

LAVOIE, F. L.; BUENO, B. S. Ensaios de Fissuramento sob Tensão (Stress Cracking) em Geomembrana de PEAD Submetida à Radiação Ultravioleta e ao Envelhecimento Térmico. Universidade de São Paulo. São Carlos, p. 8. 2007.

LAZIC, Z. R. Design of Experiments in Chemical Engineering. Morristown: Wiley VCH Verlag GmbH \& Co. KgaA, 2004.

LESTER, H. G. History and Physical Chemistry of HDPE. Plastics Pipe Institute. Irvin. 1998.

LUZ, A. B.; LINS, F. A. F. Rochas \& minerais Industriais: usos e especificações. 2. ed. Rio de Janeiro: CETEM/MCT, 2008.

MANO, E. B.; MENDES, L. C. Introdução a Polímeros. 2. ed. Rio de Janeiro: Edgard Blucher Ltda, 2004.

MESQUITA, F. A. Modificação das propriedades do polietileno de alta densidade por diferentes condições de extrusão. Escola Politécnica, Universidade de São Paulo. São Paulo, p. 97. 2010. (10.11606/D.3.2010.tde10012011-103025).

MÜLLER, W. W. HDPE Geomembranes in Geotechnics. 1 edição. ed. Berlin: Springer-Verlag Berlin Heidelberg, 2006.

NAJAFI, S. K. Use of recycled plastics in wood plastic composites - A review. Waste Management, v. 33, n. 9, p. 1898-1905, 15 jun. 2013. ISSN 10.1016/j.wasman.2013.05.017.

PANAITESCU, D. M. et al. Influence of Rutile and Anatase TiO2 Nanoparticles on Polyethylene Properties. Polymer-Plastics Technology and Engineering,

Bucharest, p. 196-202, JAN 2011. ISSN 0360-2559.

PESIC, N. et al. Mechanical properties of concrete reinforced with recycled HDPE. Construction and Building Materials, United Kingdom, v. 115, p. 362-370, 2016. 
PIVA, A. M.; NETO, M. B.; WIEBECK, H. A reciclagem do PVC no Brasil. Polímeros: Ciência e Tecnologia, São Paulo, v. 9, n. 4, p. 195-200, out. 1999.

PLASTIC OCEAN. Direção: Craig Leeson. Produção: Jo Ruxton. Intérpretes: Craig Leeson. [S.I.]: [S.n.]. 2016.

PLASTIVIDA. www.plastivida.org.br, 2018. Disponivel em: $<$ http://www.plastivida.org.br/index.php/plastivida/posicionamento/71-reciclagemmecanica?lang=pt>. Acesso em: 29 Abril 2019.

POVEDA, P. N. S. Estudo do efeito de nanopartículas de carbonato de cálcio dióxido de titânio e óxido de zinco nas propriedades dos termoplásticos Polietileno de alta densidade linear e Copolíester alifático aromático, submetidos a radiação ultra violeta. Instituto de Pesquisas Energéticas e Nucleares. São Paulo, p. 141. 2015. (10.11606/T.85.2015.tde-27072015-145659).

REIS, J. M. L.; PACHECO, L. J.; MATTOS, H. S. D. C. Temperature and variable strain rate sensitivity in recycled HDPE. Polymer Testing, Niteroi, p. 30-35, July 2014. ISSN 10.1016/j.polymertesting.2014.07.011.

SCHOUWENAARS, R. et al. Slow crack growth and failure induced by manufacturing defects in HDPE-tubes. Department of Mechanical Engineering, DIMEI, National Autonomous University of Mexico. Coyoacán, p. 1124-1134. 2007. (10.1016/j.engfailanal.2006.11.066).

SILVA, A. S. D. Frase motivacional. Angra dos Reis: [s.n.]. 1990.

SIMENDIC, J. B. et al. The Effect of Nucleants on the Crystallization Behavior of Isotactic Polypropylene. Materials Science Forum, Switzerland, v. 453-454, p. 509514, maio 2004. ISSN 10.4028/www.scientific.net/MSF.453-454.509.

SPINACÉ, M. A. S.; PAOLI, M. A. A tecnologia da reciclagem de polímeros. Química Nova, Campinas, v. 28, p. 65 a 72, 12 nov. 2005.

TECHNOLOGY, N. I. O. S. A. Handbook of Statistical Methods. U.S.: Department of Commerce, 2013.

THOMAS, R. W.; CUTTINO, D. Performance of Corrugated Pipe Manufactured with Recycled Polyethylene Content. National Cooperative Highway Research. Washington DC. 2011.

VALLE, A. C. M. Influência da adição de dióxido de titânio (Tio2) nas propriedades físico-mecânicas de painéis MDP. Universidade de São Paulo. Piracicaba. 2018. (10.11606/D.11.2018.tde-26072018-151544).

VASCONCELOS, G. C.; BASSO, B. B.; VALERA, T. S. Effect of Impurity Content on Long Term Performance of recycled HDPE for structural application.

Universidade de São Paulo - Engenharia Matelurgica e de Materiais. São Paulo, p. 5. 2018. (10.1063/1.5088325).

ZAMAN, H. U. Effect of $\mathrm{CaCO} 3$ contents on the properties of polyethylene nanocomposites sheets. Fibers and Polymers, Pahang, v. 15, n. 4, p. 839-846, may 2014. ISSN 1875-0052.

ZANIN, M.; MANCINI, S. D. Resíduos plásticos e reciclagem: aspectos gerais e tecnologia. 1. ed. São Carlos: [S.I.]: EdUFSCar, 2004. 